\title{
Immunonutrition for acute respiratory distress syndrome (ARDS) in adults
}

\section{Review information}

Review type: Intervention

Review number: EC290

\section{Authors}

Ahilanandan Dushianthan ${ }^{1}$, Rebecca Cusack ${ }^{2}$, Victoria A Burgess ${ }^{3}$, Michael PW Grocott ${ }^{4}$, Philip C Calder ${ }^{5}$

${ }^{1}$ General Intensive Care Unit, University Hospital Southampton NHS Foundation Trust, Southampton, UK

2Integrative Physiology and Critical IIIness Group, University of Southampton, Southampton, UK

${ }^{3}$ Department of Anaesthetics, University Hospital Southampton NHS Foundation Trust, Southampton, UK

${ }^{4}$ Critical Care Group, Clinical and Experimental Sciences, Faculty of Medicine, University of Southampton, Southampton, UK

${ }^{5}$ Human Development and Health Academic Unit, Faculty of Medicine, University of Southampton, Southampton, UK

Citation example: Dushianthan A, Cusack R, Burgess VA, Grocott MPW, Calder PC. Immunonutrition for acute respiratory distress syndrome (ARDS) in adults. Cochrane Database of Systematic Reviews 2016 , Issue 1 . Art. No.: CD012041. DOI: 10.1002/14651858.CD012041.

\section{Contact person}

\section{Ahilanandan Dushianthan}

Consultant in Intensive Care

General Intensive Care Unit

University Hospital Southampton NHS Foundation Trust

Tremona Road

Southampton

Hampshire

SO16 6YD

UK

E-mail: adushianthan@gmail.com

E-mail 2: ahilanadan.dushianthan@uhs.nhs.uk

Dates

Assessed as Up-to-date:25 April 2018

Date of Search: $\quad 25$ April 2018

Next Stage Expected: 30 January 2021

Protocol First Published: Issue 1, 2016

Review First Published: Not specified

Last Citation Issue: Issue 1,2016

What's new

\begin{tabular}{|l|l|l}
\hline Date & Event & Description
\end{tabular}

History

\begin{tabular}{|l|l|l}
\hline Date & Event & Description
\end{tabular}

\section{Abstract}

\section{Background}

Acute respiratory distress syndrome (ARDS) is an overwhelming systemic inflammatory process associated with significant morbidity and mortality. Pharmacotherapies that moderate inflammation in ARDS are lacking. Several trials have evaluated the effects of pharmaconutrients, given as part of a feeding formula or as a nutritional supplement, on clinical outcomes in critical illness and ARDS.

\section{Objectives}

To systematically review and critically appraise available evidence on the effects of immunonutrition compared to standard non-immunonutrition formula feeding on mechanically ventilated adults (aged 18 years or older) with acute respiratory distress syndrome (ARDS).

Search methods

We searched MEDLINE, Embase, CENTRAL, conference proceedings, and trial registries for appropriate studies up to 25 April 2018. We checked the references from published studies and reviews on this topic for potentially eligible studies. 


\section{Selection criteria}

We included all randomized controlled trials (RCTs) and quasi-randomized controlled trials comparing immunonutrition versus a control or placebo nutritional formula in adults (aged 18 years or older) with ARDS, as defined by the Berlin definition of ARDS or, for older studies, by the American-European Consensus Criteria for both ARDS and acute lung injury.

\section{Data collection and analysis}

Two review authors independently assessed the quality of studies and extracted data from the included trials. We sought additional information from study authors. We performed statistical analysis according to Cochrane methodological standards. Our primary outcome was all-cause mortality. Secondary outcomes included intensive care unit (ICU) length of stay, ventilator days, indices of oxygenation, cardiac adverse events, gastrointestinal adverse events, and total number of adverse events. We used GRADE to assess the quality of evidence for each outcome.

\section{Main results}

We identified 10 randomized controlled trials with 1015 participants. All studies compared an enteral formula or additional supplemental omega-3 fatty acids (i.e. eicosapentaenoic acid (EPA), docosahexaenoic acid (DHA)), gamma-linolenic acid (GLA), and antioxidants. We assessed some of the included studies as having high risk of bias due to methodological shortcomings. Studies were heterogenous in nature and varied in several ways, including type and duration of interventions given, calorific targets, and reported outcomes. All studies reported mortality. For the primary outcome, study authors reported no differences in all-cause mortality (longest period reported) with the use of an immunonutrition enteral formula or additional supplements of omega- 3 fatty acids and antioxidants (risk ratio (RR) $0.79,95 \%$ confidence interval (Cl) 0.59 to 1.07; participants = 1015; studies = 10; low-quality evidence).

For secondary outcomes, we are uncertain whether immunonutrition with omega- 3 fatty acids and antioxidants reduces ICU length of stay (mean difference (MD) -3.12 days. $95 \% \mathrm{Cl}-5.24$ to -1.01 ; participants = 641; studies = 8; very low-quality evidence) and ventilator days (MD -2.25 days, $95 \% \mathrm{Cl}-3.78$ to -0.71 ; participants = 583; studies = 7; very low-quality evidence). We are also uncertain whether omega-3 fatty acids and antioxidants improve oxygenation, defined as ratio of partial pressure of arterial oxygen $\left(\mathrm{PaO}_{2}\right)$ to fraction of inspired oxygen $\left(\mathrm{FiO}_{2}\right)$, at day $4(\mathrm{MD} 39 \mathrm{mmHg}, 95 \% \mathrm{Cl} 10.75$ to 67.02; participants $=676$; studies $=8)$, or whether they increase adverse events such as cardiac events $(\mathrm{RR} 0.87,95 \% \mathrm{Cl}$ 0.09 to 8.46 ; participants $=339$; studies $=3$; very low-quality evidence), gastrointestinal events $(\mathrm{RR} 1.15,95 \% \mathrm{Cl} 0.75$ to 1.76; participants $=427$; studies $=4$; very low-quality evidence), or total adverse events $(\mathrm{RR} 0.94,95 \% \mathrm{Cl} 0.69$ to 1.27 ; participants $=517$; studies $=5$; very low-quality evidence) .

\section{Authors' conclusions}

This meta-analysis of 10 studies of varying quality examined effects of omega- 3 fatty acids and/or antioxidants in adults with ARDS. This intervention may produce little or no difference in all-cause mortality between groups. We are uncertain whether immunonutrition with omega-3 fatty acids and antioxidants improves the duration of ventilator days and ICU length of stay or oxygenation at day 4 due to the very low quality of evidence. Adverse events associated with immunonutrition are also uncertain, as confidence intervals include the potential for increased cardiac, gastrointestinal, and total adverse events.

\section{Plain language summary \\ Immunonutrition for acute respiratory distress syndrome (ARDS) in adults Background}

Acute respiratory distress syndrome (ARDS) is a life-threatening condition wherein the lungs are inflamed (irritated) and damaged. In this state, the lungs cannot deliver into the blood enough oxygen for the body's vital organs. It is usually seen in patients who are already seriously ill. Currently, no specific effective therapeutic options are available for this condition. Alternatively, change in dietary intake has been deployed. Modification of the nutrition given to adults with ARDS, to include components of food that have an anti-inflammatory effect, could reduce lung inflammation and improve outcomes in adults with this condition. Omega-3 fatty acids (known as DHA and EPA) are found in fish oils and can have an anti-inflammatory effect. Reviewers examined reported outcomes and effects of changes in nutrition among studies involving adults with ARDS.

\section{Study characteristics}

The evidence is current up to April 2018. We included in this review 10 studies with 1015 adult participants. These studies were conducted in intensive care units and compared standard nutrition (the usual nutrition given to patients with ARDS) versus nutrition supplemented with omega-3 fatty acids or placebo (a substance with no active effect), and compared either with or without antioxidants. Antioxidants are molecules that can inhibit or slow down oxidation - a reaction that can cause inflammation and damage cells.

\section{Key results}

It is unclear whether use of omega- 3 fatty acids and antioxidants as part of nutritional intake in patients with ARDS improves long-term survival. It is uncertain whether omega-3 fatty acids and antioxidants reduce length of ICU stay and the number of days spent on a ventilator, or if they improve oxygenation. It is also unclear if this type of nutrition causes increased harm.

\section{Quality of evidence}

Findings of this review are limited by lack of standardization among the included studies in terms of methods, types of nutritional supplements given, and reporting of outcome measures. We rated the quality of evidence as low to very low. 


\section{Background}

\section{Description of the condition}

Acute respiratory distress syndrome (ARDS) is characterized by severe hypoxic respiratory failure with significant global inflammatory processes and multi-organ dysfunction. In the lung, diffuse epithelial and endothelial injury leads to increased alveolar capillary permeability and florid pulmonary oedema. Clinically, patients present with acute severe hypoxaemia and poor lung compliance, often necessitating invasive mechanical ventilation (Dushianthan 2011). The reported incidence of ARDS varies between countries and ranges from 16 to 78 per 100,000 population (Walkey 2012). Several predisposing conditions and risk factors contribute to the development of ARDS. Shock, sepsis, pneumonia, aspiration, and pancreatitis are the clinical conditions commonly associated with increased likelihood of developing ARDS (Gajic 2011). Hospital mortality associated with ARDS varies between $27 \%$ and $45 \%$, depending on the severity of the disease (Ranieri 2012). Survivors of ARDS have significant long-term physical, cognitive, and psychological sequelae (Herridge 2011; Wang 2014).

Since the first description of ARDS in 1967 (Ashbaugh 1967), diagnostic definitions have evolved. The AmericanEuropean Consensus Criteria, published in 1994, provide the most frequently utilized definition among published randomized controlled trials (RCTs) of patients with ARDS (Bernard 1994). According to these criteria, ARDS is recognized by bilateral pulmonary infiltrates on chest radiograph, with a ratio of partial pressure of oxygen $\left(\mathrm{PaO}_{2}\right)$-tofraction of inspired oxygen $\left(\mathrm{FiO}_{2}\right)$ of less than $200 \mathrm{mmHg}$, in the absence of raised left atrial hypertension. If less hypoxia is evident, defined as a $\mathrm{PaO}_{2} / \mathrm{FiO}_{2}$ ratio less than $300 \mathrm{mmHg}$, the syndrome is termed 'acute lung injury' (Bernard 1994). However, due to several limitations of this definition, new criteria proposed by an expert consensus panel in 2012 constitute the 'Berlin definition' of ARDS (Ranieri 2012). This definition eliminated the existing term 'acute lung injury' and identified patients as having ARDS when they fulfilled all of the following criteria.

1. Onset within seven days of a known clinical insult.

2. Bilateral opacities on chest imaging.

3. $\mathrm{PaO}_{2} / \mathrm{FiO}_{2}$ ratio less than $300 \mathrm{mmHg}$.

4. Hypoxaemia not fully explained by cardiac failure or fluid overload.

ARDS has been further subcategorized into mild $\left(\mathrm{PaO}_{2} / \mathrm{FiO}_{2} 201\right.$ to $\left.300 \mathrm{mmHg}\right)$, moderate $\left(\mathrm{PaO}_{2} / \mathrm{FiO}_{2} 100\right.$ to 200 $\mathrm{mmHg}$ ), and severe $\left(\mathrm{PaO}_{2} / \mathrm{FiO}_{2}<100 \mathrm{mmHg}\right.$ ), according to the severity of hypoxaemia (Ranieri 2012).

At present, no effective pharmacotherapies are known to moderate the disease process of ARDS. Evidence suggests survival benefit from 'protective' lung ventilation strategies designed to minimize further lung injury during mechanical ventilation.

\section{Description of the intervention}

'Immunonutrition' refers to modulation of the immune system provided by specific interventions that modify dietary nutrients (Calder 2003). It has long been recognized that supplementary immunonutrients may alter the course of critical illness following sepsis, trauma, or surgery (Beale 1999). Several specialized enteral and parenteral formulas with immunonutrients are currently available on the market. These primarily consist of a combination of antioxidant vitamins (vitamin C, vitamin E, beta-carotene), trace elements (selenium, zinc), essential amino acids (glutamine, arginine) or essential fatty acids, such as omega-3 fatty acids (eicosapentaenoic acid, docosahexaenoic acid), and gamma-linolenic acid (GLA) (Mizock 2010).

\section{How the intervention might work}

Acute respiratory distress syndrome is characterized by overt recruitment of neutrophils, significant release of proinflammatory cytokines and chemokines, and activation of pro-coagulant cascades and prostaglandin pathways with increased oxidative stress, causing damage to both lipids and proteins (Matthay 2011). In patients with ARDS, significant imbalance in the antioxidant system with a relative increase in oxidative stress leads to increased alveolar injury (Lang 2002; Metnitz 1999; Schmidt 2004). Among critically ill patients in general, supplementation of antioxidants is associated with a favourable outcome (Heyland 2005). Macronutrients such as glutamine and arginine also have immunomodulatory properties and have been used in several clinical trials of critically ill and surgical patients (Andrews 2011; Heyland 2001; Heyland 2013; Novak 2002). Glutamine improves gut barrier function and can be an energy source for lymphocytes, neutrophils, and macrophages (Newsholme 1985; Soares 2014 ), whereas arginine deficiency, which is commonly encountered following critical illness, may impair T-cell function (Popovic 2007). Omega-3 fatty acids are essential lipids, enriched in fish oil and consisting of polyunsaturated fatty acids such as eicosapentaenoic acid (EPA), alpha-linolenic acid (ALA), and docosahexaenoic acid (DHA). Therapeutic supplementation of these nutrients, which have immunomodulatory properties, has been shown to moderate the inflammatory response through suppression of pro-inflammatory eicosanoid biosynthesis (Calder 2007), attenuation of pulmonary neutrophil accumulation (Mancuso 1997a), reduction in lung permeability (Mancuso 1997b), and attenuation of cardiopulmonary dysfunction in animal models of lung injury (Murray 1995). Furthermore, in endotoxaemic rat models, EPA has been shown to reduce pulmonary oedema (Sane 2000).

\section{Why it is important to do this review}

Various types of immunonutrition have the potential to influence clinical outcomes in critically ill patients (Mizock 2010 ). Several RCTs have investigated enteral supplementation of omega-3 fatty acids and antioxidants, which, when combined in a meta-analysis, showed a significant reduction in mortality with improvement in oxygenation for patients 
with acute lung injury (ALI) and ARDS (Pontes-Arruda 2008). However, recent studies have presented conflicting results, suggesting lack of benefit and possibly even harm caused by this intervention (Rice 2011; Stapleton 2011). Among critically ill patients, enteral supplementation of glutamine conferred no clinical benefit (van Zanten 2015), and a large RCT showed a trend towards increased mortality associated with glutamine therapy (Heyland 2013). This lack of demonstrable clinical benefit in recent studies conflicts with the established literature and may be due to heterogeneity of diseases within the population of critical care patients, or variations in the type, route, and dose of immunonutrients administered. Uncertainty arising from these conflicting results remains. This review aims to provide a comprehensive evaluation of the effects of immunonutrients for patients with ARDS.

\section{Objectives}

To systematically review and critically appraise available evidence on the effects of immunonutrition compared to standard non-immunonutrition formula feeding on mechanically ventilated adults (aged 18 years or older) with acute respiratory distress syndrome (ARDS).

\section{Methods}

\section{Criteria for considering studies for this review}

\section{Types of studies}

We included all randomized and quasi-randomized controlled trials (qRCTs), with or without blinding. We did not apply language restrictions. We excluded non-randomized controlled trials and observational studies due to increased risk of bias.

\section{Types of participants}

We included all studies involving mechanically ventilated adult participants (aged 18 years or older) with ARDS as defined by the Berlin definition of ARDS (Ranieri 2012), or, for older studies, as defined by American-European Consensus Criteria for both ARDS and ALI (Bernard 1994). We restricted this review to trials conducted in critically ill adults, as pathophysiology and management strategies differ in paediatric and neonatal populations compared with adults.

\section{Types of interventions}

Eligible trials included intervention groups consisting of participants given enteral or parenteral immunonutrients, additionally supplemented with or as part of a nutritional formula. In comparison, control groups comprised participants who received placebo or standard nutrition with a non-immunonutrient formula feed. The immunonutrients could be amino acids (glutamine, arginine), antioxidants, or essential fatty acids, such as omega-3 fatty acids supplemented for any duration and at any dose.

\section{Types of outcome measures}

\section{Primary outcomes}

1. All-cause mortality (longest period reported)

\section{Secondary outcomes}

1. 28-day mortality

2. Intensive care unit (ICU) length of stay (LOS) and ICU-free days at day 28 (days)

3. Ventilator days and ventilator-free days at day 28 (days)

4. Hospital LOS (days)

5. Indices of oxygenation (measured as $\mathrm{PaO}_{2} / \mathrm{FiO}_{2}$ ratio $(\mathrm{mmHg}$ ) at days 4 and 7 )

6. Other organ failure (measured as change in organ failure scores: Sequential Organ Failure Assessment (SOFA) score, Multiple Organ Dysfunction Score (MODS); number of patients with new organ failure developed during the study period)

7. Nosocomial infection (additional infection developed during hospital stay and reported anytime during the study period)

8. Adverse events (author-defined cardiac events, gastrointestinal events, and total adverse events reported anytime during the study period)

\section{Search methods for identification of studies}

\section{Electronic searches}

We identified RCTs through literature searching with systematic and sensitive search strategies, as outlined in Chapter 6.4 of the Cochrane Handbook for Systematic Reviews of Interventions (Higgins 2011). We did not apply restrictions to language or publication status. We searched the following databases for relevant trials.

1. Cochrane Central Register of Controlled Trials (CENTRAL; 2018, Issue 4, April) in the Cochrane Library.

2. MEDLINE (OVID SP; 1966 to April week 3 2018).

3. Embase (OVID SP; 1988 to April week 3 2018).

We developed a subject-specific search strategy for MEDLINE and used that as the basis for the search strategies used in other databases listed. When appropriate, we expanded the search strategy with search terms for identifying RCTs. All search strategies can be found in Appendix 1, Appendix 2, Appendix 3, and Appendix 4.

We scanned the following trial registries for ongoing and unpublished trials (April 2018).

1. World Health Organization International Clinical Trials Resgistry Platform (WHO ICTRP).

$$
4 / 51
$$




\section{ClinicalTrials.gov.}

\section{Searching other resources}

We scanned the reference lists and citations of included trials and any relevant systematic reviews identified for further references to additional trials. We manually searched for relevant citations from published studies, previous systematic reviews, and conference proceedings from major intensive care and nutrition societies (i.e. Intensive Care Society, UK; European Society of Intensive Care Medicine; Society of Critical Care Medicine; American Thoracic Society; Canadian Critical Care Society; American Society of Parenteral and Enteral Nutrition; European Society for Parenteral and Enteral Nutrition).

When necessary, we contacted trial authors to request additional information.

\section{Data collection and analysis}

\section{Selection of studies}

Two review authors (AD and RC) independently screened appropriate studies for study characteristics and outcomes. We resolved disagreements by further discussion and with involvement of a third review author (MG).

\section{Data extraction and management}

Two review authors ( $A D$ and $R C / V L$ ) independently performed data extraction using a data extraction form that was piloted before it was applied in this study (Appendix 5). We recorded study characteristics including patient population (ARDS), intervention details (type, dose, duration), study methods (blinding, allocation, etc.), and outcome measures of interest. We resolved disagreements by consensus or by consultation with the third member of the review author team (MG).

If observations were not reported as means and standard deviations (SDs), we contacted trial authors for additional information. In the absence of any further information, we used the statistical equation from $\mathrm{Hozo} 2005$ to convert the median (range/interquartile range (IQR)) to the mean (SD). We estimated the SD as IQR/1.35, standard error of the mean (SEM) $\times$ $\sqrt{ }(\mathrm{n}), 95 \%$ confidence interval $(\mathrm{Cl}) / 1.96$. We estimated standard deviations from $\mathrm{P}$ values according to information provided in the Cochrane Handbook for Systematic Reviews of Interventions (Higgins 2011).

\section{Assessment of risk of bias in included studies}

Two review authors ( $A D$ and $R C / V L$ ) assessed the risk of bias of included studies according to criteria presented in the Cochrane Handbook for Systematic Reviews of Interventions (Higgins 2011). We resolved disagreements by discussion or by consultation with the third review author (MG). We assigned the included studies to low risk of bias (when all domains were satisfied), high risk of bias (if one or more domains were inadequate), or unclear risk of bias, according to the criteria provided in the Cochrane 'Risk of bias' tool. We used the following six domains to assess risk of bias in the included studies.

1. Selection bias (random sequence generation and allocation concealment).

2. Performance bias (blinding of participants and personnel).

3. Detection bias (blinding of outcome assessment).

4. Attrition bias (incomplete outcome data).

5. Reporting bias (selective reporting).

6. Any other potential biases that might be present.

\section{Measures of treatment effect}

We based the outcome analysis on intention-to-treat (ITT). We calculated weighted treatment effects using Review Manager 5.3 (Review Manager 2014). We expressed dichotomous outcomes, such as mortality, as risk ratios (RRs) with 95\% confidence intervals (Cls), and continuous variables as mean differences (MDs) with standard deviations (SDs).

\section{Unit of analysis issues}

To prevent unit of analysis issues, when combining groups for continuous outcomes, we used the formula suggested by the Cochrane Handbook for Systematic Reviews of Interventions (Higgins 2011).

\section{Dealing with missing data}

When we encountered missing data, we contacted the authors of included studies to request further information. In the absence of an appropriate response, we analysed the data using the best available information. We performed ITT analysis.

\section{Assessment of heterogeneity}

We assessed the clinical heterogeneity of studies in relation to study population, interventions, and outcome measures. We also assessed inconsistencies and variability in outcomes among studies using the $\mathrm{I}^{2}$ statistic. Variation greater than $40 \%$ among outcomes may not be explained by sampling variation. We assumed substantial statistical heterogeneity when the $\mathrm{I}^{2}$ statistic exceeded $40 \%$ (Higgins 2011).

\section{Assessment of reporting biases}

We included 10 studies; therefore, we used graphical evidence of reporting biases via contour-enhanced funnel plots with a subsequent Harbord or Egger's test (Egger 1997; Harbord 2006).

\section{Data synthesis}

We pooled data according to the type of immunomodulatory agent. Most studies used a combination of omega-3 fatty acid, GLA, and antioxidant solutions; therefore, we pooled the results of these studies. We conducted statistical data 
analysis using Review Manager 5.3 (Review Manager 2014), in accordance with recommendations provided in the Cochrane Handbook for Systematic Reviews of Interventions (Higgins 2011). We based our analysis on the ITT principle and utilized fixed-effect and random-effects models, depending on statistical heterogeneity. We used a fixed-effect model unless we noted significant statistical heterogeneity, defined by an $\mathrm{I}^{2}$ value $>40 \%$.

\section{Subgroup analysis and investigation of heterogeneity}

We conducted subgroup analyses for the primary outcome according to the following.

1. Type of intervention.

2. Route of intervention (parenteral/enteral).

3. Mode of intervention (continuous/bolus).

4. Intervention duration (days).

\section{Sensitivity analysis}

We performed sensitivity analysis for the primary outcome while excluding studies with high risk of bias. Continuous data for the secondary outcomes were skewed. We conducted sensitivity analysis for these secondary outcomes by log transformation. Given that we obtained no raw log-transformed data from study authors, we transformed the mean and the standard deviation in accordance with recommendations provided in the Cochrane Handbook for Systematic Reviews of Interventions (Higgins 2011). Analyses for two of the secondary outcomes - ICU-free days and ventilator-free days at day 28 - were sensitive to statistical methods; we also performed sensitivity analyses for these outcomes using both fixed-effect and random-effects models (Table 1).

\section{'Summary of findings' table and GRADE}

We used the principles of the GRADE system to assess the quality of the body of evidence associated with specific outcomes (Guyatt 2008): all-cause mortality, ICU length of stay, ventilator days, $\mathrm{PaO}_{2} / \mathrm{FiO}_{2}$ ratio at day 4, and adverse events. We constructed a 'Summary of findings' table using GRADE software (GRADEpro GDT). Through the GRADE approach, we appraised the quality of a body of evidence based on the extent to which one can be confident that an estimate of effect or association reflects the item being assessed. Assessment of the quality of a body of evidence considers within-study risk of bias (methodological quality), directness of evidence, heterogeneity of data, precision of effect estimates, and risk of publication bias.

\section{Results}

\section{Description of studies}

See characteristics of Included studies.

\section{Results of the search}

The combined search yielded 3367 studies for possible inclusion. We chose 131 abstracts for further evaluation after screening and removal of duplicates. We retrieved a total of 13 publications reporting $10 \mathrm{RCTs}(\underline{\text { Figure } 1)}$. We included the publication that reported the main clinical outcomes, and we omitted duplicate reports.

\section{Included studies}

\section{Characteristics of patient population}

Nine of the 10 included studies used the American-European Consensus Criteria (AECC) for identification of ARDS or ALI (Elamin 2012; Gadek 1999; Gupta 2012; Parish 2014; Pontes-Arruda 2006; Rice 2011; Shirai 2015; Singer 2006; Stapleton 2011). The remaining study enrolled ventilated patients with septic shock and did not explicitly define this population as ARDS/ALI or not (Grau-Camona 2011). However, baseline characteristics suggest that the $\mathrm{PaO}_{2} / \mathrm{FiO} 2$ ratio was $<300 \mathrm{mmHg}$ for all participants, and of those, $71 \%$ had ARDS at the time of recruitment. It is possible that not all of these participants may have satisfied ARDS/ALI criteria. For included studies, the mean $\mathrm{PaO}_{2} / \mathrm{FiO}{ }_{2}$ was 157 $\mathrm{mmHg}$ for intervention groups and $167 \mathrm{mmHg}$ for control groups, suggesting moderate severity according to the current Berlin definition of ARDS (Ranieri 2012). Three studies were conducted specifically in participants with sepsisinduced ARDS (Grau-Camona 2011; Pontes-Arruda 2006; Shirai 2015).

\section{Characteristics of intervention provided}

We did not identify any other intervention apart from omega-3 fatty acids (EPA and DHA) and GLA with or without antioxidant-based enteral formula or supplementation. Several clinical trials investigated the use of glutamine supplementation for critical illness, but none specifically focussed on ARDS (van Zanten 2015).

Among the 10 included studies, six studies used a similar enteral preparation (Oxepa; Abbott Nutrition/Abbott Laboratories, Columbus, OH, USA) continuously supplemented with EPA, DHA, GLA, and antioxidants (Elamin 2012; Gadek 1999; Grau-Camona 2011; Pontes-Arruda 2006; Shirai 2015; Singer 2006). Four of these six studies used an isocaloric high-fat formulation (Pulmocare; Abborr Nutrition/Abbott Laboratories, Columbus, OH, USA) for control groups (Elamin 2012; Gadek 1999; Pontes-Arruda 2006; Singer 2006). The remaining two studies used a carbohydrate-based control formulation (Ensure Plus or Ensure Liquid; Abbott Laboratories, East Windsor, NJ, USA) (GrauCamona 2011; Shirai 2015).

Three studies used additional enteral supplementation of fish oil (Stapleton 2011), omega-3 gels (Parish 2014), or intravenous formulation with $10 \%$ fish oil (Gupta 2012), and control groups received the same enteral feeding 
EC290 Immunonutrition for acute respiratory distress syndrome (ARDS) in adults

formulation as intervention groups. One study gave boluses of a high-fat formulation enriched in EPA, DHA, GLA, and antioxidants and compared this with isocaloric-isovolaemic carbohydrate-rich control nutrition (Rice 2011).

Five studies defined a target enteral nutrition delivery rate of $50 \%$ to $75 \%$ of basal/resting energy expenditure (BEE/REE) for the first 24 hours with variable increments to achieve $70 \%$ to 100\% of BEE/REE (Elamin 2012; Gadek 1999; Pontes-Arruda 2006; Shirai 2015; Singer 2006). The duration of intervention was 7 or fewer days (Elamin 2012; Gadek 1999), 14 days (Gupta 2012; Parish 2014; Shirai 2015; Singer 2006; Stapleton 2011), 21 days (Rice 2011), or 28 days (Grau-Camona 2011; Pontes-Arruda 2006).

\section{Outcome measures reported}

All 10 included studies reported mortality. One study reported this for the duration of the study period (Gadek 1999), six studies at 28 days (Elamin 2012; Grau-Camona 2011; Gupta 2012; Parish 2014; Pontes-Arruda 2006; Singer 2006), one study at hospital discharge or at day 60 (Rice 2011), one study in hospital and at 60 days ( Stapleton 2011), and another study at 60 days ( Shirai 2015).

Eight studies reported ICU LOS (Elamin 2012; Gadek 1999; Grau-Camona 2011; Gupta 2012; Parish 2014; Shirai 2015; Singer 2006; Stapleton 2011), and five reported ICU-free days at day 28 (Gadek 1999; Pontes-Arruda 2006; Rice 2011; Shirai 2015; Stapleton 2011). Three studies reported hospital LOS (Gadek 1999; Gupta 2012; Stapleton 2011).

Seven studies reported ventilator days (Elamin 2012; Gadek 1999; Grau-Camona 2011; Gupta 2012; Shirai 2015; Singer 2006; Stapleton 2011), and six reported this outcome as ventilator-free days at day 28 (Gadek 1999; Parish 2014; PontesArruda 2006; Rice 2011; Shirai 2015; Stapleton 2011).

All included studies reported changes in oxygenation index $\left(\mathrm{PaO}_{2} / \mathrm{FiO}_{2}\right.$ ratio) for various time points (baseline, day 1 , day 2 , day 3 , day 4 , day 5 , day 7 , day 8 , day 14 , and day 21 ). Six studies reported day $4 \mathrm{PaO}_{2} / \mathrm{FiO}_{2}$ ratios (Elamin 2012; Gadek 1999; Gupta 2012; Pontes-Arruda 2006; Singer 2006; Stapleton 2011), and seven studies reported day 7 $\mathrm{PaO}_{2} / \mathrm{FiO}_{2}$ ratios (Elamin 2012; Gadek 1999; Grau-Camona 2011; Gupta 2012; Parish 2014; Pontes-Arruda 2006; Shirai 2015). We used these time points for the meta-analysis.

Researchers reported new organ failure in several different ways: change in or worst MODS (Elamin 2012; Stapleton 2011 ), change in SOFA score (Grau-Camona 2011), number of participants with new organ failure (Gadek 1999; Pontes-Arruda 2006), and organ failure-free days (Rice 2011).

Three studies reported nosocomial infection (Grau-Camona 2011; Rice 2011; Shirai 2015).

Six studies reported adverse events (Gadek 1999; Grau-Camona 2011; Pontes-Arruda 2006; Rice 2011; Shirai 2015; Stapleton 2011). Two studies reported system-based adverse events with total numbers of events (Gadek 1999; PontesArruda 2006). One study reported individual and total numbers of adverse events (Stapleton 2011).

See $\underline{\text { Characteristics of included studies. }}$

\section{Excluded studies}

We excluded no randomized controlled studies.

\section{Awaiting classification}

No studies are currently awaiting classification.

\section{Ongoing studies}

We identified no ongoing studies.

Risk of bias in included studies

See Figure 2 and Figure 3.

\section{Allocation (selection bias)}

All included studies reported randomization. Elght studies reported the method of random sequence generation used ( Elamin 2012; Gadek 1999; Grau-Camona 2011; Gupta 2012; Parish 2014; Rice 2011; Singer 2006; Stapleton 2011). One study described alternating allocation (Elamin 2012), and two other studies did not describe the method of randomization used (Pontes-Arruda 2006; Shirai 2015). We categorized these studies as having high risk of selection bias. Five studies did not specifically report on allocation concealment, and we categorized these as having unclear risk of bias (Elamin 2012; Gupta 2012; Pontes-Arruda 2006; Shirai 2015; Singer 2006).

\section{Blinding (performance bias and detection bias)}

Six studies were double-blinded (Elamin 2012; Gadek 1999; Parish 2014; Pontes-Arruda 2006; Rice 2011; Stapleton 2011 ). One study was not blinded (Singer 2006). Three other studies reported single or investigator blinding (Grau-Camona 2011; Gupta 2012; Shirai 2015). We assigned these studies as having high risk of performance or detection bias (Gupta 2012; Shirai 2015; Singer 2006).

\section{Incomplete outcome data (attrition bias)}

We detected attrition bias in five studies that excluded participants from their ITT analysis for various reasons, including diarrhoea, steroid use, withdrawal of care, or treating physician preference, and as a consequence of protocol violations (Elamin 2012; Gadek 1999; Grau-Camona 2011; Pontes-Arruda 2006; Singer 2006). 
EC290 Immunonutrition for acute respiratory distress syndrome (ARDS) in adults

\section{Selective reporting (reporting bias)}

We judged that all 10 included studies had low risk of reporting bias, and they reported all prespecified outcomes.

\section{Other potential sources of bias}

Authors of four studies reported that they were industry supported (Gadek 1999; Grau-Camona 2011; Pontes-Arruda 2006; Singer 2006). We rated these studies as having unclear risk of bias.

\section{Effects of interventions}

\section{Comparison. Omega-3 fatty acids and antioxidants versus placebo or standard nutrition}

Primary outcome: all-cause mortality (longest period reported)

All studies reported mortality. The range of reported mortality varied between studies: six studies reported this outcome at day 28 (Elamin 2012; Grau-Camona 2011; Gupta 2012; Parish 2014; Pontes-Arruda 2006; Singer 2006), three studies at day 60 (Parish 2014; Rice 2011; Shirai 2015), and one for the study duration. We included all 10 studies with 1015 participants in this analysis (Elamin 2012; Gadek 1999; Grau-Camona 2011; Gupta 2012; Parish 2014; Pontes-Arruda 2006; Rice 2011; Shirai 2015; Singer 2006; Stapleton 2011). No evidence showed the use of omega-3 fatty acids and antioxidants for reducing mortality at the longest period reported (risk ratio (RR) $0.79,95 \%$ confidence interval (Cl) 0.59 to $1.07 ; I^{2}=42 \%$; participants $=1015$; Analysis 1.1 ). The pooled control group mortality rate was $28 \%$, and the pooled intervention group mortality rate was $23.5 \%$ for the longest period reported. Overall mortality varied between studies and ranged from $6 \%$ to $43 \%$. A funnel plot of the primary outcome prepared to test the effect of publication bias showed no evidence of data asymmetry (Egger's regression test, with $P=0.81$ ) (Figure 4). We downgraded the quality of evidence by two levels due to inconsistency from clinical and methodological heterogeneity and indirectness for intervention and comparator.

\section{Secondary outcomes}

\section{Mortality at 28 days}

Six studies with 466 participants reported 28-day mortality (Elamin 2012; Grau-Camona 2011; Gupta 2012; Parish 2014; Pontes-Arruda 2006; Singer 2006). We noted uncertain evidence for use of omega-3 fatty acids and antioxidants in terms of mortality at 28 days (RR $0.61,95 \% \mathrm{Cl} 0.46$ to $0.81 ; \mathrm{I}^{2}=0 \%$; Analysis 1.2 ). This analysis was limited by the small number of participants, which accounted for less than $50 \%$ of the total participants included. We downgraded the quality of evidence by three levels due to increased risk of bias, inconsistency due to clinical and methodological heterogeneity, and indirectness for both intervention and comparator.

\section{Intensive care unit length of stay (ICU LOS) and ICU-free days at day 28}

Eight studies with 641 participants reported ICU LOS (Elamin 2012; Gadek 1999; Grau-Camona 2011; Gupta 2012; Parish 2014; Shirai 2015; Singer 2006; Stapleton 2011). Two studies reported this outcome as mean \pm standard error (Gadek 1999; Shirai 2015). Two studies published separate data for participants who survived and those who did not survive (Gupta 2012; Singer 2006). We combined these groups according to recommendations provided in the Cochrane Handbook for Systematic Reviews of Interventions (Higgins 2011). We obtained further information from the authors of three studies (Elamin 2012; Grau-Camona 2011; Stapleton 2011). We found uncertain evidence suggesting that omega-3 fatty acids and antioxidants may reduce ICU LOS (mean difference (MD) -3.12 days, $95 \% \mathrm{Cl}-5.24$ to $-1.01 ; \mathrm{I}^{2}=55 \%$; Analysis 1.3 ).

Five studies with 609 participants reported ICU-free days at day 28 (Gadek 1999; Pontes-Arruda 2006; Rice 2011; Shirai 2015; Stapleton 2011). For two studies, we estimated the standard deviation from the P value or the IQR (Gadek 1999; Shirai 2015), respectively, as we were not able to obtain further information from study authors. We found uncertain evidence that omega-3 fatty acids and antioxidants may increase ICU-free days at day 28 (MD 3.44, 95\% Cl -1.17 to $8.05 ; I^{2}=87 \%$; Analysis 1.4). We performed random-effects model analysis due to significant statistical heterogeneity, with $\mathrm{I}^{2}=87 \%$.

We downgraded the quality of evidence for both of these outcomes by three levels due to increased risk of bias, inconsistency due to clinical and methodological heterogeneity, and indirectness for intervention and comparator.

\section{Ventilator days and ventilator-free days at day 28}

Seven studies with 583 participants reported duration of mechanical ventilation (Elamin 2012; Gadek 1999; Grau-Camona 2011; Gupta 2012; Shirai 2015; Singer 2006; Stapleton 2011). Uncertain evidence suggests that omega-3 fatty acids and antioxidants may reduce the duration of mechanical ventilation (MD $-2.25,95 \% \mathrm{Cl}-3.78$ to $-0.71 ; \mathrm{I}^{2}=7 \%$; Analysis 1.5 ). Six studies with 665 participants reported the duration of mechanical ventilation as ventilation-free days at day 28 (Gadek 1999; Parish 2014; Pontes-Arruda 2006; Rice 2011; Shirai 2015; Stapleton 2011). Uncertain evidence suggests that omega-3 fatty acids and antioxidants may increase ventilation-free days (MD 2.15, 95\% Cl -0.91 to $5.22 ; I^{2}=84 \%$; Analysis 1.6). We performed random-effects model analysis due to significant statistical heterogeneity, with $\mathrm{I}^{2}=84 \%$.

We downgraded the quality of evidence for both of these outcomes by three levels due to increased risk of bias, inconsistency due to clinical and methodological heterogeneity, and indirectness for intervention and comparator.

\section{Hospital length of stay (days)}

Three studies with 293 participants reported hospital length of stay (Gadek 1999; Gupta 2012; Stapleton 2011). Uncertain evidence suggests that omega- 3 fatty acids and antioxidants may reduce the duration of hospital LOS (MD $-2.72,95 \% \mathrm{Cl}$ -6.93 to $1.50 ; I^{2}=0 \%$; Analysis 1.7). We downgraded the quality of evidence by three levels due to increased risk of bias, inconsistency due to clinical and methodological heterogeneity, and indirectness for intervention and comparator. 


\section{Indices of oxygenation (measured as $\mathrm{PaO}_{2} / \mathrm{FiO}_{2}$ ratio $(\mathrm{mmHg}$ ) at day 4 and day 7 )}

Researchers commonly reported oxygenation as the $\mathrm{PaO}_{2} / \mathrm{FiO}_{2}$ ratio $(\mathrm{mmHg})$. Nine studies with 659 participants reported this outcome at day 4 (Elamin 2012; Gadek 1999; Grau-Camona 2011; Gupta 2012; Pontes-Arruda 2006; Rice 2011; Shirai 2015; Singer 2006; Stapleton 2011). Two of these studies presented their $\mathrm{PaO}_{2} / \mathrm{FiO}_{2}$ data in pictorial format (Rice 2011; Shirai 2015). We were able to obtain additional information from one study (Rice 2011). We estimated the SD from P values for two studies (Elamin 2012; Pontes-Arruda 2006). However, we were not able to include one study due to lack of further information (Shirai 2015). Uncertain evidence suggests that omega-3 fatty acids and antioxidants may improve oxygenation defined as the $\mathrm{PaO}_{2} / \mathrm{FiO}_{2}$ ratio at day 4 (MD $39 \mathrm{mmHg}, 95 \% \mathrm{Cl} 11$ to $67 \mathrm{mmHg} ; \mathrm{I}^{2}=68 \%$; Analysis 1.8 ). Nine studies reported the $\mathrm{PaO}_{2} / \mathrm{FiO}_{2}$ ratio at day 7 (Elamin 2012; Gadek 1999; Grau-Camona 2011; Gupta 2012; Parish 2014; Pontes-Arruda 2006; Rice 2011; Shirai 2015; Singer 2006; Stapleton 2011). Uncertain evidence suggests that omega-3 fatty acids and antioxidants may improve oxygenation defined as $\mathrm{PaO}_{2} / \mathrm{FiO}_{2}$ ratios at day 7 (MD $23 \mathrm{mmHg}, 95 \% \mathrm{Cl}$ 2 to $45 \mathrm{mmHg} ; \mathrm{I}^{2}=54 \%$; Analysis 1.9). We downgraded the quality of evidence for both of these outcomes by three levels due to increased risk of bias, inconsistency due to clinical and methodological heterogeneity, and indirectness for intervention and comparator.

\section{Other organ failure (measured as change in organ failure scores: SOFA score, MODS, and number of participants with new organ failure)}

Seven studies reported new organ failure in several different ways (Elamin 2012; Gadek 1999; Grau-Camona 2011; PontesArruda 2006; Rice 2011; Shirai 2015; Stapleton 2011). Only two studies (249 participants) reported the number of participants with new organ failure (Gadek 1999; Pontes-Arruda 2006), and we pooled results of these studies. Use of omega- 3 fatty acids and antioxidants for prevention of new organ failure is uncertain (RR $0.46,95 \% \mathrm{Cl} 0.33$ to $0.64 ;\left.\right|^{2}=0 \%$; Analysis 1.10). We downgraded the quality of evidence by three levels due to increased risk of bias, inconsistency due to clinical and methodological heterogeneity, and indirectness for intervention and comparator. We were not able to pool other studies due to variation in reporting this outcome as MODS (Elamin 2012), worse MODS (Stapleton 2011 ), SOFA score (Grau-Camona 2011), organ failure-free days (Rice 2011), and changes in SOFA scoring (Shirai 2015).

\section{Nosocomial infection (additional infection developed during hospital stay)}

Three studies with 450 participants reported the number of participants with new nosocomial infection (Grau-Camona 2011; Rice 2011; Shirai 2015). Uncertain evidence suggests that omega-3 fatty acids and antioxidants may reduce new nosocomial infection between groups ( $R R=1.01,95 \% \mathrm{Cl} 0.76$ to $1.33 ; \mathrm{I}^{2}=0 \%$; Analysis 1.11 ). We downgraded the quality of evidence by three levels due to increased risk of bias, inconsistency due to clinical and methodological heterogeneity, and indirectness for intervention and comparator.

\section{Adverse events (cardiac events, gastrointestinal events, and total adverse events)}

Six studies reported adverse events (Gadek 1999; Grau-Camona 2011; Pontes-Arruda 2006; Rice 2011; Shirai 2015; Stapleton 2011). Two studies reported these as system based (Gadek 1999; Pontes-Arruda 2006), and Stapleton 2011 reported all adverse events. Three studies with 339 participants reported cardiac adverse events (Gadek 1999; PontesArruda 2006; Stapleton 2011). Uncertain evidence suggests that use of omega-3 fatty acids and antioxidants may increase cardiac events (RR $0.87,95 \% \mathrm{Cl} 0.09$ to $8.46 ;\left.\right|^{2}=57 \%$; Analysis 1.12). Five studies reported gastrointestinal adverse events (Gadek 1999; Grau-Camona 2011; Pontes-Arruda 2006; Rice 2011; Shirai 2015). One study reported these as a percentage of ventilated days, and we did not include this value in the meta-analysis (Rice 2011). Uncertain evidence suggests that use of omega-3 fatty acids and antioxidants may increase gastrointestinal events (four studies with 427 participants) (RR 1.15, 95\% Cl 0.75 to 1.76; $I^{2}=0 \%$; Analysis 1.13). Five studies with 517 participants reported total numbers of adverse events (Gadek 1999; Grau-Camona 2011; Pontes-Arruda 2006; Shirai 2015; Stapleton 2011). Uncertain evidence suggests that use of omega-3 fatty acids and antioxidants may increase total numbers of adverse events between groups (RR $0.94,95 \% \mathrm{Cl} 0.69$ to $1.27 ; \mathrm{I}^{2}=0 \%$; Analysis 1.14 ). We downgraded the quality of evidence for all these outcomes by three levels due to increased risk of bias, inconsistency due to clinical and methodological heterogeneity, and indirectness for intervention and comparator.

\section{Subgroup analysis for the primary outcome: all-cause mortality (longest period reported) \\ Type of intervention}

The type of intervention varied between studies, as explained previously in the Description of studies section. For the primary outcome, we performed a subgroup analysis for types of intervention given. Four studies with 361 participants added an enteral formula enriched in EPA, GLA, DHA, and antioxidants to a lipid-rich omega-6 fatty acid-based control diet (Elamin 2012; Gadek 1999; Pontes-Arruda 2006; Singer 2006). We are uncertain of any mortality benefit when investigators compared an omega-3 fatty acid and/or antioxidant group versus a lipid-rich control group (RR $0.57,95 \% \mathrm{Cl}$ 0.42 to $0.78 ; I^{2}=0 \%$; Analysis 1.15 ), or versus a carbohydrate-rich control group (RR $1.13,95 \% \mathrm{Cl} 0.57$ to $2.22 ; I^{2}=0 \%$; participants $=178$; studies $=2$; Analysis 1.15) (Grau-Camona 2011; Shirai 2015), or versus additional supplementation of omega-3 fatty acids (RR 0.75, 95\% Cl 0.48 to $1.15 ;\left.\right|^{2}=0 \%$; participants = 204; studies = 3; Analysis 1.15 ) (Gupta 2012; Parish 2014; Stapleton 2011).

\section{Route of administration (parenteral/enteral) of intervention}

Only one study gave intravenous omega-3 fatty acid supplementation (Gupta 2012). All remaining studies gave enteral supplementation. We are uncertain of any mortality benefit derived by route of administration of the intervention (nine studies with 954 participants) (RR 0.82, 95\% Cl 0.59 to 1.14; $I^{2}=47 \%$; Analysis 1.16) (Elamin 2012; Gadek 1999; Grau-Camona 2011; Parish 2014; Pontes-Arruda 2006; Rice 2011; Shirai 2015; Singer 2006; Stapleton 2011).

\section{$9 / 51$}




\section{Mode (continuous/bolus) of intervention}

Six studies gave continuous enteral nutrition (Elamin 2012; Gadek 1999; Grau-Camona 2011; Pontes-Arruda 2006; Shirai 2015; Singer 2006), and one study used intravenous infusion (Gupta 2012). The remaining three studies used bolus supplementation (Parish 2014; Rice 2011; Stapleton 2011). We are uncertain of any mortality benefit derived by continuous infusion, received enterally or parenterally $\left(\mathrm{RR} 0.65,95 \% \mathrm{Cl} 0.50\right.$ to $0.84 ; I^{2}=0 \%$; participants $=600$; studies $=7$; Analysis 1.17). We are uncertain of any mortality benefit derived by bolus supplementation (RR $1.17,95 \% \mathrm{Cl} 0.72$ to $1.88 ; I^{2}=34 \%$; participants $=415$; studies $=3$; Analysis 1.17).

\section{Duration of intervention}

Duration of intervention varied among studies. One study reported the intervention period as 4 or fewer days (Gadek 1999 ). Others reported 7 days (Elamin 2012), 14 days (Gupta 2012; Parish 2014; Shirai 2015; Singer 2006; Stapleton 2011), 21 days (Rice 2011), and 28 days (Grau-Camona 2011; Pontes-Arruda 2006). We are uncertain of any mortality benefit associated with duration of intervention for fewer than 7 days $\left(\mathrm{RR} 0.61,95 \% \mathrm{Cl} 0.32\right.$ to $1.17 ; \mathrm{I}^{2}=0 \%$; participants $=163$; studies = 2; Analysis 1.18), for 14 days (RR $0.64,95 \% \mathrm{Cl} 0.47$ to $0.89 ; \mathrm{I}^{2}=0 \%$; participants $=345$; studies $=5$; Analysis 1.18 ), or for 28 days (RR 0.79, $95 \% \mathrm{Cl} 0.44$ to $1.44 ; I^{2}=44 \%$; participants $=235$; studies $=2$; Analysis 1.18 ).

We downgraded the quality of evidence for all subgroup analyses by three levels due to increased risk of bias, inconsistency due to clinical and methodological heterogeneity, and indirectness for intervention and comparator.

\section{Sensitivity analysis for the primary outcome excluding studies with high risk of bias}

We conducted sensitivity analysis for the primary outcome while excluding studies with high risk of bias. We included four studies in the analysis (Gadek 1999; Parish 2014; Rice 2011; Stapleton 2011). We found no evidence for the use of omega-3 fatty acids and antioxidants in reducing mortality at the longest period reported (RR $0.98,95 \% \mathrm{Cl} 0.60$ to $1.58 ; \mathrm{I}^{2}=$ $51 \%$; participants $=561$; Analysis 2.1). We graded quality of evidence as low and downgraded the evidence by two levels due to inconsistency from clinical and methodological heterogeneity and indirectness for intervention and comparator.

\section{Sensitivity analysis for secondary outcomes with log-transformed data}

Most data for continuous secondary outcomes such as ICU LOS (Analysis 1.3), ICU-free days at day 28 (Analysis 1.4 ), ventilator days (Analysis 1.5), ventilator-free days at day 28 (Analysis 1.6), and hospital LOS (Analysis 1.7) were skewed. Therefore, we performed sensitivity analysis for these outcomes from log-transformed data. We are uncertain whether this intervention confers any beneficial effect on ICU length of stay (mean log days $-0.08,95 \% \mathrm{Cl}-0.23$ to 0.06 ; participants = 641 ; studies = 8; $I^{2}=0 \%$; Analysis 2.2), ICU-free days at day 28 (mean log days $0.34,95 \% \mathrm{Cl} 0.00$ to 0.68 ; participants = 609 ; studies $=5 ; I^{2}=76 \%$; Analysis 2.3), ventilator days (mean log days $-0.08,95 \% \mathrm{Cl}-0.24$ to 0.07 ; participants $=583$; studies $=7 ; \mathrm{I}^{2}=0 \%$; Analysis 2.4), ventilator-free days at day 28 (mean log days $0.06,95 \% \mathrm{Cl}-0.06$ to 0.18 ; participants $=$ 665 ; studies $=6 ; I^{2}=0 \%$; Analysis 2.5), or hospital LOS (mean log days $-0.05,95 \% \mathrm{Cl}-0.34$ to 0.24 ; participants $=293$; studies $=3 ; I^{2}=0 \%$; Analysis 2.6). We downgraded the quality of evidence for all these outcomes by three levels due to increased risk of bias, inconsistency due to clinical and methodological heterogeneity, and indirectness for intervention and comparator.

\section{Sensitivity analysis for secondary outcomes of ICU-free days and ventilator-free days at day 28 according to} statistical method

We performed sensitivity analysis using both fixed-effect and random-effects models for secondary outcomes of ICUfree days and ventilator-free days at day 28 . Results were sensitive to the type of analytical method used (randomeffects or fixed-effect model) (Table 1).

\section{Discussion}

\section{Summary of main results}

We identified 10 randomized controlled trials (RCTs) evaluating effects of omega-3 fatty acids (eicosapentaenoic acid (EPA) and docosahexaenoic acid (DHA)), gamma-linolenic acid (GLA), and antioxidants, supplemented or given as part of an enteral nutrition formula, for the acute respiratory distress syndrome (ARDS) population. We identified no clinical trials with any other specific immunonutrition intervention for this patient population. We found no evidence that this type of nutrition improves the primary outcome of all-cause mortality at the longest period reported. Included studies showed clinical heterogeneity with respect to type, mode, and duration of intervention provided and type of enteral nutrition formulation received by the control group. We have performed subgroup analysis according to differing interventions in the control group. Although we noted a statistical reduction in mortality when omega- 3 fatty acids and/or antioxidants were compared with a lipid-rich enteral formula, we are uncertain due to very low-quality evidence whether this intervention improves mortality in the ARDS population. We also found uncertain evidence regarding reductions in duration of mechanical ventilation, intensive care unit (ICU) length of stay, improvement in oxygenation, and increased adverse events with this intervention.

\section{Overall completeness and applicability of evidence}

We performed appropriate and thorough searches of electronic databases to identify suitable studies. We applied no restrictions. We obtained additional study details from study authors when possible. Our meta-analysis incorporated 10 clinical trials of 1015 participants investigating immune-modifying nutrition in patients with ARDS. All studies used omega-3 fatty acid-based nutritional formula with or without antioxidants for the intervention. However, this approach was subject to significant clinical and statistical heterogeneity. Overall, pooled data did not support giving omega-3 fatty acids in combination with GLA and antioxidants to improve mortality in ARDS. Although results from some subgroup analyses 
indicate that the mortality risk ratio $(R R)$ was reduced when the intervention was given as a continuous enteral infusion against a lipid-rich control formulation, the quality of evidence is very low. Also, the isocaloric high-fat formula used in the control group diet was enriched in omega- 6 fatty acids with high content of linolenic acid and may have been harmful: in other words, the beneficial effect reported by those studies may have been due to potentially harmful effects of the lipid-rich diet given to the control group.

Given that mechanical ventilator days and length of ICU stay may be influenced by the death rate, critical care clinical trials more recently have widely reported ventilator and ICU-free days as better outcome measures. In general, ventilator and ICUfree days are used as a surrogate for overall ICU outcomes combining mortality with duration of mechanical ventilation and ICU length of stay, respectively. Study results show a difference in the pooled statistical analysis between outcomes of ICU days and ICU-free days. This was also true for ventilator days and ventilator-free days. Reporting of either numbers of days or numbers of free days (ventilation or ICU) can be subject to bias. For this reason, we meta-analysed both ways of reporting all available data from published trials (ventilator days/ventilator-free days and ICU length of stay (LOS)/ICU-free days). Alternatively, this disagreement between our secondary composite outcomes (ICU and ventilator-free days) and individual endpoints could be due to inclusion and exclusion of different studies from outcome analyses, based on available outcome measures or due to lack of standardized reporting. Nevertheless, due to low-quality evidence, we are uncertain whether use of an omega-3-based immune-modulating diet in ARDS improves ventilator days or ICU length of stay.

\section{Quality of the evidence}

Some studies did not provide adequate descriptive evidence for methods of randomization and allocation concealment. One study was unblinded, and two studies did not adequately clarify blinding of outcome assessment. Significant dropouts from several studies occurred for a variety of reasons, including protocol violations and intolerance of the intervention or trial. We graded these studies as having high risk of bias. Most studies reported anticipated outcomes and all reported mortality, although they were not adequately powered to detect differences between groups. We graded the quality of evidence for the primary outcome as low and for all secondary outcomes as very low because, despite the possibility of increased risk of bias, the primary outcome analysis included more than 1000 patients with more than 250 events and was not influenced by inclusion of studies with high risk of bias, as evidenced by the sensitivity analysis omitting these studies. Analyses of continuous outcome data for most secondary outcomes yielded skewed results. We were not able to obtain the raw transformed data from study authors; therefore, we performed sensitivity analysis using logarithmic transformations for these secondary outcomes. We encountered substantial statistical heterogeneity for several secondary outcomes. Significant clinical and statistical heterogeneity led to a priori defined subgroup analyses of the primary outcomes, according to the type of intervention provided. Several included studies showed indirectness, whereby the comparator was given nutrition with highly enriched omega- 6 fatty acids, which may have increased risk of harm. One study reported significant differences in the amount of protein given per day to control $(20 \mathrm{~g})$ and intervention groups $(4 \mathrm{~g})$. Overall, we rated the quality of evidence as low to very low because of increased risk of bias, skewed data, inconsistency, and indirectness. Further research on this topic is essential both to address the overall objective of this review and to focus on specific questions. Future RCTs should consider standardized reporting of ICU outcomes to facilitate the combination and comparison of data between studies.

\section{Potential biases in the review process}

To our knowledge, we have identified and included all published studies on this topic. Lack of standardization in reporting outcomes resulted in some studies reporting duration of ICU stay as ICU LOS and others as ICU-free days at day 28 . We encountered similar issues when dealing with duration of mechanical ventilation. This resulted in pooling of these studies separately, which was not planned when the protocol was drafted. Lack of standardized statistical data from the included studies led to assumptions of normal distribution and calculations of standard deviation from standard error, interquartile ratio (IQR), and $P$ value, which may have introduced additional bias.

\section{Agreements and disagreements with other studies or reviews}

Pontes-Arruda 2008 conducted the first meta-analysis on this topic. These review authors included three earlier studies and reported a survival advantage, improvement in oxygenation (days 4 and 7), and other clinical variables such as ICU and ventilator-free days with immune-enhancing diets (Gadek 1999; Pontes-Arruda 2006; Singer 2006). Another metaanalysis that focussed on mortality and oxygenation yielded the same conclusions (Dee 2011). Results from a subsequent meta-analysis of seven studies contraindicated these previous positive findings and revealed that enteral supplementation of omega-3 fatty acids, GLA, and antioxidants provides no benefit in reducing clinical outcomes such as 28-day mortality, ventilator-free days, and ICU-free days (Zhu 2014). However, these results show improvement in oxygenation at days 4 and 7 with immune-modulating diets. A more recent meta-analysis led to similar conclusions (Li 2015 ). These review authors also subanalysed studies with high overall mortality and demonstrated a positive outcome with the intervention for patient groups with higher mortality, inferring potential benefit for those with severe ARDS (Li 2015).

Our meta-analysis was consistent with the findings of recently published reviews in finding no mortality benefit derived from immunomodulatory diets based on inclusion of omega- 3 fatty acids, GLA, and antioxidants. We noted no improvement in ventilator and ICU-free days at day 28 , and this was sensitive to analytical methods. These findings were also consistent with those revealed by a previous meta-analysis (Zhu 2014). Our findings are also consistent with guidelines of the Society of Critcal Care Medicine and the American Society for Parenteral and Enteral Nutrition for provision of nutritional support for adult critically ill patients, which do not recommend use of omega-3 fatty acids in the ARDS population (McClave 2016).

\section{Authors' conclusions}




\section{Implications for practice}

This meta-analysis evaluated 10 heterogenous studies of varying quality and analysed effects of omega- 3 fatty acids and/or antioxidants in critically ill adults with ARDS. We were not able to find clinical trials of any other immunonutrition intervention provided to this patient group. Despite inclusion of all studies in our meta-analysis, we were not able to pool all studies for every anticipated clinical outcome due to lack of standardized outcome reporting. This may have introduced bias into our analysis. Our results suggest that no mortality benefit is derived from the use of omega-3 fatty acids and/or antioxidants in ARDS. Uncertain evidence suggests reductions in duration of mechanical ventilation and ICU length of stay, along with improved oxygenation. The quality of evidence was very low due to several factors, including poor quality small trials with high risk of bias, clinical and methodological heterogeneity, and issues due to imprecision and inconsistency between trials, with additional indirectness due to an imbalance in nutrition provided to the comparator groups.

\section{Implications for research}

Research shows no mortality benefit associated with use of immunonutrition in ARDS populations. Current data do not justify a large randomized controlled trial on this topic but would support targeted proof-of-concept studies in particular groups of patients to refine the intervention. Consistent reporting of outcome measures by researchers will be important to allow combinations of results in subsequent meta-analyses. Mortality is unlikely to be the best outcome measure for such studies. Cost-effectiveness data are notably absent from current studies and should be collected in the future. The most promising areas for future evaluation include continuous supplementation with a balanced formula for both control and intervention groups with additional supplementation for the intervention group.

\section{Acknowledgements}

We would like to thank Karen Hovhannisyan for help to design the searches, and Jane Cracknell, Managing Editor of the Cochrane Anaesthesia Critical and Emergency Care Group, for her assistance.

We would like to thank Bronagh Blackwood (Content Editor), Nathan Pace (Statistical Editor), Davoud Vahabzadeh and Thomas Bongers (Peer Reviewers), Patricia Tong (Consumer Referee), and Harald Herkner (Co-ordinating Editor) for help and editorial advice provided during preparation of this systematic review.

We also would like to thank Rodrigo Cavallazzi (Content Editor), Jing Xie (Statistical Editor), and Todd Rice and Davoud Vahabzadeh (Peer Reviewers) for help and editorial advice provided during preparation of the protocol for this systematic review.

\section{Contributions of authors}

Ahilanandan Dushianthan (AD), Rebecca Cusack (RC), Victoria Burgess (VB), Michael PW Grocott (MPWG), Philip Calder (PCC).

Conceiving the review: AD, MPWG.

Co-ordinating the review: RC.

Undertaking manual searches: AD, RC, VB.

Screening search results: $A D, R C, V B$.

Organizing retrieval of papers: $A D, R C, V B$.

Screening retrieved papers against inclusion criteria: $A D, R C, V B$.

Appraising the quality of papers: $A D, R C, V B$.

Abstracting data from papers: $A D, R C, V B$.

Writing to authors of papers for additional information: AD.

Providing additional data about papers: AD.

Obtaining and screening data on unpublished studies: $A D, R C, V B$.

Managing data for the review: $A D, R C$.

Entering data into Review Manager (Review Manager 2014): AD, RC.

Analysing RevMan statistical data: AD, RC, MPWG.

Performing other statistical analysis not using RevMan: AD, RC.

Interpreting data: AD, RC, MPWG, PCC.

Making statistical inferences: AD, RC, MPWG.

Writing the review: AD, RC, MPWG, RC.

Securing funding for the review: NA.

Performing previous work that was the foundation of the present study: NA.

Serving as guarantor for the review (one review author): AD.

Taking responsibility for reading and checking the review before submission: AD, MPWG, PCC.

12 / 51 


\section{Declarations of interest}

AD: none known.

RC: none known.

VB: none known.

MPWG: leads the Xtreme-Everest Oxygen Research Consortium, which has received unrestricted grant funding from BOC Medical (Linde Group), Eli Lilly Critical Care, Smith Medical, Deltex Medical, London Clinic, and Rolex. None of this funding has been paid to Dr. Grocott; rather, all funds have been paid directly to the home institutions of researchers within the Consortium. Dr. Grocott has also received honoraria for speaking (not related to this review) and/or travel expenses from Baxter, Fresenius-Kabi, BOC Medical (Linde Group), and Eli Lilly Critical Care (all before 2010).

PCC: In the last three years, PCC has received advisory and/or speaking honoraria from Fresenius-Kabi (2016 to 2018), Baxter Healthcare (2016), Abbott Nutrition (2017), and Danone/Nutricia (2016, 2017) - sellers of parenteral and enteral feeds, some of which were used in the studies included in this review, and from Pronova BioPharma/BASF AS (2016, 2017, 2018) and Smartfish $(2016,2017,2018)$ - sellers of products containing omega-3 fatty acids.

\section{Differences between protocol and review}

We made the following changes to the published protocol (Dushianthan 2016).

1. We included additional outcome measures such as ventilator-free days and ICU-free days at day 28 for the secondary outcomes after reviewing the published studies, as nearly $50 \%$ of the included studies reported these outcomes.

2. We included nosocomial infection as part of the secondary outcome and removed it from adverse events. This outcome is not an adverse event resulting from this intervention.

\section{Published notes}

\section{Characteristics of studies}

Characteristics of included studies

\section{Elamin 2012}


EC290 Immunonutrition for acute respiratory distress syndrome (ARDS) in adults

\begin{tabular}{|c|c|}
\hline Methods & $\begin{array}{l}\text { Design: prospective, randomized, controlled, double-blinded } \\
\text { Country: USA } \\
\text { Setting: mixed surgical and medical intensive care unit } \\
\text { Multi-centre: yes } \\
\text { Date of study: not stated }\end{array}$ \\
\hline Participants & $\begin{array}{l}\text { Inclusion criteria: age } 18 \text { to } 80 \text { years, patients with ARDS defined by AECC criteria } \\
\text { Control group }(\mathrm{N})=8 \\
\text { Intervention group }(\mathrm{N})=9 \\
\text { Age (mean, } \mathrm{SD} \text { ): } \\
\text { Control group: } 55.2 \pm 16.5 \\
\text { Intervention group: } 50 \pm 22.2 \\
\text { Exclusion criteria: } \\
\text { 1. Left ventricular heart failure defined as pulmonary capillary wedge pressure }>18 \\
\text { mmHg or left ventricular ejection fraction }<40 \% \\
\text { 3. Aung cancer (primary or metastatic) } \\
\text { 4. Active gastroblastic leukaemia } \\
\text { 5. Immune suppressinal bleed } \\
\text { 5. Prednisone }>0.25 \mathrm{mg} / \mathrm{kg} / \mathrm{d} \text { as recent chemotherapy } \\
\text { 7. HIV disease } \\
\text { 3. Glasgow Coma Scale score }<5 \text { secondary to head trauma } \\
\text { 9. Pregnancy } \\
\text { 1). Admission MODS }>9\end{array}$ \\
\hline Interventions & $\begin{array}{l}\text { Control group: lipid-rich ( } 55 \%) \text { enteral formula (Pulmocare) } \\
\text { Intervention group: lipid-rich (55\%) enteral formula consisting of EPA and GLA } \\
\text { (Oxepa) } \\
\text { Duration of intervention: } 7 \text { days }\end{array}$ \\
\hline Outcomes & $\begin{array}{l}\text { Primary outcome: } \\
\text { 1. Oxygenation }\left(\mathrm{PaO}_{2} / \mathrm{FiO}_{2} \text { ratio days } 1,2,4 \text {, and } 7\right) \\
\text { Secondary outcomes reported: } \\
\text { 1. Lung injury score }(\mathrm{LIS}) \\
\text { 2. Multiple organ dysfunction score (MODS) } \\
\text { 3. Duration of mechanical ventilation (days) } \\
\text { 4. ICU length of stay (days) } \\
\text { j. 28-day mortality }\end{array}$ \\
\hline Notes & $\begin{array}{l}\text { Funding source: not stated } \\
\text { Declaration of conflict of interest: not stated } \\
\text { Trial registration: not stated } \\
\text { Further information obtained from study author: standard deviations for ventilation } \\
\text { days and ICU LOS }\end{array}$ \\
\hline
\end{tabular}

Risk of bias table 
EC290 Immunonutrition for acute respiratory distress syndrome (ARDS) in adults

\begin{tabular}{|l|l|l|}
\hline Bias & Authors' judgement & Support for judgement \\
\hline $\begin{array}{l}\text { Random sequence generation } \\
\text { (selection bias) }\end{array}$ & High risk & Randomized on an alternating number basis \\
\hline $\begin{array}{l}\text { Allocation concealment (selection } \\
\text { bias) }\end{array}$ & Unclear risk & Not mentioned \\
\hline $\begin{array}{l}\text { Blinding of participants and } \\
\text { personnel (performance bias) }\end{array}$ & Low risk & Double-blinded \\
\hline $\begin{array}{l}\text { Blinding of outcome assessment } \\
\text { (detection bias) }\end{array}$ & Low risk & 20\% not reported; no ITT analysis \\
\hline $\begin{array}{l}\text { Incomplete outcome data (attrition } \\
\text { bias) }\end{array}$ & High risk & No selective reporting \\
\hline Selective reporting (reporting bias) & Low risk & Small numbers of participants \\
\hline Other bias & Unclear risk & \\
\hline
\end{tabular}

\section{Gadek 1999}


EC290 Immunonutrition for acute respiratory distress syndrome (ARDS) in adults

\begin{tabular}{|c|c|}
\hline Methods & $\begin{array}{l}\text { Design: prospective, randomized, controlled, double-blinded } \\
\text { Country: USA } \\
\text { Setting: intensive care unit at } 5 \text { academic and teaching hospitals } \\
\text { Multi-centre: yes } \\
\text { Dates of study: July } 1993 \text { to March } 1997\end{array}$ \\
\hline Participants & $\begin{array}{l}\text { Inclusion criteria: age } 18 \text { to } 80 \text { years, patients with } \mathrm{ARDS} \text { with } \mathrm{PaO}_{2} / \mathrm{FiO}_{2} \text { ratio }<250 \\
\text { mmHg } \\
\text { Control group }(\mathrm{N})=47 \\
\text { Intervention group }(\mathrm{N})=51 \\
\text { Age (mean, } \mathrm{SD} \text { ): } \\
\text { Control group: } 51 \pm 20.6 \\
\text { Intervention group: } 51 \pm 14.3 \\
\text { Exclusion criteria: } \\
\text { 1. Left ventricular failure } \\
\text { 2. Lung cancer } \\
\text { 3. Haematological malignancy } \\
\text { 4. Acute gastrointestinal bleeding precluding enteral feeding } \\
\text { 5. Head trauma (Glasgow Coma Scale score } \leq 5) \\
\text { 5. Stroke or subarachnoid haemorrhage } \\
\text { 7. Severe immunosuppression (defined as cytotoxic therapy within } 15 \text { days or white } \\
\text { blood cell count }<5000) \\
\text { 3. Use of steroids }(>0.25 \mathrm{mg} / \mathrm{kg} / \mathrm{d} \text { prednisone or equivalent dose of corticosteroids) } \\
\text { 9. Use of non-steroidal anti-inflammatory drugs (including aspirin) within the previous } \\
24 \text { hours } \\
\text { 1). HIV-positive status } \\
\text { 11. Pregnancy }\end{array}$ \\
\hline Interventions & $\begin{array}{l}\text { Control group: lipid-rich ( } 55 \%) \text { enteral formula (Pulmocare) } \\
\text { Intervention group: lipid-rich (55\%) enteral formula consisting of EPA and GLA } \\
\text { (Oxepa) } \\
\text { Duration of intervention: }>4 \text { days }\end{array}$ \\
\hline Outcomes & $\begin{array}{l}\text { Primary outcome: } \\
\text { 1. Time receiving ventilatory support (days) } \\
\text { 2. ICU LOS (days) } \\
\text { 3. Time on supplemental oxygen (days) } \\
\text { Secondary outcomes: } \\
\text { 1. New organ failure } \\
\text { 2. Adverse events } \\
\text { 3. Lung neutrophil recruitment } \\
\text { 4. PaO } 2 / \mathrm{FiO}_{2} \text { ratio at days } 4 \text { and } 7 \\
\text { 5. Hospital length of stay (days) } \\
\text { 6. Mortality (study period) }\end{array}$ \\
\hline Notes & $\begin{array}{l}\text { Funding source: supported in part by a grant from Ross Products Division, Abbott } \\
\text { Laboratories } \\
\text { Declaration of conflict of interest: not stated } \\
\text { Trial registration: not stated } \\
\text { Significant numbers of protocol violations }(\mathrm{N}=48) \text { and dropouts }\end{array}$ \\
\hline
\end{tabular}


EC290 Immunonutrition for acute respiratory distress syndrome (ARDS) in adults

\begin{tabular}{|l|l|l|}
\hline Bias & Authors' judgement & Support for judgement \\
\hline $\begin{array}{l}\text { Random sequence generation } \\
\text { (selection bias) }\end{array}$ & Low risk & Permuted block randomization \\
\hline $\begin{array}{l}\text { Allocation concealment (selection } \\
\text { bias) }\end{array}$ & Low risk & Independent randomization allocation \\
\hline $\begin{array}{l}\text { Blinding of participants and } \\
\text { personnel (performance bias) }\end{array}$ & Low risk & Study blinded for participants \\
\hline $\begin{array}{l}\text { Blinding of outcome assessment } \\
\text { (detection bias) }\end{array}$ & Low risk & Study blinded for clinical investigators and caregivers \\
\hline $\begin{array}{l}\text { Incomplete outcome data (attrition } \\
\text { bias) }\end{array}$ & Low risk & Significant number excluded for protocol violations; ITT used \\
\hline Selective reporting (reporting bias) & Low risk & No selective reporting \\
\hline Other bias & High risk & $\begin{array}{l}\text { Significant number excluded due to protocol violations } \\
\text { Pharma-supported; industry bias }\end{array}$ \\
\hline
\end{tabular}

Grau-Camona 2011 
EC290 Immunonutrition for acute respiratory distress syndrome (ARDS) in adults

\begin{tabular}{|c|c|}
\hline Methods & $\begin{array}{l}\text { Design: prospective, randomized, controlled, open-label, parallel-group } \\
\text { Country: Spain } \\
\text { Setting: } 11 \text { Spanish intensive care units } \\
\text { Multi-centre: no } \\
\text { Dates of study: January } 2004 \text { to December } 2007\end{array}$ \\
\hline Participants & $\begin{array}{l}\text { Inclusion criteria: age }>18 \text { years, ventilated patients with sepsis, ARDS } 71 \% \text {. All } \\
\text { participants fulfilled criteria for ARDS or ALI according to AECC } \\
\text { Control group }(\mathrm{N})=71 \\
\text { Intervention group }(\mathrm{N})=61 \\
\text { Age (mean, range): } \\
\text { Control group: } 65 \text { ( } 51 \text { to } 75) \\
\text { Intervention group: } 62 \text { ( } 40 \text { to } 71) \\
\text { Exclusion criteria: } \\
\text { 1. Pregnancy } \\
\text { 2. Treatment with artificial nutrition in the } 15 \text { days before inclusion in the study } \\
\text { 3. Food allergy } \\
\text { 4. Severe hyperlipidaemia } \\
\text { 5. Gastrointestinal disease precluding enteral nutrition } \\
\text { 6. Acute upper gastrointestinal bleeding } \\
\text { 3. Immunosuppression } \\
\text { 3. Severe heart failure } \\
\text { 1. Neoplasm } \\
\text { 11. End-stage severe neurological processes } \\
\text { refractory to treatment, post cardiopulmonary resuscitation with serious neurological } \\
\text { damage) }\end{array}$ \\
\hline Interventions & $\begin{array}{l}\text { Control group: carbohydrate-rich (54\%) enteral formula (Ensure Plus) } \\
\text { Intervention group: lipid-rich (55\%) enteral formula with EPA and GLA (Oxepa) } \\
\text { Duration of intervention: } 28 \text { days }\end{array}$ \\
\hline Outcomes & $\begin{array}{l}\text { Primary outcomes: } \\
\text { 1. New organ dysfunction measured by total daily SOFA score } \\
\text { 2. SOFA score changes measured at } 1,3,7,14 \text {, and } 21 \text { days } \\
\text { Secondary outcomes: } \\
\text { 1. ICU LOS (days) } \\
\text { 2. Hospital LOS (days) } \\
\text { 3. Ventilator days (days) } \\
\text { 4. Mortality (ICU, } 28 \text { days and } 180 \text { days) } \\
\text { 5. Incidence of nosocomial infection }\end{array}$ \\
\hline Notes & $\begin{array}{l}\text { Funding source: pharma-supported (Abbott Laboratories) } \\
\text { Declaration of conflict of interest: declared by study authors } \\
\text { Trial registration: ISRCTN67182335 } \\
\text { Further information obtained from study author: standard deviation for ventilation days, } \\
\text { ICU LOS, and } \mathrm{PaO}_{2} / \mathrm{FiO}_{2} \text { ratio }\end{array}$ \\
\hline
\end{tabular}

Risk of bias table 
EC290 Immunonutrition for acute respiratory distress syndrome (ARDS) in adults

\begin{tabular}{|l|l|l|}
\hline Bias & Authors' judgement & Support for judgement \\
\hline $\begin{array}{l}\text { Random sequence generation } \\
\text { (selection bias) }\end{array}$ & Low risk & Computer-generated random sequence \\
\hline $\begin{array}{l}\text { Allocation concealment (selection } \\
\text { bias) }\end{array}$ & Low risk & Central computer-based allocation \\
\hline $\begin{array}{l}\text { Blinding of participants and } \\
\text { personnel (performance bias) }\end{array}$ & High risk & Only participants blinded \\
\hline $\begin{array}{l}\text { Blinding of outcome assessment } \\
\text { (detection bias) }\end{array}$ & High risk & Investigators blinded until end of study \\
\hline $\begin{array}{l}\text { Incomplete outcome data (attrition } \\
\text { bias) }\end{array}$ & High risk & 28 participants randomized but not analysed \\
\hline Selective reporting (reporting bias) & Low risk & No selective reporting identified \\
\hline Other bias & Unclear risk & Pharma-supported; industry bias \\
\hline
\end{tabular}

Gupta 2012 
EC290 Immunonutrition for acute respiratory distress syndrome (ARDS) in adults

\begin{tabular}{|c|c|}
\hline Methods & $\begin{array}{l}\text { Design: prospective, randomized, placebo-controlled, investigator-blinded } \\
\text { Country: India } \\
\text { Setting: medical ICU } \\
\text { Multi-centre: no } \\
\text { Dates of study: July } 2009 \text { to December } 2009\end{array}$ \\
\hline Participants & $\begin{array}{l}\text { Inclusion criteria: age } 18 \text { to } 80 \text { years, patients with ARDS defined by AECC criteria } \\
\text { with } \mathrm{PaO}_{2} / \mathrm{FiO}{ }_{2} \text { ratio }<200 \mathrm{mmHg} \\
\text { Control group }(\mathrm{N})=30 \\
\text { Intervention group }(\mathrm{N})=31 \\
\text { Age (mean, } \mathrm{SD} \text { ): } \\
\text { Control group: } 46.6 \pm 16.4 \\
\text { Intervention group: } 51.2 \pm 15.6 \\
\text { Exclusion criteria: } \\
\text { 1. Pregnancy } \\
\text { 2. Liver failure } \\
\text { 3. HIV } \\
\text { 4. Leucopaenia }\left(<3500 \mathrm{~mm}^{3}\right) \\
\text { 5. Thrombocytopaenia }\left(<100,000 \mathrm{~mm}^{3}\right) \\
\text { 3. Acute bleeding } \\
\text { 7. Severe renal insufficiency (creatinine }>2.5 \mathrm{mg} / \mathrm{dL} \text { ) or need for renal dialysis } \\
\text { 3. Heart failure } \\
\text { 9. Tansplantation } \\
\text { 1. Multiple blood transfusions } \\
\text { 11. Multiple organ failure } \\
\text { 12. Treatment with nitrous oxide or corticosteroids } \\
\text { 13. Cerebral haemorrhage } \\
\text { 1. Radiation } \\
\text { 1. Treatment with immunosuppressive drugs } \\
\text { 15. Allergy to constituents of nutritional products }\end{array}$ \\
\hline Interventions & $\begin{array}{l}\text { Control group: high-fat, low-carbohydrate formula } \\
\text { Intervention group: high-fat, low-carbohydrate formula, supplemented with parenteral } \\
\text { omega-3 fatty acids (Omegaven) } \\
\text { Duration of intervention: } 14 \text { days }\end{array}$ \\
\hline Outcomes & $\begin{array}{l}\text { Primary outcome: } \\
\text { 1. Changes in oxygenation and breathing pattern at days } 4,7 \text {, and } 14 \\
\text { Secondary outcomes: } \\
\text { 1. Duration of mechanical ventilation (days) } \\
\text { 2. ICU LOS (days) } \\
\text { 3. Hospital LOS (days) } \\
\text { 4. Hospital mortality }\end{array}$ \\
\hline Notes & $\begin{array}{l}\text { Funding source: not stated } \\
\text { Declarations of conflict of interest: not stated } \\
\text { Trial registration: not stated }\end{array}$ \\
\hline
\end{tabular}

Risk of bias table 
EC290 Immunonutrition for acute respiratory distress syndrome (ARDS) in adults

\begin{tabular}{|l|l|l|}
\hline Bias & Authors' judgement & Support for judgement \\
\hline $\begin{array}{l}\text { Random sequence generation } \\
\text { (selection bias) }\end{array}$ & Low risk & Computer-generated random blocks \\
\hline $\begin{array}{l}\text { Allocation concealment (selection } \\
\text { bias) }\end{array}$ & Unclear risk & Not mentioned \\
\hline $\begin{array}{l}\text { Blinding of participants and } \\
\text { personnel (performance bias) }\end{array}$ & High risk & Only investigator blinded \\
\hline $\begin{array}{l}\text { Blinding of outcome assessment } \\
\text { (detection bias) }\end{array}$ & Low risk & Investigator blinded \\
\hline $\begin{array}{l}\text { Incomplete outcome data (attrition } \\
\text { bias) }\end{array}$ & Low risk & No obvious attrition bias \\
\hline Selective reporting (reporting bias) & Low risk & No selective reporting \\
\hline Other bias & Unclear risk & Single-centre, small study \\
\hline
\end{tabular}

Parish 2014 
EC290 Immunonutrition for acute respiratory distress syndrome (ARDS) in adults

\begin{tabular}{|c|c|}
\hline Methods & $\begin{array}{l}\text { Design: prospective, randomized, double-blinded } \\
\text { Country: Iran } \\
\text { Setting: } 2 \text { ICUs from university hospitals } \\
\text { Multi-centre: yes } \\
\text { Dates of study: June } 2011 \text { to September } 2013\end{array}$ \\
\hline Participants & $\begin{array}{l}\text { Inclusion criteria: age }>18 \text { years, mild to moderate } \mathrm{ARDS} \text { with } \mathrm{PaO}_{2} / \mathrm{FiO}_{2} \text { between } \\
100 \text { and } 300 \mathrm{mmHg} \\
\text { Control group }(\mathrm{N})=29 \\
\text { Intervention group }(\mathrm{N})=29 \\
\text { Age (mean, SD): } \\
\text { Control group: } 62.7 \pm 13.7 \\
\text { Intervention group: } 64.4 \pm 10.2 \\
\text { Exclusion criteria: } \\
\text { 1. Age }<18 \text { years } \\
\text { 2. Plasma triglyceride levels }>400 \mathrm{mg} / \mathrm{dL} \\
\text { 3. Liver and kidney failure } \\
\text { 4. Platelets }<50,000 \mu \mathrm{L} \text {, leucocyte count }<3 \times 10^{9} / \mathrm{L} \\
\text { 5. Previous history of frequent transfusion }\end{array}$ \\
\hline Interventions & $\begin{array}{l}\text { Control group: isocaloric, isovolaemic carbohydrate-rich enteral formula } \\
\text { Intervention group: isocaloric, isovolaemic carbohydrate-rich enteral formula } \\
\text { supplemented with omega- } 3 \text { gel (EPA and DHA), } 6 \text { gels/d } \\
\text { Duration of intervention: } 14 \text { days }\end{array}$ \\
\hline Outcomes & $\begin{array}{l}\text { Primary outcome: } \\
\text { 1. Oxygenation parameters }\left(\mathrm{PaO}_{2}, \mathrm{SaO}_{2}, \mathrm{PaO}_{2} / \mathrm{FiO}_{2} \text { ratio }\right) \\
\text { Secondary outcomes: } \\
\text { 1. Ventilator-free days } \\
\text { 2. Number of organ failures } \\
\text { 3. ICU LOS } \\
\text { 4. 28-day mortality }\end{array}$ \\
\hline Notes & $\begin{array}{l}\text { Funding source: not stated } \\
\text { Declarations of conflict of interest: declared by study authors } \\
\text { Trial registration: IRCT2013020612387N1 }\end{array}$ \\
\hline
\end{tabular}

Risk of bias table 
EC290 Immunonutrition for acute respiratory distress syndrome (ARDS) in adults

\begin{tabular}{|l|l|l|}
\hline Bias & Authors' judgement & Support for judgement \\
\hline $\begin{array}{l}\text { Random sequence generation } \\
\text { (selection bias) }\end{array}$ & Low risk & Web-based software for random generation \\
\hline $\begin{array}{l}\text { Allocation concealment (selection } \\
\text { bias) }\end{array}$ & Low risk & Web-based allocation \\
\hline $\begin{array}{l}\text { Blinding of participants and } \\
\text { personnel (performance bias) }\end{array}$ & Low risk & Double-blinded \\
\hline $\begin{array}{l}\text { Blinding of outcome assessment } \\
\text { (detection bias) }\end{array}$ & Low risk \\
\hline $\begin{array}{l}\text { Incomplete outcome data (attrition } \\
\text { bias) }\end{array}$ & Low risk & Double-blinded \\
\hline Selective reporting (reporting bias) & Low risk & All included in analysis; ITT \\
\hline Other bias & Unclear risk & No selective reporting \\
\hline
\end{tabular}

\section{Pontes-Arruda 2006}


EC290 Immunonutrition for acute respiratory distress syndrome (ARDS) in adults

\begin{tabular}{|c|c|}
\hline Methods & $\begin{array}{l}\text { Design: prospective, randomized, controlled, double-blinded } \\
\text { Country: Brazil } \\
\text { Setting: } 3 \text { tertiary intensive care units } \\
\text { Multi-centre: no } \\
\text { Dates of study: not stated }\end{array}$ \\
\hline Participants & $\begin{array}{l}\text { Inclusion criteria: age }>18 \text { years, severe sepsis or septic shock requiring mechanical } \\
\text { ventilation, } \mathrm{PaO}_{2} / \mathrm{FiO}_{2}<200 \mathrm{mmHg} \\
\text { Control group }(\mathrm{N})=48 \\
\text { Intervention group }(\mathrm{N})=55 \\
\text { Age (mean, } \mathrm{SD} \text { ): } \\
\text { Control group: } 66 \pm 20 \\
\text { Intervention group: } 64.3 \pm 18.7 \\
\text { Exclusion criteria: } \\
\text { 1. < } 18 \text { years old } \\
\text { 2. Significant limitation of survival prognosis (<28 days) } \\
\text { 3. Pre-existing renal insufficiency } \\
\text { 4. Acute pancreatitis without established origin } \\
\text { 5. Head trauma with } \mathrm{GCS} \leq 5 \\
\text { 6. Recent stroke or subarachnoid haemorrhage } \\
\text { 7. Immunosuppression } \\
\text { 3. HIV infection } \\
\text { 9. Parenteral nutrition } \\
\text { 1). Presence of uncontrolled diarrhoea } \\
\text { 11. Recent gastrointestinal bleeding } \\
\text { 12. Planned weaning from mechanical ventilation before study day } 4\end{array}$ \\
\hline Interventions & $\begin{array}{l}\text { Control group: lipid-rich ( } 55 \%) \text { enteral formula (Pulmocare) } \\
\text { Intervention group: lipid-rich (55\%) enteral formula consisting of EPA, DHA, and GLA } \\
\text { (Oxepa) } \\
\text { Duration of intervention: } 28 \text { days }\end{array}$ \\
\hline Outcomes & $\begin{array}{l}\text { Primary outcome: } \\
\text { 1. Mortality at } 28 \text { days } \\
\text { Secondary outcomes: } \\
\text { 1. Change in oxygenation } \\
\text { 2. Ventilator-free days at day } 28 \\
\text { 3. ICU-free days at day } 28 \\
\text { 4. New organ failure } \\
\text { 5. Adverse events }\end{array}$ \\
\hline Notes & $\begin{array}{l}\text { Funding source: supported in part by Abbott Laboratories } \\
\text { Declarations of conflict of interest: declared by study authors } \\
\text { Trial registration: not stated } \\
\text { Significant proportion discontinued before study day } 4\end{array}$ \\
\hline
\end{tabular}


EC290 Immunonutrition for acute respiratory distress syndrome (ARDS) in adults

\begin{tabular}{|l|l|l|}
\hline Bias & $\begin{array}{l}\text { Authors' } \\
\text { judgement }\end{array}$ & Support for judgement \\
\hline $\begin{array}{l}\text { Random sequence generation } \\
\text { (selection bias) }\end{array}$ & Unclear risk & Quote. "randomized in a 1:1 ratio in a blinded way" \\
\hline $\begin{array}{l}\text { Allocation concealment (selection } \\
\text { bias) }\end{array}$ & Unclear risk & Not clarified \\
\hline $\begin{array}{l}\text { Blinding of participants and } \\
\text { personnel (performance bias) }\end{array}$ & Low risk & Double-blinded \\
\hline $\begin{array}{l}\text { Blinding of outcome assessment } \\
\text { (detection bias) }\end{array}$ & Low risk & Double-blinded \\
\hline $\begin{array}{l}\text { Incomplete outcome data (attrition } \\
\text { bias) }\end{array}$ & High risk & $\begin{array}{l}\text { Out of 165 participants, only } 103 \text { evaluated due to protocol } \\
\text { violations }\end{array}$ \\
\hline Selective reporting (reporting bias) & Low risk & No selective reporting \\
\hline Other bias & Unclear risk & Pharma-supported; industry bias \\
\hline
\end{tabular}

\section{Rice 2011}

\begin{tabular}{|l|l|}
\hline Methods & Design: prospective, randomized, double-blinded, placebo-controlled \\
Country: USA \\
Setting: ICU at 44 hospitals \\
Multi-centre: yes \\
Dates of study: January 2008 to February 2009
\end{tabular}




\begin{tabular}{|c|c|}
\hline Participants & 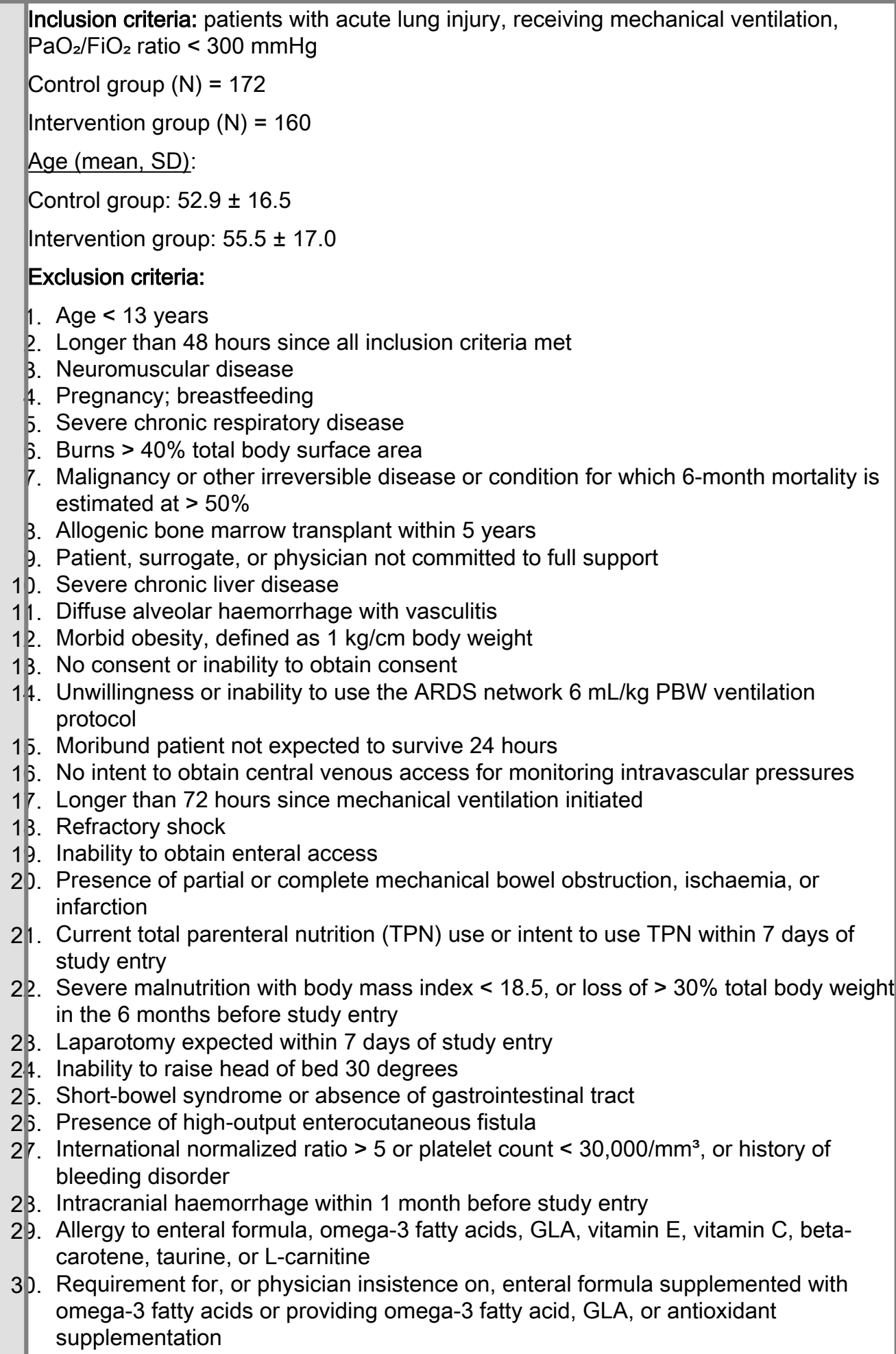 \\
\hline Interventions & $\begin{array}{l}\text { Control group: twice-daily bolus enteral carbohydrate-rich formula } \\
\text { Intervention group: twice-daily bolus enteral lipid-rich formula supplemented with EPA, } \\
\text { DHA, GLA, and antioxidants } \\
\text { Duration of intervention: } 21 \text { days }\end{array}$ \\
\hline
\end{tabular}


EC290 Immunonutrition for acute respiratory distress syndrome (ARDS) in adults

\begin{tabular}{|c|c|}
\hline Outcomes & $\begin{array}{l}\text { Primary outcomes: } \\
\text { 1. Ventilator-free days } \\
\text { 2. Mortality before hospital discharge } \\
\text { Secondary outcomes: } \\
\text { 1. ICU-free days at day } 28 \\
\text { 2. Organ failure-free days } \\
\text { 3. Ventilator-free days at day } 28 \\
\text { 4. Gastrointestinal intolerance } \\
\text { 5. Plasma IL-6, IL- } 8 \text { levels and fatty acid, urinary leukotrienes } \\
\text { 6. New infection } \\
\text { 7. Mortality at day } 60\end{array}$ \\
\hline Notes & $\begin{array}{l}\text { Funding source: Centers for Disease Control and Prevention } \\
\text { Declarations of conflict of interest: declared by study authors } \\
\text { Trial registration: NCT00609180 } \\
\text { Participants co-enrolled to EDEN study (low- vs full-calorie enteral nutrition) } \\
\text { Control group received } 20 \mathrm{~g} \text { protein/d compared to } 4 \mathrm{~g} \text { protein in the intervention group } \\
\text { Further information obtained from study author: } \mathrm{PaO}_{2} / \mathrm{FiO}_{2} \text { ratio, new nosocomial } \\
\text { infection }\end{array}$ \\
\hline
\end{tabular}

\section{Risk of bias table}

\begin{tabular}{|l|l|l|}
\hline $\begin{array}{l}\text { Bias } \\
\text { Random sequence generation } \\
\text { (selection bias) }\end{array}$ & Luthors' judgement & Support for judgement \\
\hline $\begin{array}{l}\text { Allocation concealment (selection } \\
\text { bias) }\end{array}$ & Low risk & Randomized by central Web-based system \\
\hline $\begin{array}{l}\text { Blinding of participants and } \\
\text { personnel (performance bias) }\end{array}$ & Low risk & Double-blinded \\
\hline $\begin{array}{l}\text { Blinding of outcome assessment } \\
\text { (detection bias) }\end{array}$ & Low risk & Double-blinded \\
\hline $\begin{array}{l}\text { Incomplete outcome data (attrition } \\
\text { bias) }\end{array}$ & Low risk & All data reported \\
\hline Selective reporting (reporting bias) & Low risk & No selective reporting \\
\hline Other bias & Low risk & No other bias detected \\
\hline
\end{tabular}

\section{Shirai 2015}

\begin{tabular}{|l|l|}
\hline Methods & Design: prospective, randomized, single-blinded, controlled \\
Country: Japan \\
Setting: advanced critical care centre \\
Multi-centre: no \\
Study dates: March 2008 to March 2010
\end{tabular}


EC290 Immunonutrition for acute respiratory distress syndrome (ARDS) in adults

\begin{tabular}{|c|c|}
\hline Participants & 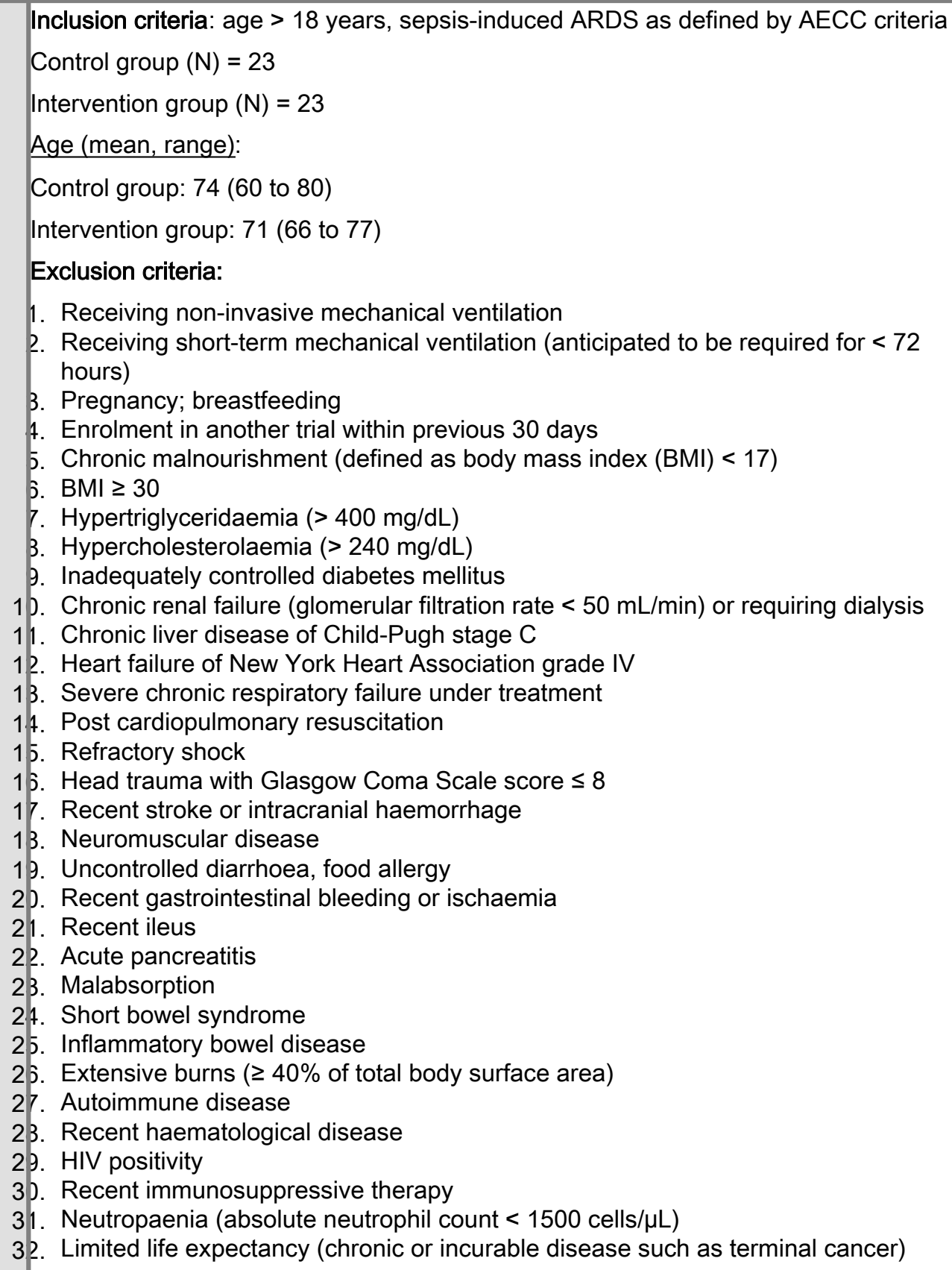 \\
\hline Interventions & $\begin{array}{l}\text { Control group: carbohydrate-rich (55\%) enteral formula (Ensure Liquid) } \\
\text { Intervention group: lipid-rich (55\%) enteral formula consisting of EPA, DHA, and GLA } \\
\text { (Oxepa) } \\
\text { Duration of intervention: } 14 \text { days }\end{array}$ \\
\hline Outcomes & $\begin{array}{l}\text { Primary outcome: } \\
\text { 1. Duration of mechanical ventilation (days) } \\
\text { Secondary outcomes: } \\
\text { 1. Duration of ICU stay (days) } \\
\text { 2. Changes in SOFA scores } \\
\text { 3. } \mathrm{PaO}_{2} / \mathrm{FiO} \text { ratio at } 1,3,5,7 \text {, and } 14 \text { days } \\
\text { 4. New nosocomial infection } \\
\text { 5. } 60 \text {-day mortality }\end{array}$ \\
\hline
\end{tabular}


EC290 Immunonutrition for acute respiratory distress syndrome (ARDS) in adults

\begin{tabular}{|l|l|}
\hline Notes & Funding source: not stated \\
Declarations of interest: declared by study authors & \\
Trial registration: not stated \\
Single-blinded; whom blinding referred to not specified
\end{tabular}

Risk of bias table

\begin{tabular}{|l|l|l|}
\hline $\begin{array}{l}\text { Bias } \\
\text { Random sequence generation } \\
\text { (selection bias) }\end{array}$ & High risk & Randomly assigned by principal investigator in a 1:1 ratio \\
\hline $\begin{array}{l}\text { Allocation concealment (selection } \\
\text { bias) }\end{array}$ & Unclear risk & Not explained \\
\hline $\begin{array}{l}\text { Blinding of participants and } \\
\text { personnel (performance bias) }\end{array}$ & High risk & Single-blinded \\
\hline $\begin{array}{l}\text { Blinding of outcome assessment } \\
\text { (detection bias) }\end{array}$ & High risk & Single-blinded; blinding of outcome assessment not clarified \\
\hline $\begin{array}{l}\text { Incomplete outcome data (attrition } \\
\text { bias) }\end{array}$ & Low risk & All data reported \\
\hline Selective reporting (reporting bias) & Low risk & No selective reporting \\
\hline Other bias & Unclear risk & Small, single-centre study \\
\hline
\end{tabular}

Singer 2006 
EC290 Immunonutrition for acute respiratory distress syndrome (ARDS) in adults

\begin{tabular}{|c|c|}
\hline Methods & $\begin{array}{l}\text { Design: prospective, randomized, open, controlled } \\
\text { Country: Israel } \\
\text { Setting: general intensive care unit } \\
\text { Multi-centre: no } \\
\text { Dates of study: February } 2002 \text { to August } 2003\end{array}$ \\
\hline Participants & $\begin{array}{l}\text { Inclusion criteria: patients with ARDS according to AECC criteria } \\
\text { Control group }(\mathrm{N})=49 \\
\text { Intervention group }(\mathrm{N})=46 \\
\text { Age (mean, } \mathrm{SD} \text { ): } \\
\text { Control group: } 62.3 \pm 17.2 \\
\text { Intervention group: } 57.0 \pm 18.7 \\
\text { Exclusion criteria: } \\
\text { 1. Head trauma } \\
\text { 2. Cerebral haemorrhage, or active bleeding } \\
\text { 3. Patients receiving an immunosuppression regimen including steroids }(>0.25 \\
\text { mg/kg/d prednisolone) } \\
\text { 4. HIV positivity } \\
\text { 5. Pregnancy }\end{array}$ \\
\hline Interventions & $\begin{array}{l}\text { Control group: lipid-rich ( } 55 \%) \text { enteral formula (Pulmocare) } \\
\text { Intervention group: lipid-rich (55\%) enteral formula consisting of EPA, DHA, and GLA } \\
\text { (Oxepa) } \\
\text { Duration of intervention: } 14 \text { days }\end{array}$ \\
\hline Outcomes & $\begin{array}{l}\text { Primary outcome: } \\
\text { 1. Change in oxygenation and breathing patterns } \\
\text { Seconday outcomes: } \\
\text { 1. Duration of mechanical ventilatory support (days) } \\
\text { 2. ICU length of stay (days) } \\
\text { 3. Length of hospital stay (days) } \\
\text { 4. Hospital mortality }\end{array}$ \\
\hline Notes & $\begin{array}{l}\text { Funding source: supported by Ross Laboratories } \\
\text { Declarations of conflict of interest: not stated } \\
\text { Trial registration: not stated } \\
\text { > } 50 \% \text { surgical participants }\end{array}$ \\
\hline
\end{tabular}

Risk of bias table 
EC290 Immunonutrition for acute respiratory distress syndrome (ARDS) in adults

\begin{tabular}{|l|l|l|}
\hline $\begin{array}{l}\text { Bias } \\
\begin{array}{l}\text { Random sequence generation } \\
\text { (selection bias) }\end{array}\end{array}$ & Low risk & Support for judgement \\
\hline $\begin{array}{l}\text { Allocation concealment (selection } \\
\text { bias) }\end{array}$ & Unclear risk & Not mentioned \\
\hline $\begin{array}{l}\text { Blinding of participants and } \\
\text { personnel (performance bias) }\end{array}$ & High risk & Unblinded study \\
\hline $\begin{array}{l}\text { Blinding of outcome assessment } \\
\text { (detection bias) }\end{array}$ & High risk & Unblinded study \\
\hline $\begin{array}{l}\text { Incomplete outcome data (attrition } \\
\text { bias) }\end{array}$ & High risk & Five participants dropped out; not used as ITT \\
\hline Selective reporting (reporting bias) & Low risk & No selective reporting \\
\hline Other bias & Unclear risk & Pharma-supported; industry bias \\
\hline
\end{tabular}

\section{Stapleton 2011}

\begin{tabular}{|c|c|}
\hline Methods & $\begin{array}{l}\text { Design: prospective, randomized, controlled, double-blinded } \\
\text { Country: USA } \\
\text { Setting: } 5 \text { ICUs in North America } \\
\text { Multi-centre: yes } \\
\text { Dates of study: March } 2006 \text { to December } 2008\end{array}$ \\
\hline Participants & 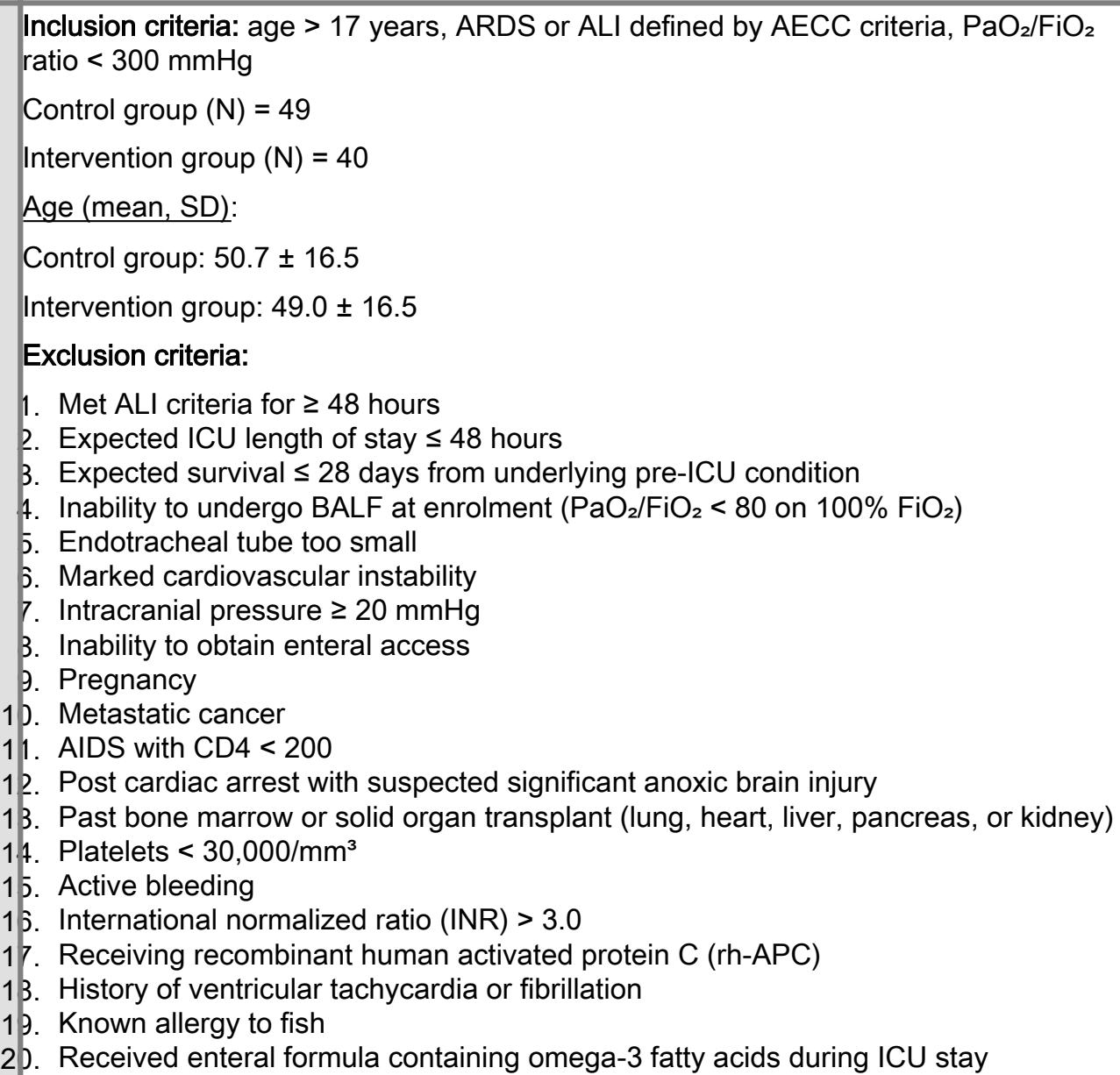 \\
\hline
\end{tabular}


EC290 Immunonutrition for acute respiratory distress syndrome (ARDS) in adults

\begin{tabular}{|c|c|}
\hline \multirow[t]{3}{*}{ Interventions } & Control group: enteral nutrition according to discretion of treating physician \\
\hline & $\begin{array}{l}\text { Intervention group: enteral nutrition according to discretion of treating physician with } \\
\text { additional enteral fish oil supplemented every } 6 \text { hours }\end{array}$ \\
\hline & Duration of intervention: 14 days \\
\hline Outcomes & $\begin{array}{l}\text { Primary outcome: } \\
\text { 1. BALF IL-8 } \\
\text { Secondary outcomes: } \\
\text { 1. BALF markers } \\
\text { 2. Plasma markers } \\
\text { 3. Multiple organ dysfunction score (MODS) throughout the study to day } 28 \\
\text { 4. Ventilator-free days at day } 28 \\
\text { b. ICU-free days at day } 28 \\
\text { 6. Changes in oxygen } \\
\text { 7. Hospital mortality } \\
\text { 3. 60-day mortality } \\
\text { 9. Adverse events }\end{array}$ \\
\hline \multirow[t]{5}{*}{ Notes } & $\begin{array}{l}\text { Funding source: American Thoracic Society/Acute Respiratory Distress Syndrome } \\
\text { Foundation Award, an American Society for Parenteral and Enteral Nutrition Rhodes } \\
\text { Research Foundation Award, National Institute of Health grants. Nordic Naturals } \\
\text { donated the fish oil }\end{array}$ \\
\hline & Declarations of interest: declared by study authors \\
\hline & Trial registration: NCT00351533 \\
\hline & More participants with aspiration in the fish oil group \\
\hline & $\begin{array}{l}\text { Further information obtained from study author: Numerical data for mortality, ICU-free } \\
\text { days, ventilator-free days, duration of mechanical ventilation, ICU LOS, and hospital } \\
\text { LOS }\end{array}$ \\
\hline
\end{tabular}

Risk of bias table

\begin{tabular}{|l|l|l|}
\hline $\begin{array}{l}\text { Bias } \\
\text { Random sequence generation } \\
\text { (selection bias) }\end{array}$ & Low risk & Computer-generated permuted blocks \\
\hline $\begin{array}{l}\text { Allocation concealment (selection } \\
\text { bias) }\end{array}$ & Low risk & Sealed opaque envelopes \\
\hline $\begin{array}{l}\text { Blinding of participants and } \\
\text { personnel (performance bias) }\end{array}$ & Low risk & Participants blinded \\
\hline $\begin{array}{l}\text { Blinding of outcome assessment } \\
\text { (detection bias) }\end{array}$ & Low risk & Study investigators blinded \\
\hline $\begin{array}{l}\text { Incomplete outcome data (attrition } \\
\text { bias) }\end{array}$ & Low risk & No attrition bias \\
\hline Selective reporting (reporting bias) & Low risk & None \\
\hline Other bias & Unclear risk & $<5 \%$ of participants meeting the inclusion criteria randomized \\
\hline
\end{tabular}

\section{Footnotes}

\section{Acronyns and abbreviation used in this table}

AECC: American-European Consensus Criteria; ALI: acute lung injury; ARDS: acute respiratory distress syndrome; BALF: bronchoalveolar lavage fluid; BMI: body mass index; CD4: cluster of differentiation 4; DHA: docosahexaenoic acid; EPA: eicosapentaenoic acid; $\mathrm{FiO}_{2}$ : fraction of inspired oxygen; GCS: Glascow Coma Scale; GLA: gamma-linolenic acid; ICU: intensive care unit; IL: interleukin; INR: international normalized ratio; ITT: intension-to-treat; LIS: lung injury score; LOS: length of stay; MODS: Multiple Organ Dysfunction Score; $\mathrm{N}$ : number; $\mathrm{PaO}_{2}$ : partial pressure of arterial oxygen; PBW: per body weight; rh-APC: recombinant human activated protein C; $\mathrm{SaO}_{2}$ : oxygen saturation; SD: standard deviation; SOFA: Sequential Organ Failure Assessment; TPN: total parenteral nutrition. 
EC290 Immunonutrition for acute respiratory distress syndrome (ARDS) in adults

Characteristics of excluded studies

Footnotes

Characteristics of studies awaiting classification

Footnotes

Characteristics of ongoing studies

Footnotes

Summary of findings tables

1 Omega-3 fatty acids and antioxidants compared with placebo or standard nutrition for acute respiratory distress syndrome (ARDS) 
Omega-3 fatty acids and antioxidants compared with placebo or standard nutrition for acute respiratory distress syndrome (ARDS)

Patient or population: adults (aged 18 years or older), mechanically ventilated participants with ARDS as defined by the Berlin definition of ARDS or, for older studies, the American-European Consensus Criteria for both ARDS and acute lung injury

Settings: intensive care units in USA, Brazil, India, Iran, Israel, Japan, and Spain

Intervention: omega-3 fatty acids and antioxidants

Comparison: placebo or standard nutrition

\begin{tabular}{|c|c|c|c|c|c|}
\hline \multirow[t]{2}{*}{ Outcomes } & \multicolumn{2}{|c|}{ Illustrative comparative risks* $(95 \% \mathrm{Cl})$} & \multirow{2}{*}{$\begin{array}{l}\text { Relative } \\
\text { effect } \\
(95 \% \mathrm{Cl})\end{array}$} & \multirow{2}{*}{$\begin{array}{l}\text { No. of } \\
\text { participants } \\
\text { (studies) }\end{array}$} & \multirow{2}{*}{$\begin{array}{l}\text { Quality of the } \\
\text { evidence } \\
\text { (GRADE) }\end{array}$} \\
\hline & $\begin{array}{l}\text { Risk with placebo or } \\
\text { standard nutrition }\end{array}$ & $\begin{array}{l}\text { Risk with omega- } 3 \text { fatty } \\
\text { acids and antioxidants }\end{array}$ & & & \\
\hline $\begin{array}{l}\text { All-cause mortality } \\
\text { (longest period reported) }\end{array}$ & 280 per 1000 & $\begin{array}{l}221 \text { per } 1000 \\
(165 \text { to } 299)\end{array}$ & $\begin{array}{l}\text { RR } 0.79 \\
(0.59 \text { to } \\
1.07)\end{array}$ & $\begin{array}{l}1015 \\
(10 \mathrm{RCTs})\end{array}$ & $\begin{array}{l}\oplus \oplus \ominus \ominus \\
\text { low }^{a, b}\end{array}$ \\
\hline $\begin{array}{l}\text { ICU LOS } \\
\text { (days) }\end{array}$ & Mean 18.09 days & $\begin{array}{l}\text { MD } 3.12 \text { days lower } \\
\text { (5.24 lower to } 1.01 \text { lower) }\end{array}$ & - & $\begin{array}{l}641 \\
(8 \mathrm{RCTs})\end{array}$ & $\begin{array}{l}\oplus \ominus \ominus \ominus \\
\text { very low } a, b, c\end{array}$ \\
\hline $\begin{array}{l}\text { Ventilator days } \\
\text { (days) }\end{array}$ & Mean 12.95 days & $\begin{array}{l}\text { MD } 2.25 \text { days lower } \\
\text { (3.78 days lower to } 0.71 \\
\text { days lower) }\end{array}$ & - & $\begin{array}{l}583 \\
(7 \mathrm{RCTs})\end{array}$ & $\begin{array}{l}\oplus \ominus \ominus \ominus \\
\text { very low } a, b, c\end{array}$ \\
\hline $\begin{array}{l}\text { Indices of oxygenation } \\
\text { (measured as } \mathrm{PaO}_{2} / \mathrm{FiO}_{2} \text { ratio } \\
\text { at day } 4 \text { ) }\end{array}$ & Mean $180.10 \mathrm{mmHg}$ & $\begin{array}{l}\text { MD } 39 \mathrm{mmHg} \text { higher } \\
\text { (10.75 mmHg higher to } \\
67.02 \mathrm{mmHg} \text { higher) }\end{array}$ & - & $\begin{array}{l}659 \\
(7 \mathrm{RCTs})\end{array}$ & $\begin{array}{l}\oplus \ominus \ominus \ominus \\
\text { very low } a, b, c\end{array}$ \\
\hline $\begin{array}{l}\text { Cardiac adverse events } \\
\text { (study author reported anytime } \\
\text { during study period) }\end{array}$ & 40 per 1000 & $\begin{array}{l}35 \text { per } 1000 \\
(4 \text { to } 342)\end{array}$ & $\begin{array}{l}\text { RR } 0.87 \\
(0.09 \text { to } \\
8.46)\end{array}$ & $\begin{array}{l}339 \\
(3 \mathrm{RCTs})\end{array}$ & $\begin{array}{l}\oplus \ominus \ominus \ominus \\
\text { very low } a, b, c\end{array}$ \\
\hline $\begin{array}{l}\text { Gastrointestinal adverse } \\
\text { events } \\
\text { (study author reported anytime } \\
\text { during study period) }\end{array}$ & 151 per 1000 & $\begin{array}{l}174 \text { per } 1000 \\
\text { (114 to } 266)\end{array}$ & $\begin{array}{l}\text { RR } 1.15 \\
(0.75 \text { to } \\
1.76)\end{array}$ & $\begin{array}{l}427 \\
(4 \mathrm{RCTs})\end{array}$ & $\begin{array}{l}\oplus \ominus \ominus \ominus \\
\text { very low } a, b, c\end{array}$ \\
\hline $\begin{array}{l}\text { Total number of adverse } \\
\text { events } \\
\text { (study author reported anytime } \\
\text { during study period) }\end{array}$ & 240 per 1000 & $\begin{array}{l}225 \text { per } 1000 \\
(165 \text { to } 304)\end{array}$ & $\begin{array}{l}\text { RR } 0.94 \\
(0.69 \text { to } \\
1.27)\end{array}$ & $\begin{array}{l}517 \\
(5 \mathrm{RCTs})\end{array}$ & $\begin{array}{l}\oplus \ominus \ominus \ominus \\
\text { very low }\end{array}$ \\
\hline \multicolumn{6}{|c|}{$\begin{array}{l}\text { The corresponding risk (and its } 95 \% \text { confidence interval) is based on the assumed risk in the comparison group and the } \\
\text { relative effect of the intervention (and its } 95 \% \mathrm{Cl} \text { ). } \\
\text { ARDS: acute respiratory distress syndrome; } \mathrm{Cl} \text { : confidence interval; } \mathrm{FiO}_{2} \text { : fraction of inspired oxygen; ICU: intensive care } \\
\text { unit; LOS: length of stay; } \mathrm{MD} \text { : mean difference; } \mathrm{PaO}_{2} \text { : partial pressure of arterial oxygen; RCT: randomized controlled trial; } \\
\text { RR: risk ratio. }\end{array}$} \\
\hline \multicolumn{6}{|c|}{$\begin{array}{l}\text { GRADE Working Group grades of evidence. } \\
\text { High quality: further research is very unlikely to change our confidence in the estimate of effect. } \\
\text { Moderate quality: further research is likely to have an important impact on our confidence in the estimate of effect and may } \\
\text { change the estimate. } \\
\text { Low quality: further research is very likely to have an important impact on our confidence in the estimate of effect and is } \\
\text { likely to change the estimate. } \\
\text { Very low quality: we are very uncertain about the estimate. }\end{array}$} \\
\hline
\end{tabular}

\section{Footnotes}

aRisk of bias downgraded (-1) due to selection, performance, and attrition bias in the included studies.

bInconsistency downgraded (-1) due to both clinical and methodological inconsistency in the included studies.

cIndirectness downgraded (-1) due to indirect intervention and comparator in the included studies. In some included studies, control participants' nutritional formula may have increased the risk of harm.

\section{Additional tables}

1 Sensitivity analysis for the outcomes ICU-free days and ventilator-free days according to statistical methods 
EC290 Immunonutrition for acute respiratory distress syndrome (ARDS) in adults

\begin{tabular}{|l|l|l|}
\hline Outcome & Statistical analysis & Results \\
\hline ICU-free days at day 28 & Mean difference (IV, random-effects, 95\% Cl) & $3.44(-1.17$ to 8.05), $\mathrm{P}=0.14$ \\
\hline ICU-free days at day 28 & Mean difference (IV, fixed-effect, 95\% CI) & $1.95(0.42$ to 3.48), $\mathrm{P}=0.01$ \\
\hline Ventilator-free days at day 28 & Mean difference (IV, random-effects, 95\% Cl) & $2.15(-0.91$ to 5.22), $\mathrm{P}=0.17$ \\
\hline Ventilator-free days at day 28 & Mean difference (IV, fixed-effect, 95\% Cl) & 1.00 (0.06 to 1.94), P = 0.04 \\
\hline
\end{tabular}

Footnotes

\section{References to studies}

Included studies

Elamin 2012

Elamin EM, Miller AC, Ziad S. Immune enteral nutrition can improve outcomes in medical-surgical patients with ARDS: a prospective randomized controlled trial. Journal of Nutritional Disorders and Therapy 2012;2:109. [PubMed: 24761313]

\section{Gadek 1999}

* Gadek JE, DeMichele SJ, Karlstad MD, Pacht ER, Donahoe M, Albertson TE, et al. Effect of enteral feeding with eicosapentaenoic acid, gamma-linoleic acid, and antioxidants in patients with acute respiratory distress syndrome. Critical Care Medicine 1999;27(8):1409-20. [PubMed: 10470743]

Nelson JL, DeMichele SJ, Pacht ER, Wennberg AK; Enteral Nutrition in ARDS Study Group. Effect of enteral feeding with eicosapentaenoic acid, gamma-linolenic acid, and antioxidants on antioxidant status in patients with acute respiratory distress syndrome. Journal of Parenteral and Enteral Nutrition 2003;27(2):98-104. [Other: ; PubMed: 12665164]

Pacht ER, DeMichele SJ, Nelson JL, Hart J, Wennberg AK, Gadek JE. Enteral nutrition with eicosapentaenoic acid, gammalinolenic acid, and antioxidants reduces alveolar inflammatory mediators and protein influx in patients with acute respiratory distress syndrome. Critical Care Medicine 2003;31(2):491-500. [PubMed: 12576957]

\section{Grau-Camona 2011}

Grau-Carmona T, Morán-García V, García-de-Lorenzo A, Heras-de-la-Calle G, Quesada-Bellver B, López-Martínez J, et al. Effect of an enteral diet enriched with eicosapentaenoic acid, gamma-linolenic acid and anti-oxidants on the outcome of mechanically ventilated, critically ill, septic patients. Clinical Nutrition 2011;30(5):578-84. [PubMed: 21474219]

\section{Gupta 2012}

Gupta A, Govil D, Bhatnagar S, Gupta S, Goyal J, Patel S, et al. Efficacy and safety of parenteral omega 3 fatty acids in ventilated patients with acute lung injury. Indian Journal of Critical Care Medicine 2011;15(2):108-13. [PubMed: 21814375]

\section{Parish 2014}

Parish M, Valiyi F, Hamishehkar H, Sanaie S, Asghari Jafarabadi M, Golzari SE, et al. The effect of omega-3 fatty acids on ARDS: a randomized double-blind study. Advanced Pharmaceutical Bulletin 2014;4(Suppl 2):555-61. [PubMed: 25671189]

\section{Pontes-Arruda 2006}

Pontes-Arruda A, Aragão AM, Albuquerque JD. Effects of enteral feeding with eicosapentaenoic acid, gamma-linolenic acid, and antioxidants in mechanically ventilated patients with severe sepsis and septic shock. Critical Care Medicine 2006; 34(9):2325-33. [PubMed: 16850002]

\section{Rice 2011}

Rice TW, Wheeler AP, Thompson BT, deBoisblanc BP, Steingrub J, Rock P. Enteral omega-3 fatty acid, gamma-linolenic acid, and antioxidant supplementation in acute lung injury. JAMA 2011;306(14):1574-81. [PubMed: 21976613]

\section{Shirai 2015}

Shirai K, Yoshida S, Matsumaru N, Toyoda I, Ogura S. Effect of enteral diet enriched with eicosapentaenoic acid, gammalinolenic acid, and antioxidants in patients with sepsis-induced acute respiratory distress syndrome. Journal of Intensive Care 2015;3:24. [PubMed: 26015869]

\section{Singer 2006}

* Singer P, Theilla M, Fisher H, Gibstein L, Grozovski E, Cohen J. Benefit of an enteral diet enriched with eicosapentaenoic acid and gamma-linolenic acid in ventilated patients with acute lung injury. Critical Care Medicine 2006;34(4):1033-8. [_ PubMed: 16484911]

Theilla M, Singer P, Cohen J, Dekeyser F. A diet enriched in eicosapentaenoic acid, gamma-linolenic acid and antioxidants in the prevention of new pressure ulcer formation in critically ill patients with acute lung injury: a randomized, prospective, controlled study. Clinical Nutrition 2007;26(6):752-7. [PubMed: 17933438]

\section{Stapleton 2011}

Stapleton RD, Martin TR, Weiss NS, Crowley JJ, Gundel SJ, Nathens AB, et al. A phase II randomized placebo-controlled trial of omega-3 fatty acids for the treatment of acute lung injury. Critical Care Medicine 2011;39(7):1655-62. [ PubMed: 
21423000

\section{Excluded studies}

Studies awaiting classification

Ongoing studies

\section{Other references}

\section{Additional references}

\section{Andrews 2011}

Andrews PJ, Avenell A, Noble DW, Campbell MK, Croal BL, Simpson WG, et al. Randomised trial of glutamine, selenium, or both, to supplement parenteral nutrition for critically ill patients. BMJ 2011;342:d1542. [PubMed: 21415104]

\section{Ashbaugh 1967}

Ashbaugh DG, Bigelow DB, Petty TL, Levine BE. Acute respiratory distress in adults. Lancet 1967;2(7511):319-23. [ PubMed: 4143721]

\section{Beale 1999}

Beale RJ, Bryg DJ, Bihari DJ. Immunonutrition in the critically ill: a systematic review of clinical outcome. Critical Care Medicine 1999;27(12):2799-805. [PubMed: 10628629]

\section{Bernard 1994}

Bernard GR, Artigas A, Brigham KL, Carlet J, Falke K, Hudson L, et al. The American-European Consensus Conference on ARDS. Definitions, mechanisms, relevant outcomes, and clinical trial coordination. American Journal of Respiratory and Critical Care Medicine 1994;149:818-24. [PubMed: 7509706]

\section{Calder 2003}

Calder PC. Immunonutrition. BMJ 2003;327(7407):117-8. [PubMed: 12869428]

\section{Calder 2007}

Calder PC. Immunonutrition in surgical and critically ill patients. British Journal of Nutrition 2007;98(Suppl 1):S133-9. [_ PubMed: 17922951]

\section{Dee 2011}

Dee BM, Bruno JJ, Lal LS, Canada TW. Effects of immune-enhancing enteral nutrition on mortality and oxygenation in acute lung injury and acute respiratory distress syndrome: a meta-analysis. Hospital Pharmacy 2011;46(1):33-40.

\section{Dushianthan 2011}

Dushianthan A, Grocott MP, Postle AD, Cusack R. Acute respiratory distress syndrome and acute lung injury. Postgraduate Medical Journal 2011;87(1031):612-22. [PubMed: 21642654]

\section{Egger 1997}

Egger M, Davey Smith G, Schneider M, Minder C. Bias in meta-analysis detected by a simple, graphical test. BMJ 1997; 315(7109):629-34. [PubMed: 9310563]

\section{Gajic 2011}

Gajic O, Dabbagh O, Park PK, Adesanya A, Chang SY, Hou P, et al. Early identification of patients at risk of acute lung injury: evaluation of lung injury prediction score in a multicenter cohort study. American Journal of Respiratory and Critical Care Medicine 2011;183(4):462-70. [PubMed: 20802164]

\section{GRADEpro GDT}

GRADEpro GDT [Computer program]. Version accessed 6 August 2016. Hamilton (ON): McMaster University (developed by Evidence Prime), 2015.Available at gradepro.org.

\section{Guyatt 2008}

Guyatt GH, Oxman AD, Kunz R, Vist GE, Falck-Ytter Y, Schunemann HJ. What is 'quality of evidence' and why is it important to clinicians. BMJ 2008;336:995-8. [MEDLINE: 18456631]

\section{Harbord 2006}

Harbord RM, Egger M, Sterne JA. A modified test for small-study effects in meta-analyses of controlled trials with binary endpoints. Statistics in Medicine 2006;25(20):3443-57. [ PubMed: 16345038]

\section{Herridge 2011}

Herridge MS, Tansey CM, Matté A, Tomlinson G, Diaz-Granados N, Cooper A, et al. Functional disability 5 years after acute respiratory distress syndrome. New England Journal of Medicine 2011;364(14):1293-304. [PubMed: 21470008] 


\section{EC290 Immunonutrition for acute respiratory distress syndrome (ARDS) in adults}

Heyland DK, Novak F, Drover JW, Jain M, Su X, Suchner U. Should immunonutrition become routine in critically ill patients? A systematic review of the evidence. JAMA 2001;286(8):944-53. [PubMed: 11509059]

\section{Heyland 2005}

Heyland DK, Dhaliwal R, Suchner U, Berger MM. Antioxidant nutrients: a systematic review of trace elements and vitamins in the critically ill patient. Intensive Care Medicine 2005;31(3):327-37. [PubMed: 15605227]

\section{Heyland 2013}

Heyland DK, Muscedere J, Wischmeyer PE, Cook D, Jones G, Albert M, et al. A randomized trial of glutamine and antioxidants in critically ill patients. New England Journal of Medicine 2013;368(16):1489-97. [PubMed: 23594003]

\section{Higgins 2011}

Higgins JP, Green S, editor(s). Cochrane Handbook for Systematic Reviews of Interventions Version 5.1.0 (updated March 2011). The Cochrane Collaboration, 2011. Available from handbook.cochrane.org.

\section{Hozo 2005}

Hozo PS, Djulbegovic B, Hozo I. Estimating the mean and variance from the median, range, and the size of a sample. BMC Medical Research Methodology 2005;5:13. [PubMed: 15840177]

\section{Lang 2002}

Lang JD, McArdle PJ, O'Reilly PJ, Matalon S. Oxidant-antioxidant balance in acute lung injury. Chest 2002;122(Suppl 6):314S-20S. [ PubMed: 12475808 ]

\section{Li 2015}

Li C, Bo L, Liu W, Lu X, Jin F. Enteral immunomodulatory diet (omega-3 fatty acid, y-linolenic acid and antioxidant supplementation) for acute lung injury and acute respiratory distress syndrome: an updated systematic review and metaanalysis. Nutrients 2015;7(7):5572-85. [PubMed: 26184293]

\section{Mancuso 1997a}

Mancuso P, Whelan J, DeMichele SJ, Snider CC, Guszcza JA, Karlstad MD. Dietary fish oil and fish and borage oil suppress intrapulmonary proinflammatory eicosanoid biosynthesis and attenuate pulmonary neutrophil accumulation in endotoxic rats. Critical Care Medicine 1997;25(7):1198-206. [

\section{Mancuso 1997b}

Mancuso P, Whelan J, DeMichele SJ, Snider CC, Guszcza JA, Claycombe KJ, et al. Effects of eicosapentaenoic and gamma-linolenic acid on lung permeability and alveolar macrophage eicosanoid synthesis in endotoxic rats. Critical Care Medicine 1997;25(3):523-32. [PubMed: 9118672]

\section{Matthay 2011}

Matthay MA, Zemans RL. The acute respiratory distress syndrome: pathogenesis and treatment. Annual Review of Pathology 2011;6:147-63. [PubMed: 20936936]

\section{McClave 2016}

McClave SA, Taylor BE, Martindale RG, Warren MM, Johnson DR, Braunschweig C, et al. Guidelines for the provision and assessment of nutrition support therapy in the adult critically ill patient: Society of Critical Care Medicine (SCCM) and American Society of Parenteral and Enteral Nutrition (A.S.P.E.N). Journal of Parenteral and Enteral Nutrition 2016; 40(2):159-211. [PubMed: 26773077]

\section{Metnitz 1999}

Metnitz PG, Bartens C, Fischer M, Fridrich P, Steltzer H, Druml W. Antioxidant status in patients with acute respiratory distress syndrome. Intensive Care Medicine 1999;25(2):180-5. [PubMed: 10193545]

\section{Mizock 2010}

Mizock BA. Immunonutrition and critical illness: an update. Nutrition 2010;26:701-7. [PubMed: 20381315 ]

\section{Murray 1995}

Murray MJ, Kumar M, Gregory TJ, Banks PL, Tazelaar HD, DeMichele SJ. Select dietary fatty acids attenuate cardiopulmonary dysfunction during acute lung injury in pigs. American Journal of Physiology 1995;269(6 Pt 2):H2090-9. [ PubMed: 8594921]

\section{Newsholme 1985}

Newsholme EA, Crabtree B, Ardawi MS. Glutamine metabolism in lymphocytes: its biochemical, physiological and clinical importance. Quarterly Journal of Experimental Physiology 1985;70(4):473-89. [PubMed: 3909197]

\section{Novak 2002}

Novak F, Heyland DK, Avenell A, Drover JW, Su X. Glutamine supplementation in serious illness: a systematic review of the evidence. Critical Care Medicine 2002;30(9):2022-9. [MEDLINE: 12352035] 
EC290 Immunonutrition for acute respiratory distress syndrome (ARDS) in adults

\section{Pontes-Arruda 2008}

Pontes-Arruda A, Demichele S, Seth A, Singer P. The use of an inflammation-modulating diet in patients with acute lung injury or acute respiratory distress syndrome: a meta-analysis of outcome data. Journal of Parenteral and Enteral Nutrition 2008;32(6):596-605. [PubMed: 18974237]

\section{Popovic 2007}

Popovic PJ, Zeh HJ 3rd, Ochoa JB. Arginine and immunity. Journal of Nutrition 2007;137(6 Suppl 2):1681S-6S. [PubMed: 17513447]

\section{Ranieri 2012}

ARDS Definition Task Force, Ranieri VM, Rubenfeld GD, Thompson BT, Ferguson ND, Caldwell E, Fan E, et al. Acute respiratory distress syndrome: the Berlin Definition. JAMA 2012;307(23):2526-33. [PubMed: 22797452]

\section{Review Manager 2014}

Review Manager 5 (RevMan 5) [Computer program]. Version 5.3. Copenhagen: Nordic Cochrane Centre, The Cochrane Collaboration, 2014.

\section{Sane 2000}

Sane S, Baba M, Kusano C, Shirao K, Andoh T, Kamada T, et al. Eicosapentaenoic acid reduces pulmonary edema in endotoxemic rats. Journal of Surgical Research 2000;93(1):21-7. [PubMed: 10945939]

\section{Schmidt 2004}

Schmidt R, Luboeinski T, Markart P, Ruppert C, Daum C, Grimminger F, et al. Alveolar antioxidant status in patients with acute respiratory distress syndrome. European Respiratory Journal 2004;24(6):994-9. [PubMed: 15572544]

\section{Soares 2014}

Soares AD, Costa KA, Wanner SP, Santos RG, Fernandes SO, Martins FS, et al. Dietary glutamine prevents the loss of intestinal barrier function and attenuates the increase in core body temperature induced by acute heat exposure. British Journal of Nutrition 2014;112(10):1601-10. [PubMed: 25322775]

\section{van Zanten 2015}

van Zanten AR, Dhaliwal R, Garrel D, Heyland DK. Enteral glutamine supplementation in critically ill patients: a systematic review and meta-analysis. Critical Care 2015;19:294. [PubMed: 26283217]

\section{Walkey 2012}

Walkey AJ, Summer R, Ho V, Alkana P. Acute respiratory distress syndrome: epidemiology and management approaches. Clinical Epidemiology 2012;4:159-69. [PubMed: 22866017]

\section{Wang 2014}

Wang CY, Calfee CS, Paul DW, Janz DR, May AK, Zhuo H, et al. One-year mortality and predictors of death among hospital survivors of acute respiratory distress syndrome. Intensive Care Medicine 2014;40(3):388-96. [PubMed: 24435201]

\section{Zhu 2014}

Zhu D, Zhang Y, Li S, Gan L, Feng H, Nie W. Enteral omega-3 fatty acid supplementation in adult patients with acute respiratory distress syndrome: a systematic review of randomized controlled trials with meta-analysis and trial sequential analysis. Intensive Care Medicine 2014;40(4):504-12. [PubMed: 24556914]

\section{Other published versions of this review}

\section{Dushianthan 2016}

Dushianthan A, Cusack R, Grocott MPW. Immunonutrition for acute respiratory distress syndrome (ARDS) in adults. Cochrane Database of Systematic Reviews 2016, Issue 1. Art. No.: CD012041 DOI: 10.1002/14651858.CD012041.

\section{Classification pending references}

\section{Data and analyses}

1 Omega-3 fatty acids and antioxidants versus placebo or standard nutrition

\begin{tabular}{|l|l|l|l|l|l|}
\hline Outcome or Subgroup & Studies & Participants & Statistical Method & Effect Estimate \\
\hline $\begin{array}{l}1.1 \text { All-cause mortality (longest } \\
\text { period reported) }\end{array}$ & 10 & 1015 & Risk Ratio(M-H, Random, 95\% CI) & $0.79[0.59,1.07]$ \\
\hline 1.2 28-day mortality & 6 & 466 & Risk Ratio(M-H, Fixed, 95\% Cl) & $0.64[0.49,0.84]$ \\
\hline $1.3 \underline{\text { ICU LOS }}$ & 8 & 641 & $\begin{array}{l}\text { Mean Difference(IV, Random, 95\% } \\
\text { Cl) }\end{array}$ & $-3.12[-5.24,-1.01]$ \\
\hline $1.4 \underline{\text { ICU-free days at day 28 }}$ & 5 & 609 & $\begin{array}{l}\text { Mean Difference(IV, Random, 95\% } \\
\text { Cl) }\end{array}$ & $3.44[-1.17,8.05]$ \\
\hline
\end{tabular}


EC290 Immunonutrition for acute respiratory distress syndrome (ARDS) in adults

\begin{tabular}{|c|c|c|c|c|}
\hline 1.5 Ventilator days & 7 & 583 & Mean Difference(IV, Fixed, 95\% Cl) & $-2.25[-3.78,-0.71]$ \\
\hline 1.6 Ventilator-free days at day 28 & 6 & 665 & $\begin{array}{l}\text { Mean Difference(IV, Random, 95\% } \\
\text { CI) }\end{array}$ & $2.15[-0.91,5.22]$ \\
\hline 1.7 Hospital LOS & 3 & 293 & Mean Difference(IV, Fixed, 95\% Cl) & $-2.72[-6.93,1.50]$ \\
\hline $1.8 \mathrm{PaO}_{2} / \mathrm{FiO}_{2}$ ratio at day 4 & 8 & 676 & $\begin{array}{l}\text { Mean Difference(IV, Random, 95\% } \\
\mathrm{CI})\end{array}$ & $38.88[10.75,67.02]$ \\
\hline $1.9 \mathrm{PaO}_{2} / \mathrm{FiO}_{2}$ ratio at day 7 & 9 & 465 & $\begin{array}{l}\text { Mean Difference(IV, Random, 95\% } \\
\mathrm{CI})\end{array}$ & $23.44[1.73,45.15]$ \\
\hline 1.10 Patients with new organ failure & 2 & 249 & Risk Ratio(M-H, Fixed, 95\% Cl) & $0.46[0.33,0.64]$ \\
\hline $\begin{array}{l}\text { 1.11 Patients with nosocomial } \\
\text { infection }\end{array}$ & 3 & 450 & Risk Ratio(M-H, Fixed, 95\% Cl) & $1.01[0.76,1.33]$ \\
\hline 1.12 Adverse events - cardiac & 3 & 339 & Risk Ratio(M-H, Random, 95\% Cl) & $0.87[0.09,8.46]$ \\
\hline $\begin{array}{l}1.13 \text { Adverse events - } \\
\text { gastrointestinal }\end{array}$ & 4 & 427 & Risk Ratio(M-H, Fixed, 95\% Cl) & $1.15[0.75,1.76]$ \\
\hline 1.14 Total adverse events & 5 & 517 & Risk Ratio(M-H, Fixed, 95\% Cl) & $0.94[0.69,1.27]$ \\
\hline $\begin{array}{l}1.15 \text { Subgroup analysis for the } \\
\text { primary outcome (all-cause } \\
\text { mortality) - type of intervention }\end{array}$ & 10 & 1015 & Risk Ratio(M-H, Random, 95\% Cl) & $0.79[0.59,1.07]$ \\
\hline $\begin{array}{l}1.15 .1 \text { Immunonutrition formula } \\
\text { compared with lipid-based control } \\
\text { diet }\end{array}$ & 4 & 361 & Risk Ratio(M-H, Random, 95\% Cl) & $0.57[0.42,0.78]$ \\
\hline $\begin{array}{l}1.15 .2 \text { Immunonutrition formula } \\
\text { compared with carbohydrate-based } \\
\text { control diet }\end{array}$ & 2 & 178 & Risk Ratio(M-H, Random, 95\% Cl) & $1.13[0.57,2.22]$ \\
\hline $\begin{array}{l}1.15 .3 \text { Immunonutrition } \\
\text { supplemented to same intervention } \\
\text { and control diet }\end{array}$ & 3 & 204 & Risk Ratio(M-H, Random, 95\% Cl) & $0.75[0.48,1.15]$ \\
\hline $\begin{array}{l}1.15 .4 \text { Immunonutrition } \\
\text { supplemented to different } \\
\text { intervention and control formula }\end{array}$ & 1 & 272 & Risk Ratio(M-H, Random, 95\% Cl) & $1.63[1.01,2.63]$ \\
\hline $\begin{array}{l}1.16 \text { Subgroup analysis for the } \\
\text { primary outcome (all-cause } \\
\text { mortality) - route of intervention }\end{array}$ & 10 & 1015 & Risk Ratio(M-H, Random, 95\% Cl) & $0.79[0.59,1.07]$ \\
\hline 1.16.1 Enteral & 9 & 954 & Risk Ratio(M-H, Random, 95\% Cl) & $0.82[0.59,1.14]$ \\
\hline 1.16.2 Intravenous & 1 & 61 & Risk Ratio(M-H, Random, 95\% Cl) & $0.62[0.32,1.22]$ \\
\hline $\begin{array}{l}1.17 \text { Subgroup analysis for the } \\
\text { primary outcome (all-cause } \\
\text { mortality) - mode of intervention } \\
\text { (bolus or continuous) }\end{array}$ & 10 & 1015 & Risk Ratio(M-H, Random, 95\% Cl) & $0.80[0.60,1.08]$ \\
\hline 1.17.1 Continuous infusion & 7 & 600 & Risk Ratio(M-H, Random, 95\% Cl) & $0.65[0.50,0.84]$ \\
\hline 1.17.2 Bolus supplementation & 3 & 415 & Risk Ratio(M-H, Random, 95\% Cl) & $1.17[0.72,1.88]$ \\
\hline $\begin{array}{l}1.18 \text { Subgroup analysis for the } \\
\text { primary outcome (all-cause } \\
\text { mortality) - duration of intervention }\end{array}$ & 10 & 1015 & Risk Ratio(M-H, Random, 95\% Cl) & $0.79[0.59,1.07]$ \\
\hline 1.18.1 Duration $<7$ days & 2 & 163 & Risk Ratio(M-H, Random, 95\% Cl) & $0.61[0.32,1.17]$ \\
\hline 1.18.2 Duration 14 days & 5 & 345 & Risk Ratio(M-H, Random, 95\% Cl) & $0.64[0.47,0.89]$ \\
\hline 1.18.3 Duration 21 days & 1 & 272 & Risk Ratio(M-H, Random, 95\% Cl) & $1.63[1.01,2.63]$ \\
\hline 1.18.4 Duration 28 days & 2 & 235 & Risk Ratio(M-H, Random, 95\% Cl) & $0.79[0.44,1.44]$ \\
\hline
\end{tabular}

2 Sensitivity analysis: omega-3 fatty acids and antioxidants versus placebo or standard nutrition

\begin{tabular}{|c|c|c|c|c|}
\hline Outcome or Subgroup & Studies & \multicolumn{2}{|c|}{ Participants Statistical Method } & Effect Estimate \\
\hline $\begin{array}{l}2.1 \text { All-cause mortality (longest } \\
\text { period reported) excluding studies at } \\
\text { high risk of bias }\end{array}$ & & 561 & Risk Ratio(M-H, Random, 95\% Cl) & $0.98[0.60,1.58]$ \\
\hline 2.2 ICU LOS & 8 & 641 & Mean Difference(IV, Fixed, 95\% Cl) & $-0.08[-0.23,0.06]$ \\
\hline $2.3 \mathrm{ICU}$-free days at day 28 & 5 & 609 & $\begin{array}{l}\text { Mean Difference(IV, Random, 95\% } \\
\text { Cl) }\end{array}$ & $0.34[0.00,0.68]$ \\
\hline 2.4 Ventilator days & 7 & 583 & Mean Difference(IV, Fixed, 95\% Cl) & $-0.08[-0.24,0.07]$ \\
\hline
\end{tabular}


EC290 Immunonutrition for acute respiratory distress syndrome (ARDS) in adults

\begin{tabular}{|l|l|l|l|l|l|}
\hline 2.5 Ventilator-free days at dav 28 & 6 & 665 & Mean Difference(IV, Fixed, 95\% Cl) & $0.06[-0.06,0.18]$ \\
\hline 2.6 Hospital LOS & 3 & 293 & Mean Difference(IV, Fixed, 95\% Cl) & $-0.05[-0.34,0.24]$ \\
\hline
\end{tabular}

\section{Figures}

Figure 1

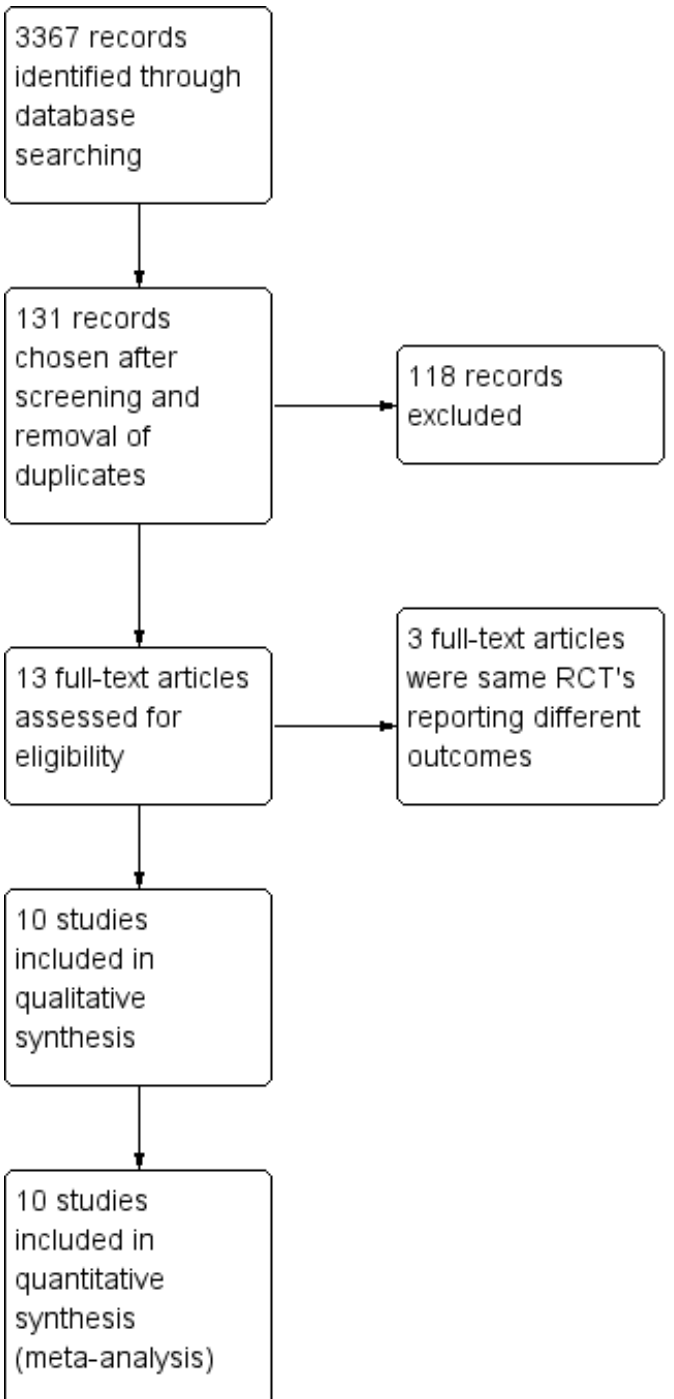

Caption

Study flow diagram.

Figure 2

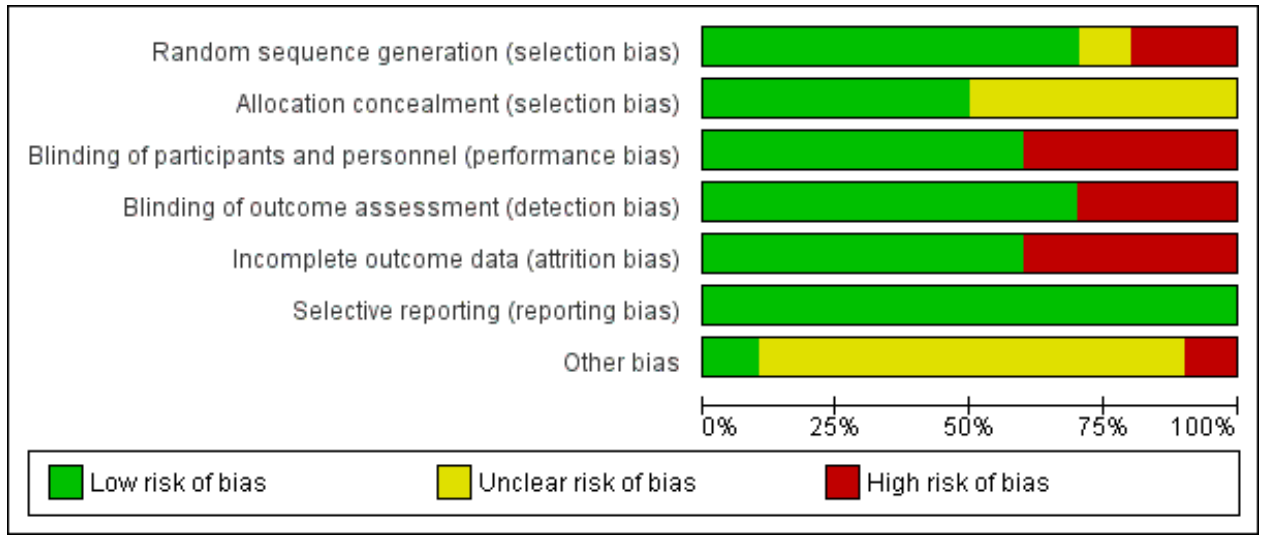

\section{Caption}

Risk of bias graph: review authors' judgements about each risk of bias item presented as percentages across all included studies.

Figure 3 
EC290 Immunonutrition for acute respiratory distress syndrome (ARDS) in adults

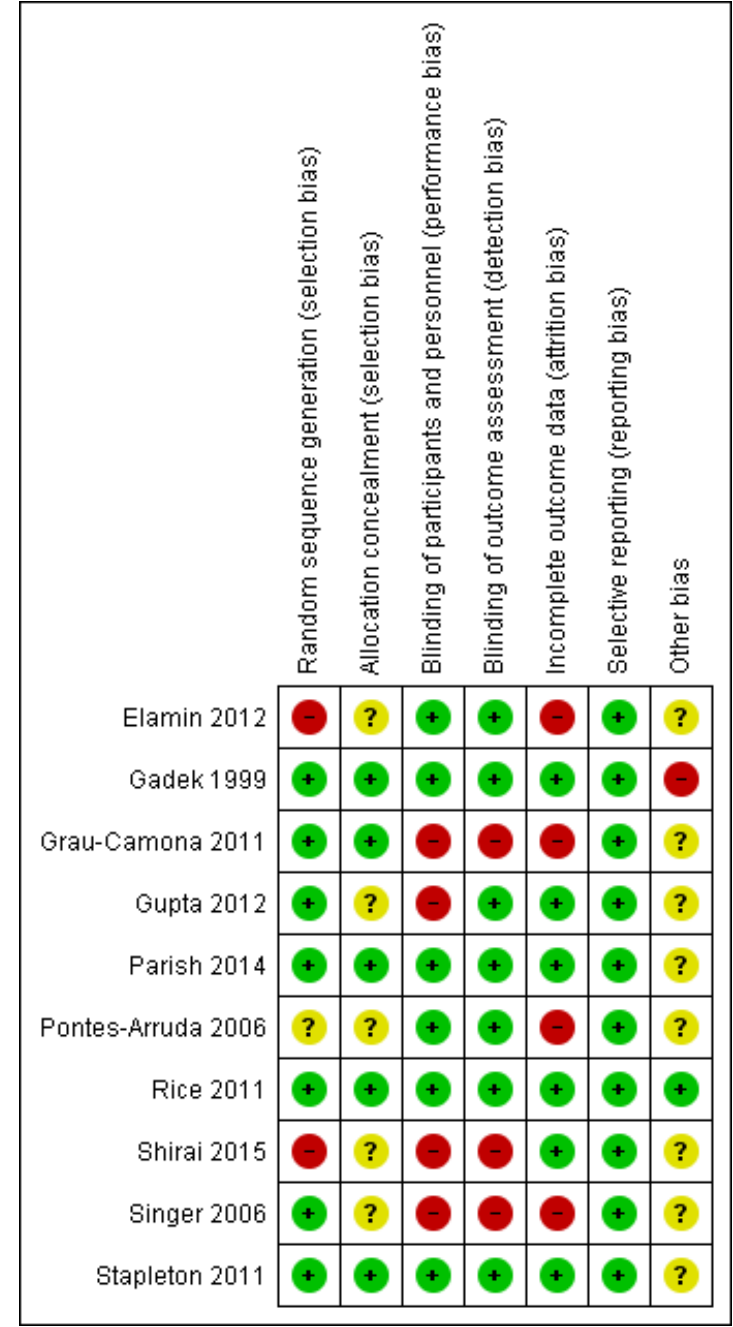

Caption

Risk of bias summary: review authors' judgements about each risk of bias item for each included study.

Figure 4 (Analysis 1.1)

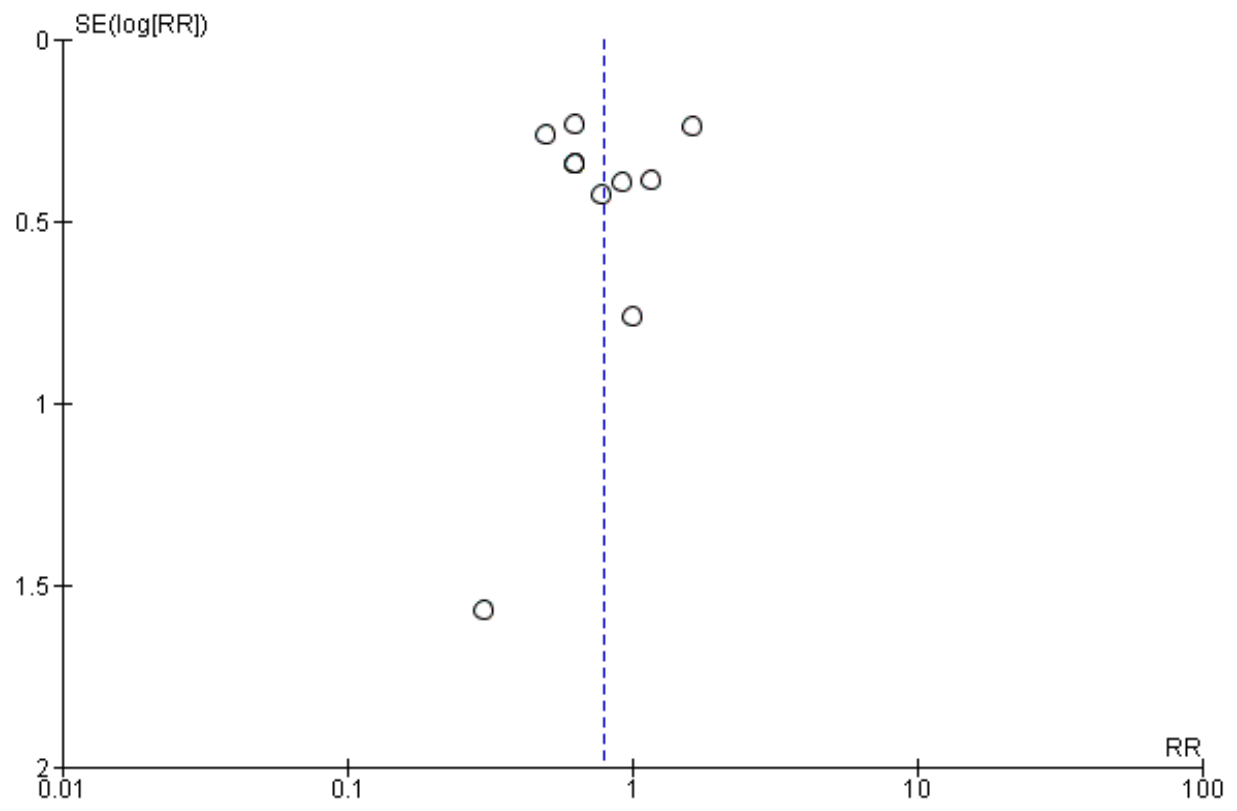

Caption

Funnel plot of comparison: omega-3 fatty acids and antioxidants versus placebo or standard nutrition, outcome: 1.1 All-cause mortality (longest period reported).

Sources of support

Internal sources 


\section{Internal sources}

- University Hospital Southampton NHS Foundation Trust - University of Southampton Respiratory Biomedical Research Unit, UK

Some of this work was undertaken at the University Hospital Southampton NHS Foundation Trust - University of Southampton Respiratory Biomedical Research Unit, which received a proportion of funding from the UK Department of Health's National Institute for Health Research Biomedical Research Units funding scheme.

\section{External sources}

- No sources of support provided

\section{Feedback}

\section{Appendices}

\section{Free-text terms}

\section{ARDS}

2. Acute respiratory distress syndrome

3. Acute lung injury

4. ALI

5. Essential fatty acids

6. Diet

7. Nutrition

8. Immunonutrition

9. Micronutrient

10. Macronutrient

11. Glutamine

12. Arginine

13. Leucine

14. Antioxidants

15. Vitamin C

16. Vitamin $\mathrm{E}$

17. Fish oil

18. Omega-3 fatty acid

19. n-3 fatty acid

20. Eicosapentaenoic acid

21. Docosahexaenoic acid

22. Gamma-linolenic acid

23. Clinical trials

24. Controlled clinical trials

25. Randomized controlled trials

2 CENTRAL search strategy

\#1 Acute respiratory distress syndrome

\#2 Acute lung injury

\#3 \#1 OR \#2

\#4 Diet

\#5 Nutrition

\#6 Immunonutrition

\#7 Macronutrient

\#8 Micronutrient

\#9 Amino acids

\#10 Glutamine 
\#11 Arginine

\#12 Leucine

\#13 Vitamin

\#14 Carotenoids

\#15 Ascorbic acid

\#16 Selenium

\#17 Zinc

\#18 Antioxidants

\#19 Omega-3 fatty acids

\#20 n-3 fatty acids

\#21 Eicosapentaenoic acid

\#22 Docosahexaenoic acid

$\# 23$ \#4 or \#5 or \#6 or \#7 or \#8 or \#9 or \#10 or \#11 or \#12 or \#13 or \#14 or \#15 or \#16 or \#17 or \#18 or \#19 or \#20 or \#21 or $\# 22$

\#24 \#3 and \#23

\section{OVID MEDLINE search strategy}

1. exp Acute Lung Injury/ or exp Respiratory Distress Syndrome, Adult/ or (ALI or ARDS).ti,ab. or (acute adj4 (lung injur* or distress syndrome)).mp. or ((severe or hypoxic) adj4 (respiratory and failure)).mp.

2.(Enteral Nutrition/ and Immune System/) or ((dietary or nutrient $\left.{ }^{\star}\right)$ adj3 (modulation or immune system)).mp. or dietary nutrient*.ti,ab. or immunonutrition.af. or Antioxidants/ or Vitamin E/ or Carotenoids/ or Ascorbic Acid/ or Selenium/ or Zinc/ or $\exp$ Amino Acids, Essential/ or Glutamine/ or Arginine/ or exp Fatty Acids, Essential/ or Fatty Acids, Omega-3/ or (anti?oxidant* or vitamin* or beta?caroten* or glutamine or arginine or omega?3 or selenium or zinc).ti,ab.

3. 1 and 2

4. ((randomized controlled trial or controlled clinical trial).pt. or randomized.ab. or placebo.ab. or drug therapy.fs. or randomly.ab. or trial.ab. or groups.ab.) not (animals not (humans and animals)).sh.

5. 3 and 4

\section{Embase search strategy}

1. exp Acute Lung Injury/ or exp Respiratory Distress Syndrome, Adult/ or (ALI or ARDS).ti,ab. or (acute adj4 (lung injur* or distress syndrome)).mp. or ((severe or hypoxic) adj4 (respiratory and failure)).mp.

2.(Enteral Nutrition/ and Immune System/) or ((dietary or nutrient*) adj3 (modulation or immune system)).mp. or dietary nutrient*.ti,ab. or immunonutrition.af. or Antioxidants/ or Vitamin E/ or Carotenoids/ or Ascorbic Acid/ or Selenium/ or Zinc/ or exp Amino Acids, Essential/ or Glutamine/ or Arginine/ or exp Fatty Acids, Essential/ or Fatty Acids, Omega-3/ or (anti?oxidant* or vitamin* or beta?caroten* or glutamine or arginine or omega?3 or selenium or zinc).ti,ab.

3. 1 and 2

4. ((randomized controlled trial or controlled clinical trial).pt. or randomized.ab. or placebo.ab. or drug therapy.fs. or randomly.ab. or trial.ab. or groups.ab.) not (animals not (humans and animals)).sh.

5. 3 and 4

\section{Data extraction form}


EC290 Immunonutrition for acute respiratory distress syndrome (ARDS) in adults

\begin{tabular}{|l|l|}
\hline 1. General study information & \\
\hline Study title & [Title] \\
\hline Study ID & \\
\hline Study reference & \\
\hline Publication type & \\
\hline Study sites & \\
\hline Population studied & \\
\hline ARDS definition & \\
\hline Timing of recruitment to onset & \\
\hline No. of patients screened/randomized/ITT in control & \\
\hline No. of patients screened/randomized/ITT in intervention & \\
\hline Inclusion criteria & \\
\hline Exclusion criteria & \\
\hline Intervention type & \\
\hline Ontervention delivery method & \\
\hline
\end{tabular}

\begin{tabular}{|c|c|c|}
\hline 2. 'Risk of bias' assessment - domains & Risk & Supporting statement \\
\hline Random sequence generation & Low/Unclear/High & \\
\hline Allocation concealment & Low/Unclear/High & \\
\hline Blinding of participants and personnel & Low/Unclear/High & \\
\hline Blinding of outcome assessment & Low/Unclear/High & \\
\hline Incomplete outcome data & Low/Unclear/High & \\
\hline Selective outcome reporting & Low/Unclear/High & \\
\hline Other bias & Low/Unclear/High & \\
\hline
\end{tabular}


EC290 Immunonutrition for acute respiratory distress syndrome (ARDS) in adults

\begin{tabular}{|c|c|}
\hline 3. Outcomes rep & \\
\hline Outcome (type) & \\
\hline Definition of outc & \\
\hline Dichotomous/col & \\
\hline Unit of measurer & \\
\hline Time points mea & \\
\hline Results & Intervention group Control group \\
\hline Dropouts & \\
\hline ITT & \\
\hline Statistical analys & \\
\hline Unit of analysis & \\
\hline Any other notes & \\
\hline
\end{tabular}

4. Additional key notes

\section{Graphs}

1 - Omega-3 fatty acids and antioxidants versus placebo or standard nutrition

1.1 All-cause mortality (longest period reported)

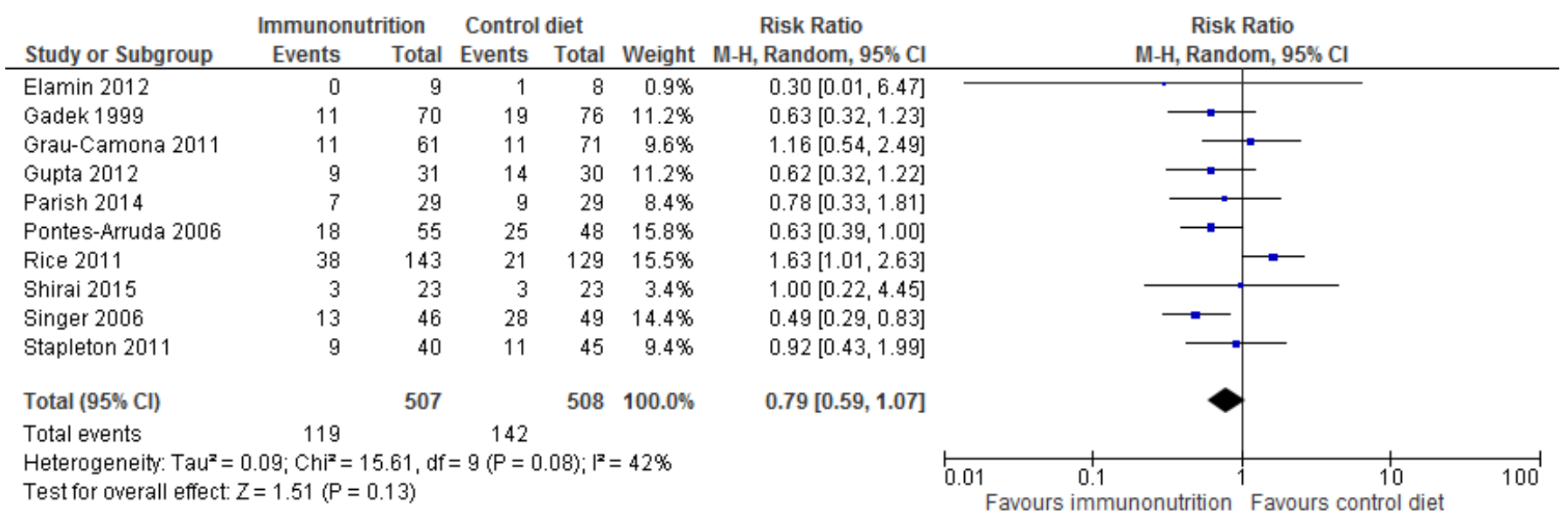

1.2 28-day mortality

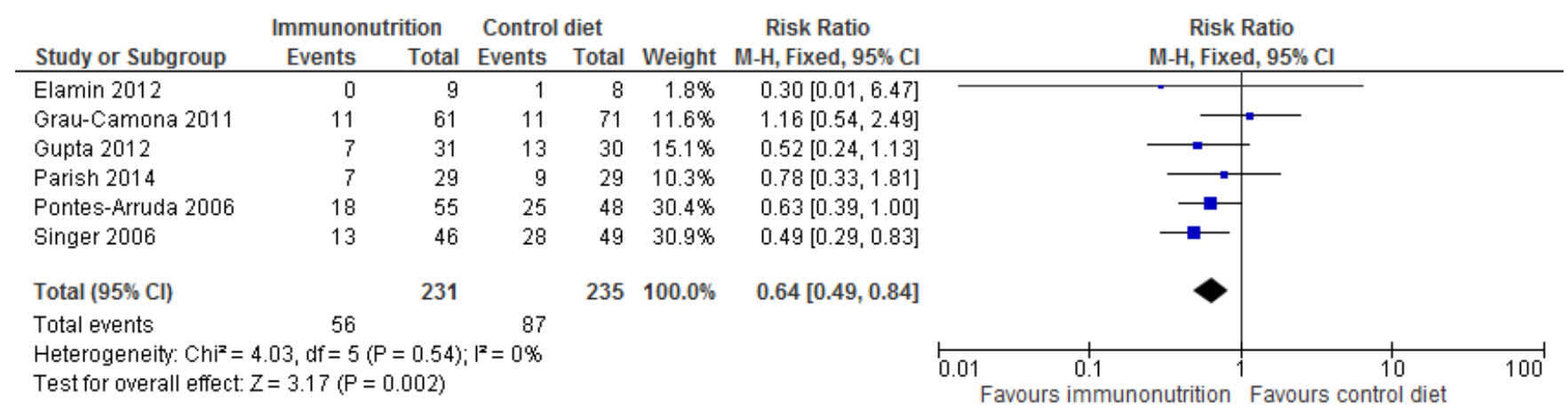


EC290 Immunonutrition for acute respiratory distress syndrome (ARDS) in adults

1.3 ICU LOS

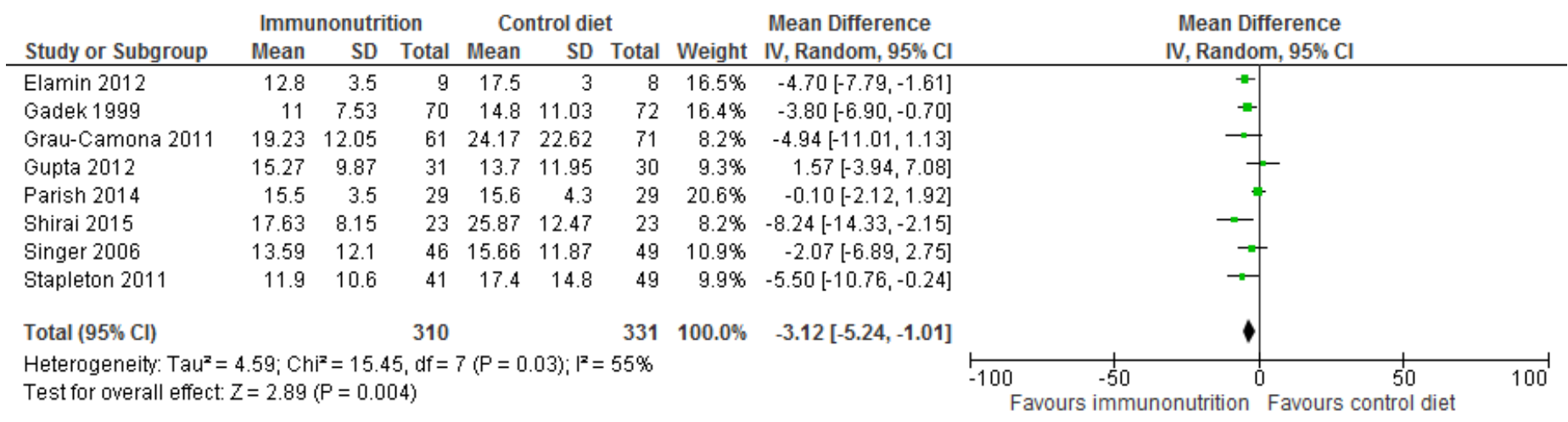

1.4 ICU-free days at day 28

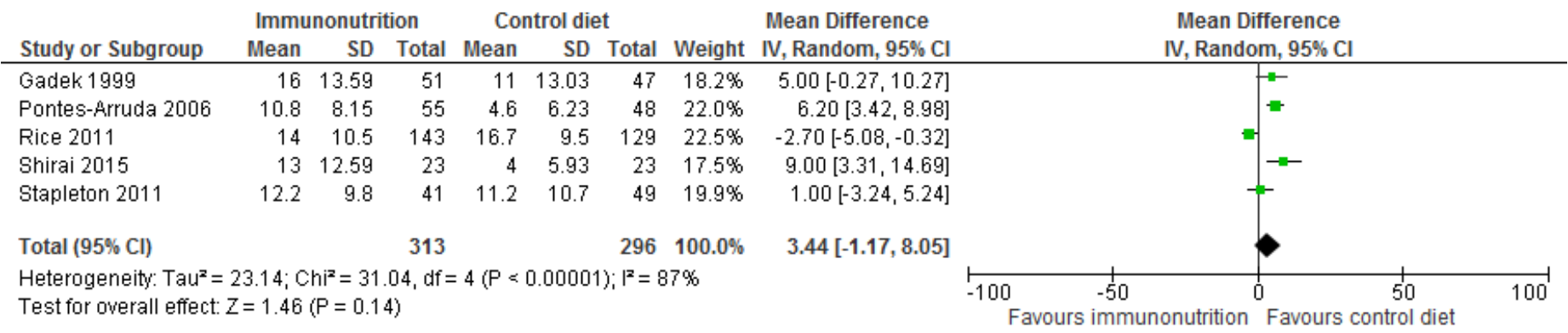

1.5 Ventilator days

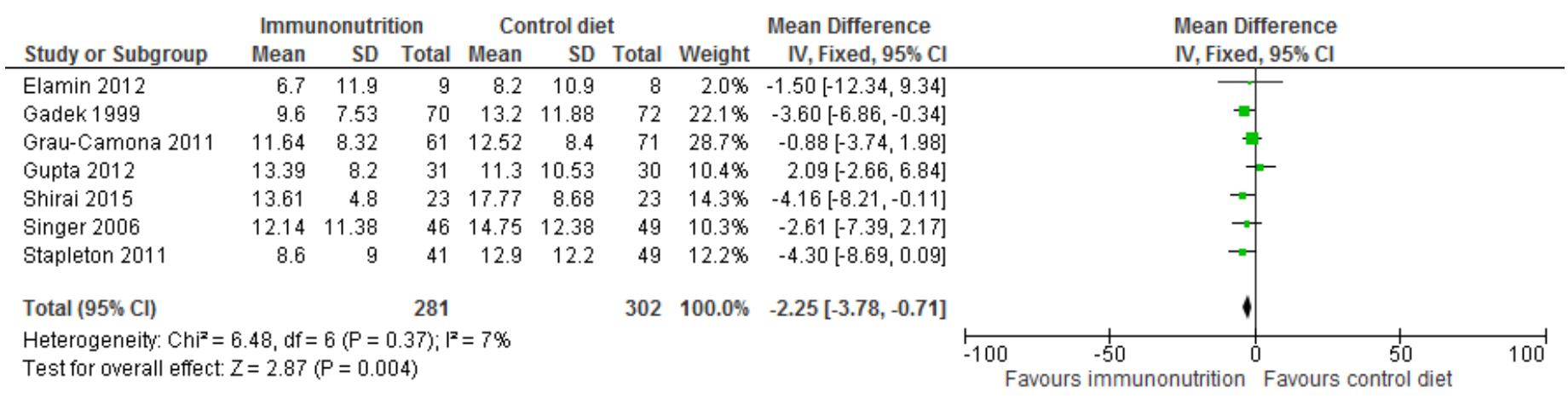

1.6 Ventilator-free days at day 28

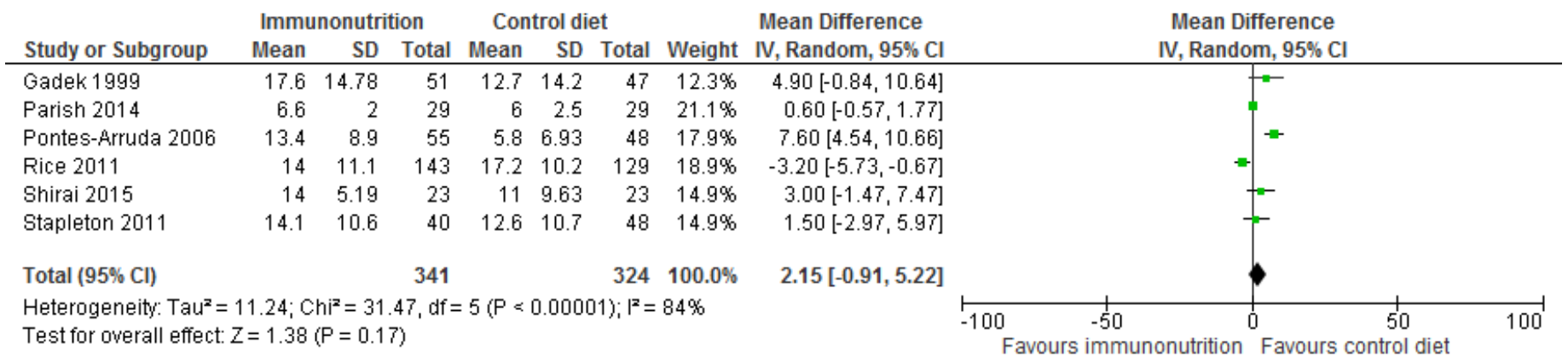

1.7 Hospital LOS

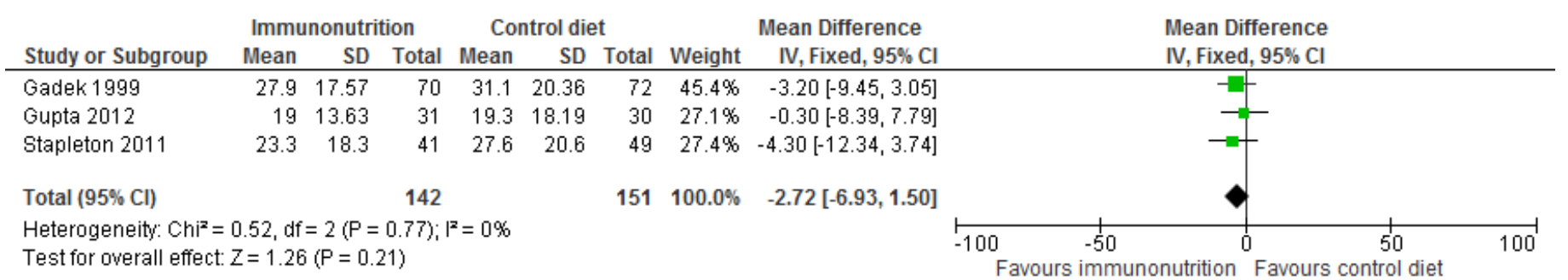


EC290 Immunonutrition for acute respiratory distress syndrome (ARDS) in adults

$1.8 \mathrm{PaO}_{2} / \mathrm{FiO}_{2}$ ratio at day 4

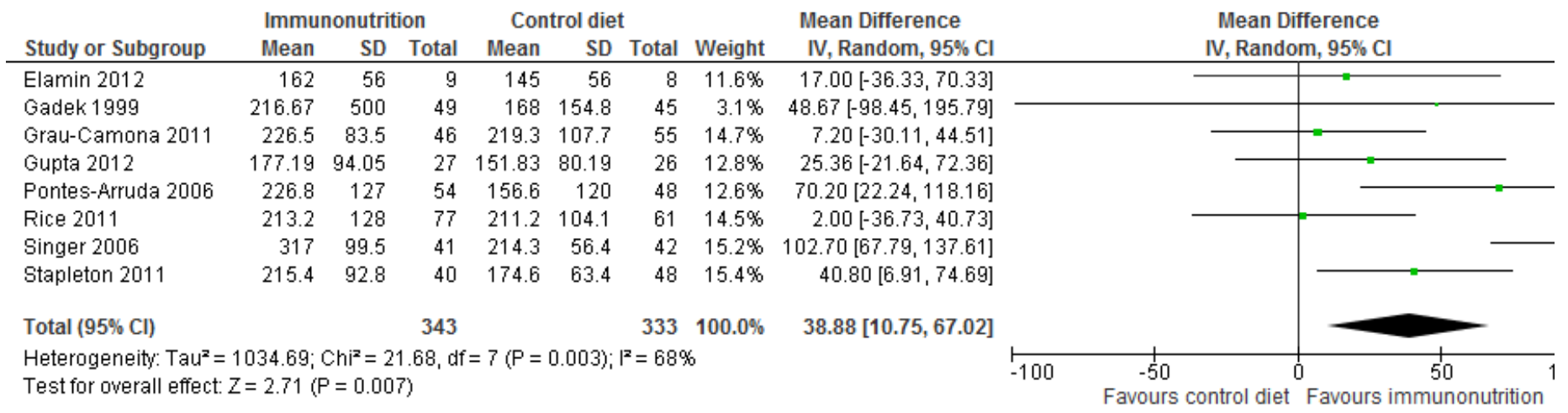

$1.9 \mathrm{PaO}_{2} / \mathrm{FiO}_{2}$ ratio at day 7

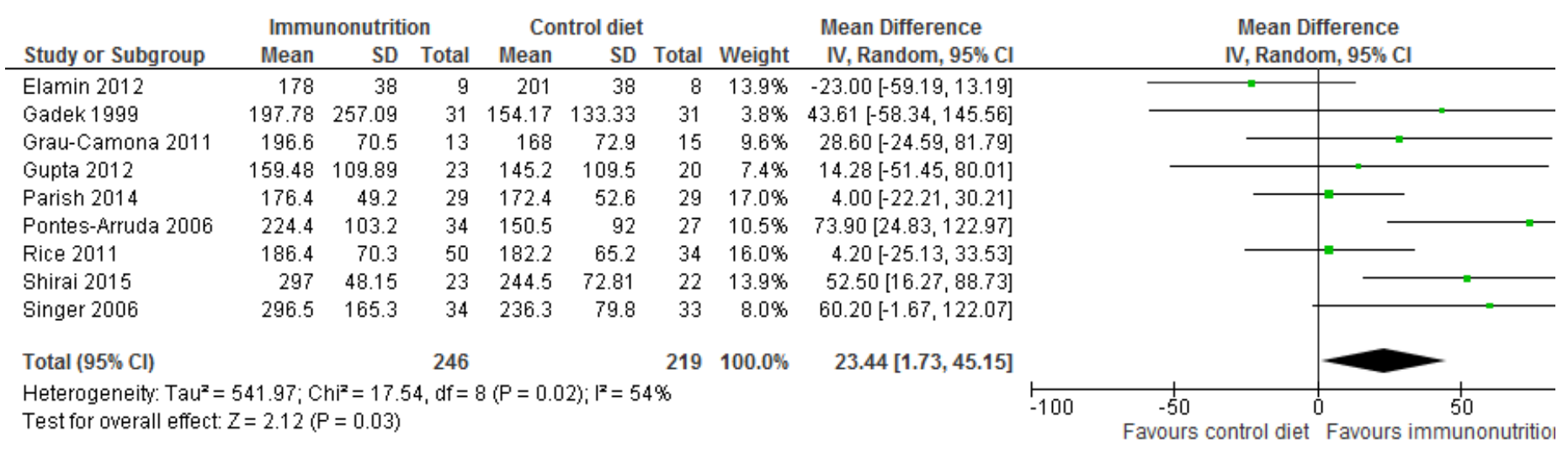

1.10 Patients with new organ failure

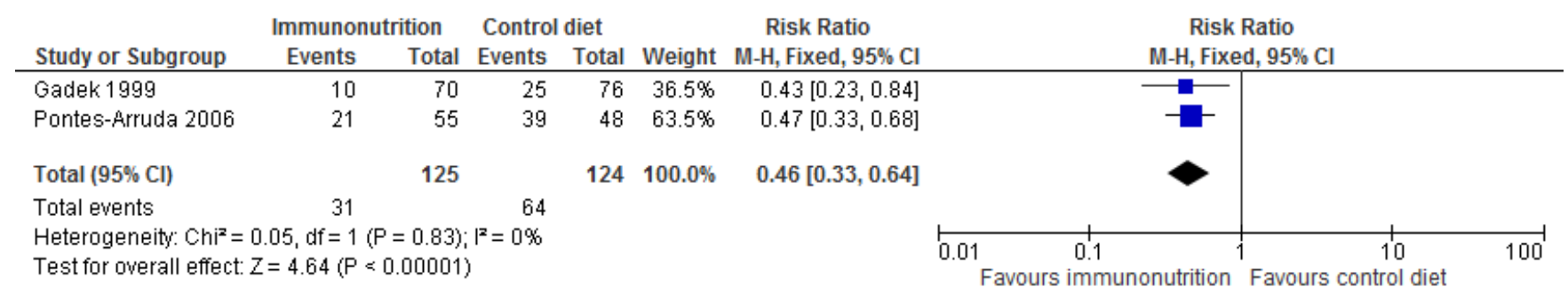

1.11 Patients with nosocomial infection

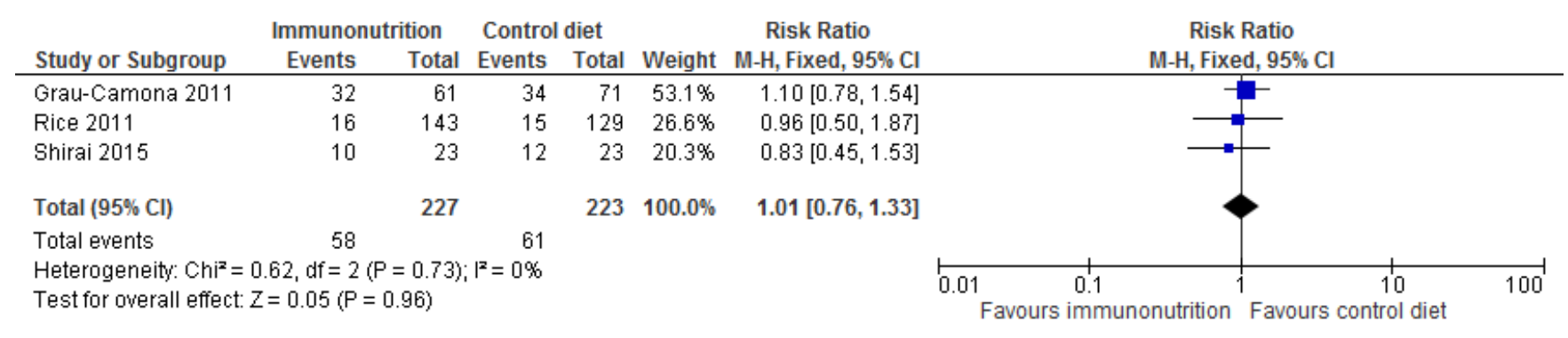

1.12 Adverse events - cardiac

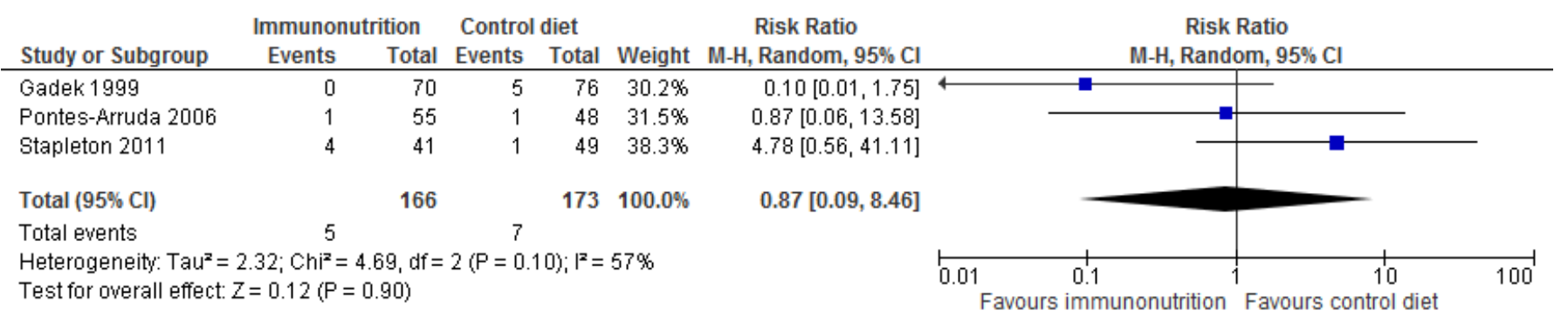


EC290 Immunonutrition for acute respiratory distress syndrome (ARDS) in adults

1.13 Adverse events - gastrointestinal

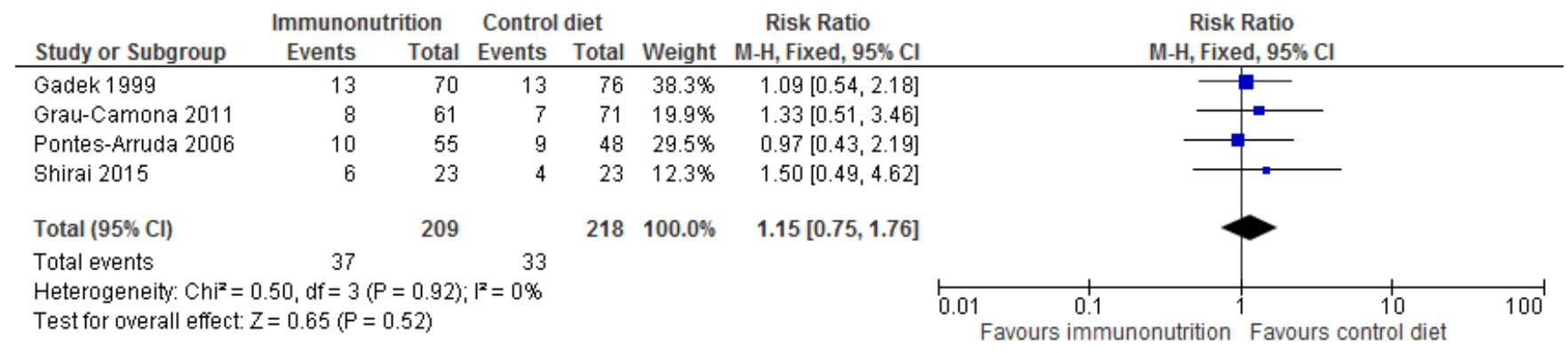

1.14 Total adverse events

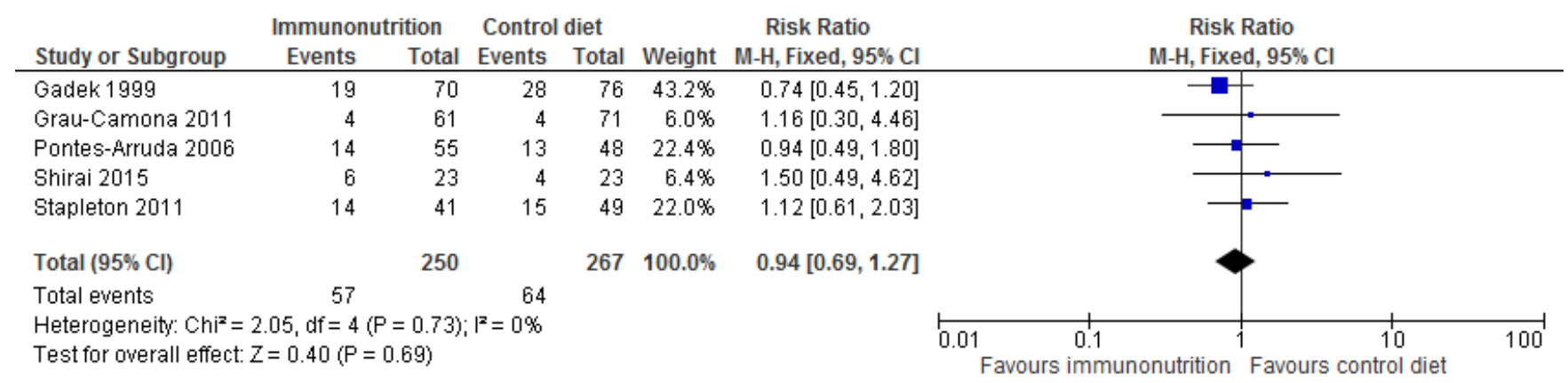

1.15 Subgroup analysis for the primary outcome (all-cause mortality) - type of intervention

Immunonutrition Control diet Risk Ratio

Study or Subgroup Events Total Events Total Weight M-H, Random, $95 \% \mathrm{Cl}$

1.15.1 Immunonutrition formula compared with lipid-based control diet

$\begin{array}{lrrrrrr}\text { Elamin 2012 } & 0 & 9 & 1 & 8 & 0.9 \% & 0.30[0.01,6.47] \\ \text { Gadek 1999 } & 11 & 70 & 19 & 76 & 11.2 \% & 0.63[0.32,1.23] \\ \text { Pontes-Arruda 2006 } & 18 & 55 & 25 & 48 & 15.8 \% & 0.63[0.39,1.00] \\ \text { Singer 2006 } & 13 & 46 & 28 & 49 & 14.4 \% & 0.49[0.29,0.83] \\ \text { Subtotal (95\% Cl) } & & 180 & & 181 & 42.4 \% & 0.57[0.42,0.78]\end{array}$

Total events
Heterogeneity: $\mathrm{Tau}^{2}=0.00 ; \mathrm{Chi}^{2}=0.70, \mathrm{df}=3(\mathrm{P}=0.87) ; \mathrm{I}^{2}=0 \%$

Test for overall effect: $Z=3.55(P=0.0004)$

1.15.2 Immunonutrition formula compared with carbohydrate-based control diet

$\begin{array}{lrrrrrr}\text { Grau-Camona 2011 } & 11 & 61 & 11 & 71 & 9.6 \% & 1.16[0.54,2.49] \\ \text { Shirai 2015 } & 3 & 23 & 3 & 23 & 3.4 \% & 1.00[0.22,4.45] \\ \text { Subtotal (95\% Cl) } & & 84 & & 94 & \mathbf{1 3 . 0 \%} & 1.13[0.57,2.22] \\ \text { Total events } & 14 & & 14 & & & \end{array}$

Heterogeneity: $\operatorname{Tau}^{2}=0.00 ; \mathrm{Chi}^{2}=0.03, \mathrm{df}=1(\mathrm{P}=0.86) ; \mathrm{I}^{2}=0 \%$

Test for overall effect: $Z=0.35(P=0.73)$

1.15.3 Immunonutrition supplemented to same intervention and control diet

$\begin{array}{lrrrrrr}\text { Gupta 2012 } & 9 & 31 & 14 & 30 & 11.2 \% & 0.62[0.32,1.22] \\ \text { Parish 2014 } & 7 & 29 & 9 & 29 & 8.4 \% & 0.78[0.33,1.81] \\ \text { Stapleton 2011 } & 9 & 40 & 11 & 45 & 9.4 \% & 0.92[0.43,1.99] \\ \text { Subtotal (95\% Cl) } & & 100 & & 104 & 29.0 \% & 0.75[0.48,1.15] \\ \text { Total events } & 25 & & 34 & & & \end{array}$

Heterogeneity: $\operatorname{Tau}^{2}=0.00 ; \mathrm{Chi}^{2}=0.58, \mathrm{df}=2(\mathrm{P}=0.75) ; \mathrm{I}^{2}=0 \%$

Test for overall effect: $Z=1.32(P=0.19)$

1.15.4 Immunonutrition supplemented to different intervention and control formula

$\begin{array}{lcccccr}\text { Rice } 2011 & 38 & 143 & 21 & 129 & 15.5 \% & 1.63[1.01,2.63] \\ \text { Subtotal }(95 \% \mathrm{Cl}) & & \mathbf{1 4 3} & & \mathbf{1 2 9} & \mathbf{1 5 . 5 \%} & \mathbf{1 . 6 3 [ 1 . 0 1 , 2 . 6 3 ]} \\ \text { Total events } & 38 & & 21 & & & \end{array}$

Total events

Heterogeneity: Not applicable

Test for overall effect: $Z=2.01(P=0.04)$

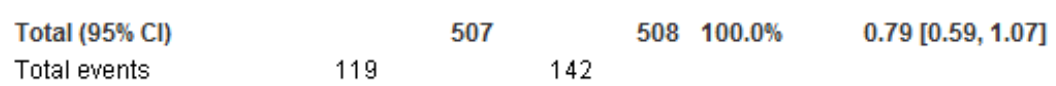

Heterogeneity: Tau $^{2}=0.09 ; \mathrm{Chi}^{2}=15.61, \mathrm{df}=9(\mathrm{P}=0.08) ; \mathrm{I}^{2}=42 \%$

Test for overall effect: $Z=1.51(P=0.13)$

Test for subaroup differences: $\mathrm{Chi}^{2}=14.18, \mathrm{df}=3(\mathrm{P}=0.003), \mathrm{I}^{2}=78.8 \%$

Risk Ratio

M-H, Random, $95 \% \mathrm{Cl}$

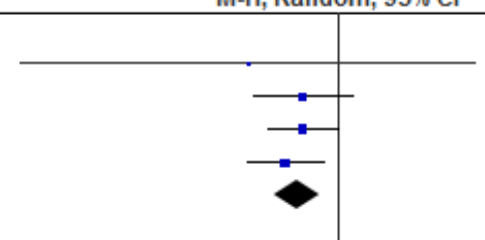


EC290 Immunonutrition for acute respiratory distress syndrome (ARDS) in adults

1.16 Subgroup analysis for the primary outcome (all-cause mortality) - route of intervention

Immunonutrition Control diet Risk Ratio Study or Subgroup Events Total Events Total Weight M-H, Random, $95 \% \mathrm{Cl}$

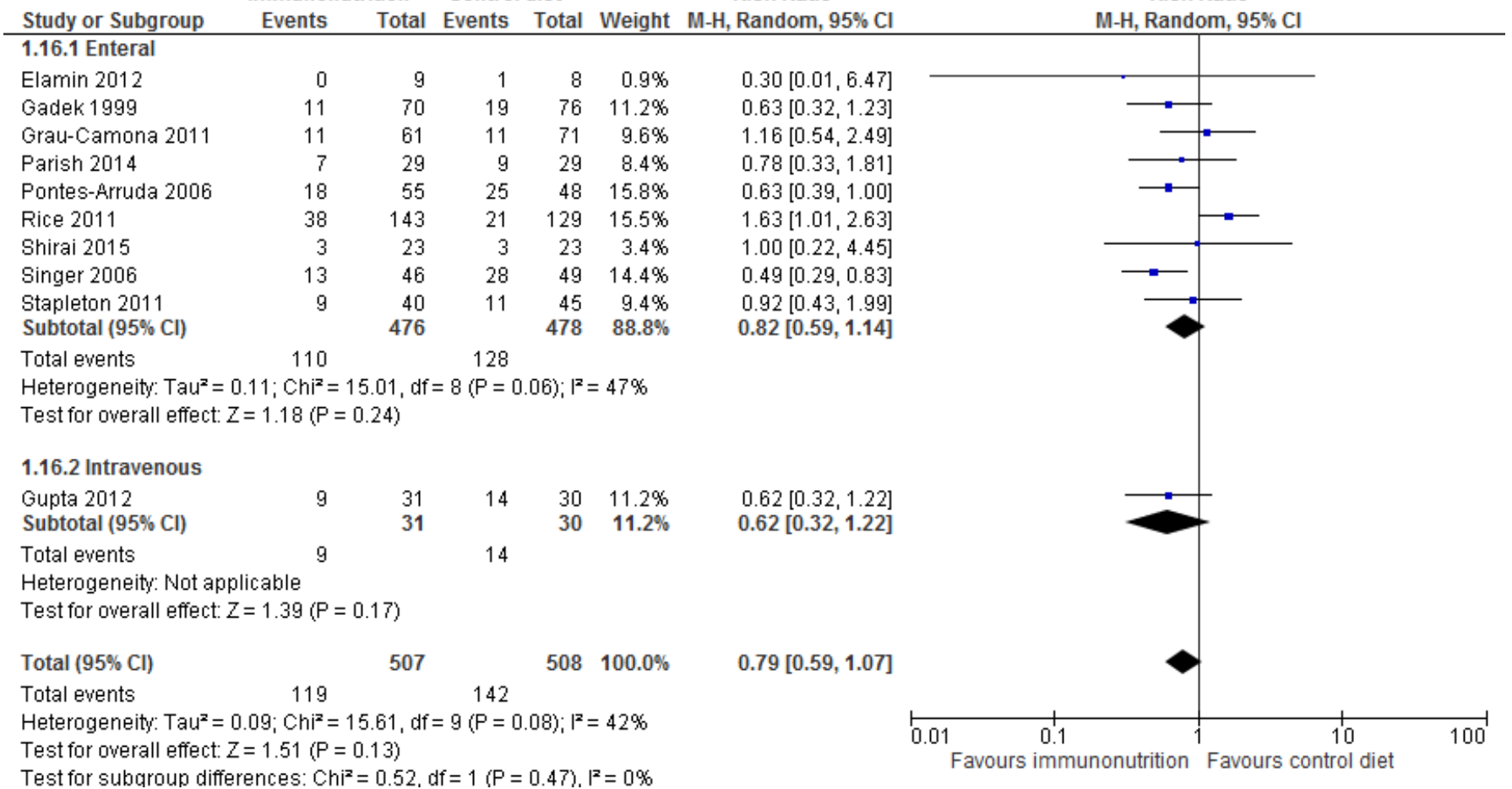

1.17 Subgroup analysis for the primary outcome (all-cause mortality) - mode of intervention (bolus or continuous)

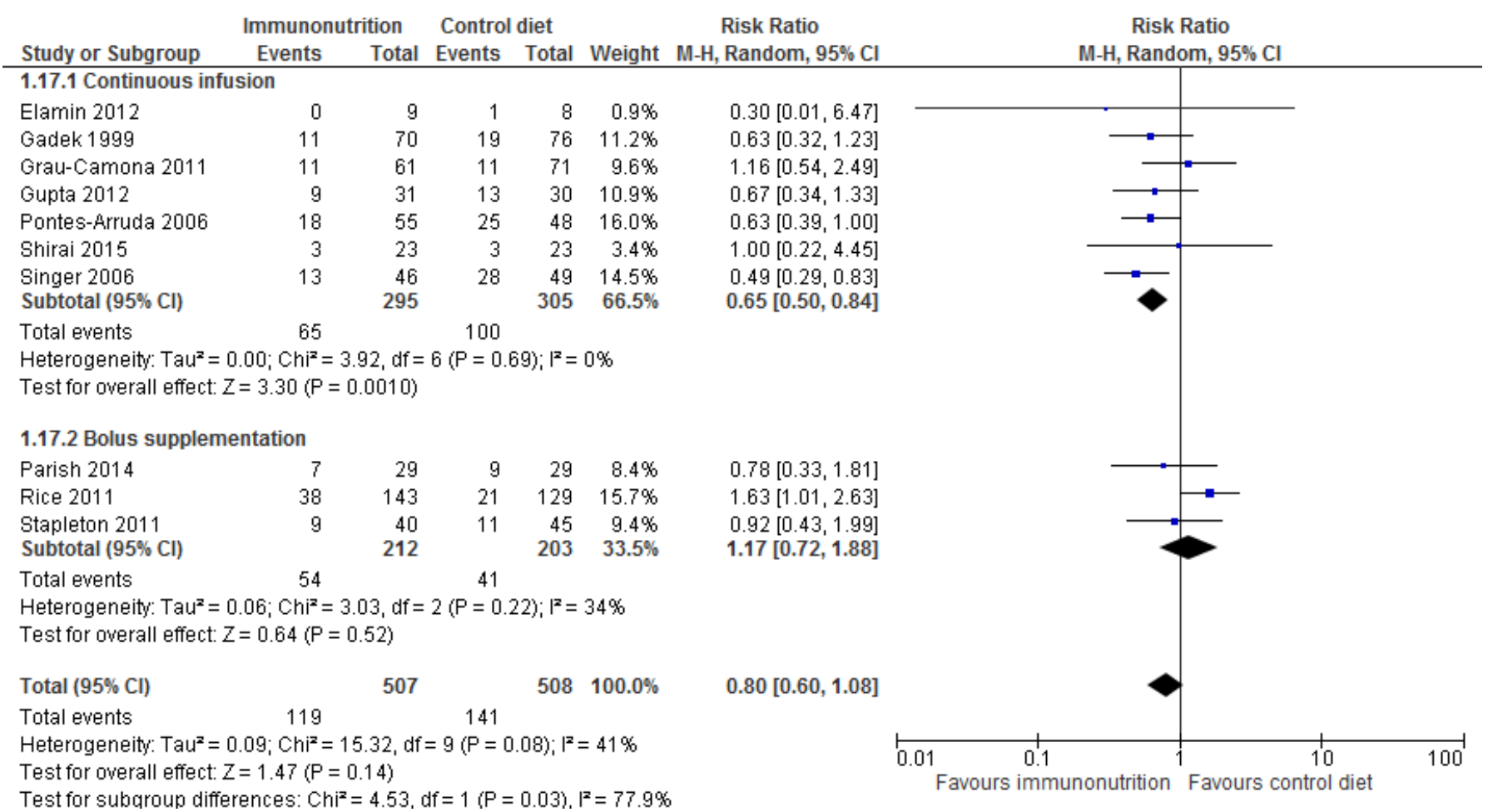


EC290 Immunonutrition for acute respiratory distress syndrome (ARDS) in adults

1.18 Subgroup analysis for the primary outcome (all-cause mortality) - duration of intervention

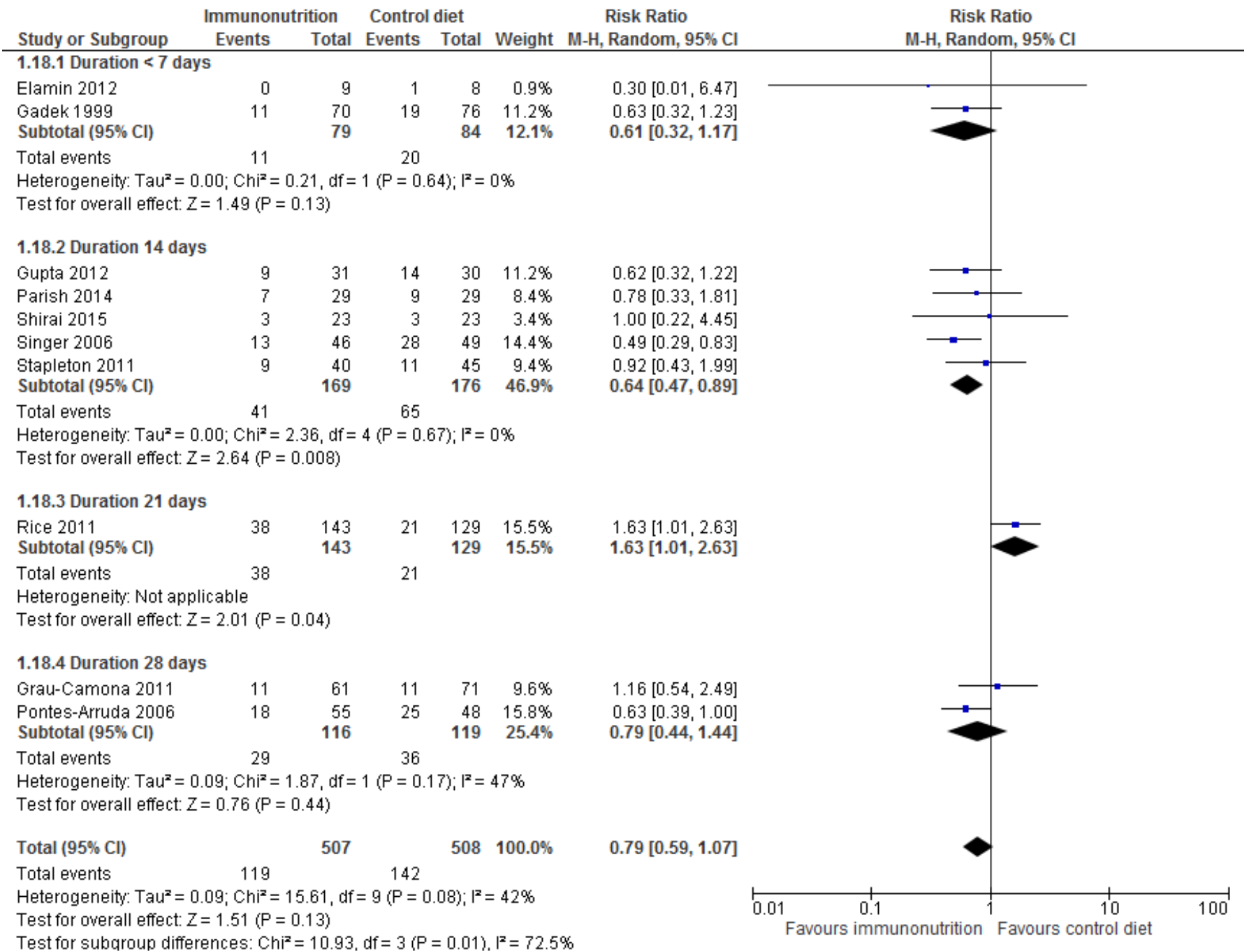

2 - Sensitivity analysis: omega-3 fatty acids and antioxidants versus placebo or standard nutrition

2.1 All-cause mortality (longest period reported) excluding studies at high risk of bias

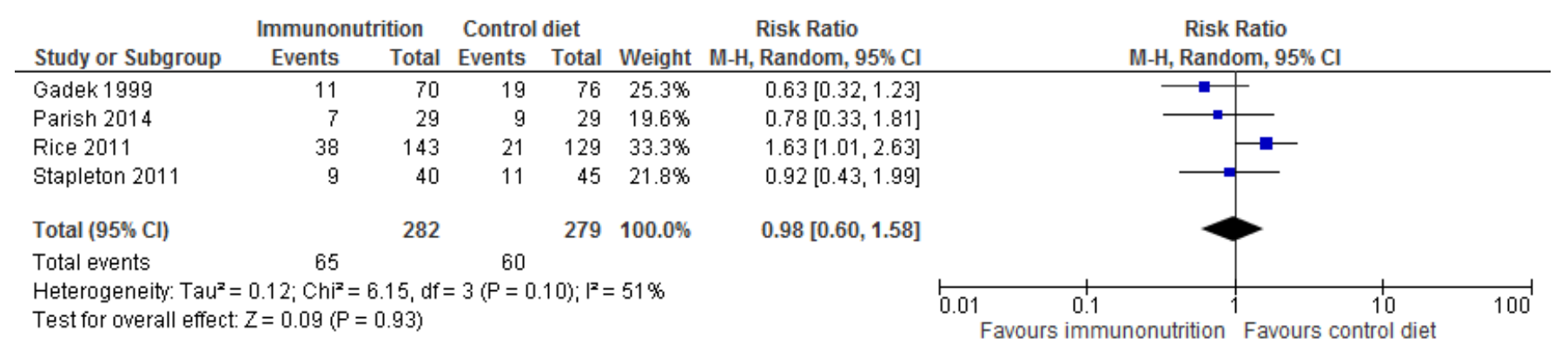

\subsection{ICU LOS [log days]}

Immunonutrition

Control diet

Mean Difference

Study or Subgroup Mean [log days] SD [log days] Total Mean [log days] SD [log days] Total Weight IV, Fixed,95\% Cl [log days]

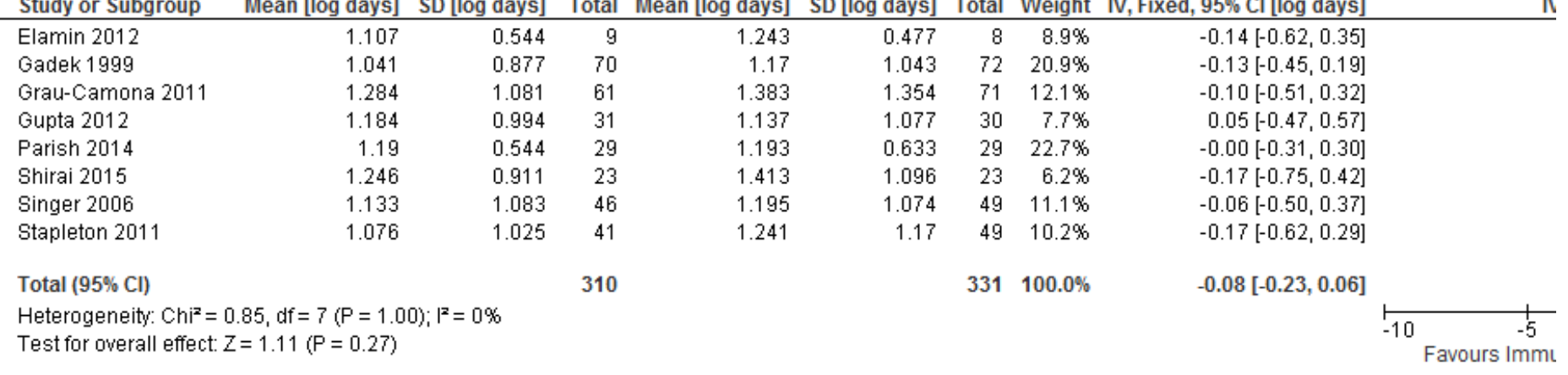


EC290 Immunonutrition for acute respiratory distress syndrome (ARDS) in adults

2.3 ICU-free days at day 28 [log days]

Immunonutrition

Control diet

Mean Difference

Study or Subgroup Mean [log days] SD [log days] Total Mean [log days] SD [log days] Total Weight IV, Random, 95\% CI [log days]

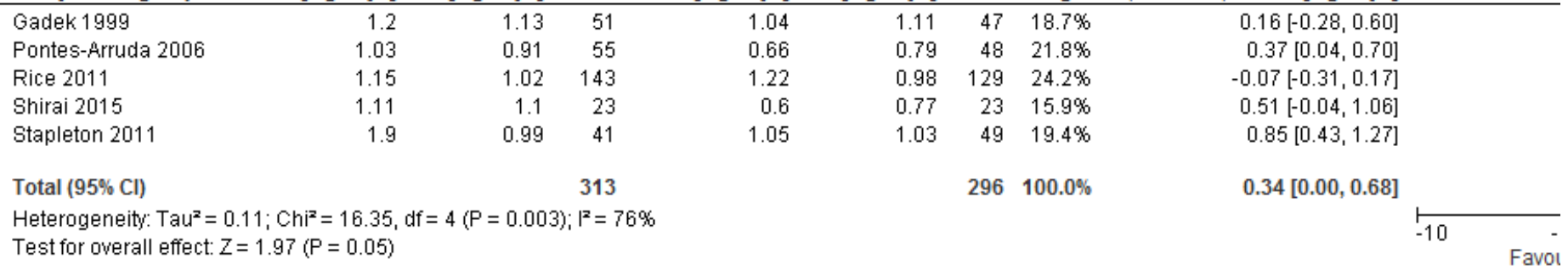

2.4 Ventilator days [log days]

Immunonutrition

Control diet

Mean Difference

Study or Subgroup Mean [log days] SD [log days] Total Mean [log days] SD [log days] Total Weight IV, Fixed, 95\% Cl [log days]

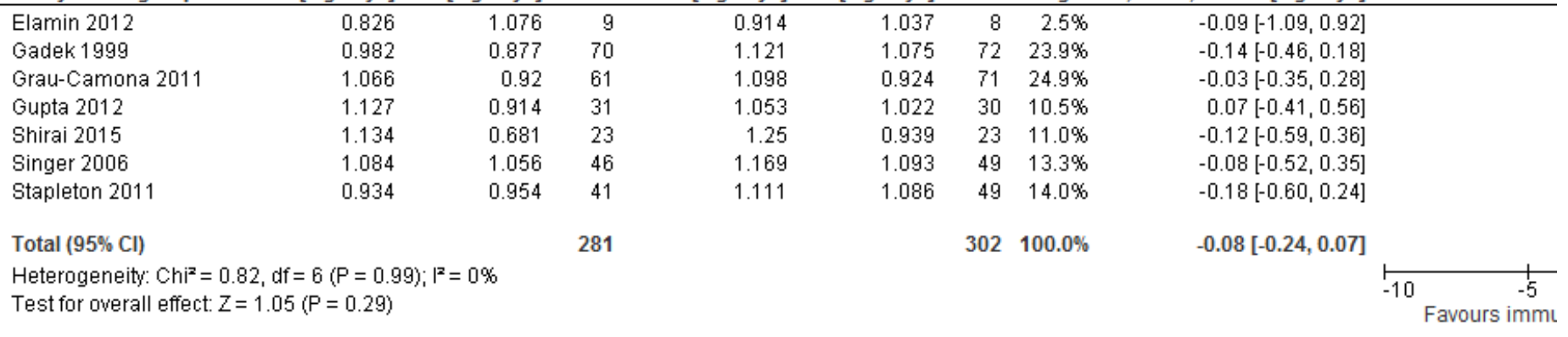

2.5 Ventilator-free days at day 28 [log days]

Immunonutrition

Control diet

Mean Difference

Study or Subgroup Mean [log days] SD [log days] Total Mean [log days] SD [log days] Total Weight IV, Fixed, 95\% CI [log days]

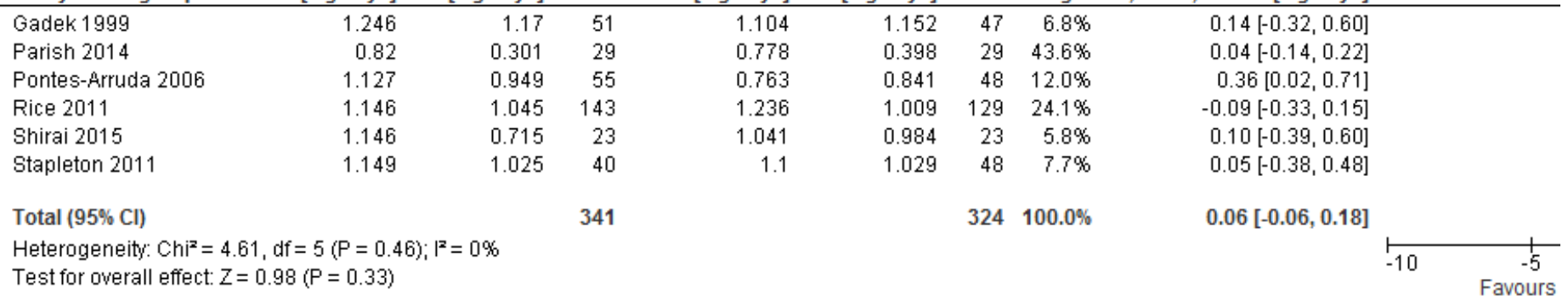

2.6 Hospital LOS [log days]

Immunonutrition

Control diet

Mean Difference

Study or Subgroup Mean [log days] SD [log days] Total Mean [log days] SD [log days] Total Weight IV, Fixed, 95\% CI [log days]

\begin{tabular}{|c|c|c|c|c|c|c|c|c|c|}
\hline Study or Subgroup & Wean [log days] & SD [log days] & Iotal & Mean [log days] & SD [log days] & Iotal & Welgnt & IV, rixed, 95\% Cl [log days] & IV, \\
\hline Gadek 1999 & 1.446 & 1.245 & 70 & 1.493 & 1.309 & 72 & $47.5 \%$ & $-0.05[-0.47,0.37]$ & \\
\hline Gupta 2012 & 1.279 & 1.134 & 31 & 1.286 & 1.26 & 30 & $23.1 \%$ & $-0.01[-0.61,0.60]$ & \\
\hline Stapleton 2011 & 1.367 & 1.262 & 41 & 1.441 & 1.314 & 49 & $29.4 \%$ & $-0.07[-0.61,0.46]$ & \\
\hline Total $(95 \% \mathrm{Cl})$ & & & 142 & & & 151 & $100.0 \%$ & $-0.05[-0.34,0.24]$ & \\
\hline $\begin{array}{l}\text { Heterogeneity: } \mathrm{Chi}^{2}= \\
\text { Test for overall effect }\end{array}$ & $\begin{array}{l}0.03, d f=2(P=0.9 \\
Z=0.31(P=0.76)\end{array}$ & $99 ; 1^{2}=0 \%$ & & & & & & & $\begin{array}{lc}-10 & -5 \\
& \text { Favours immul }\end{array}$ \\
\hline
\end{tabular}

